
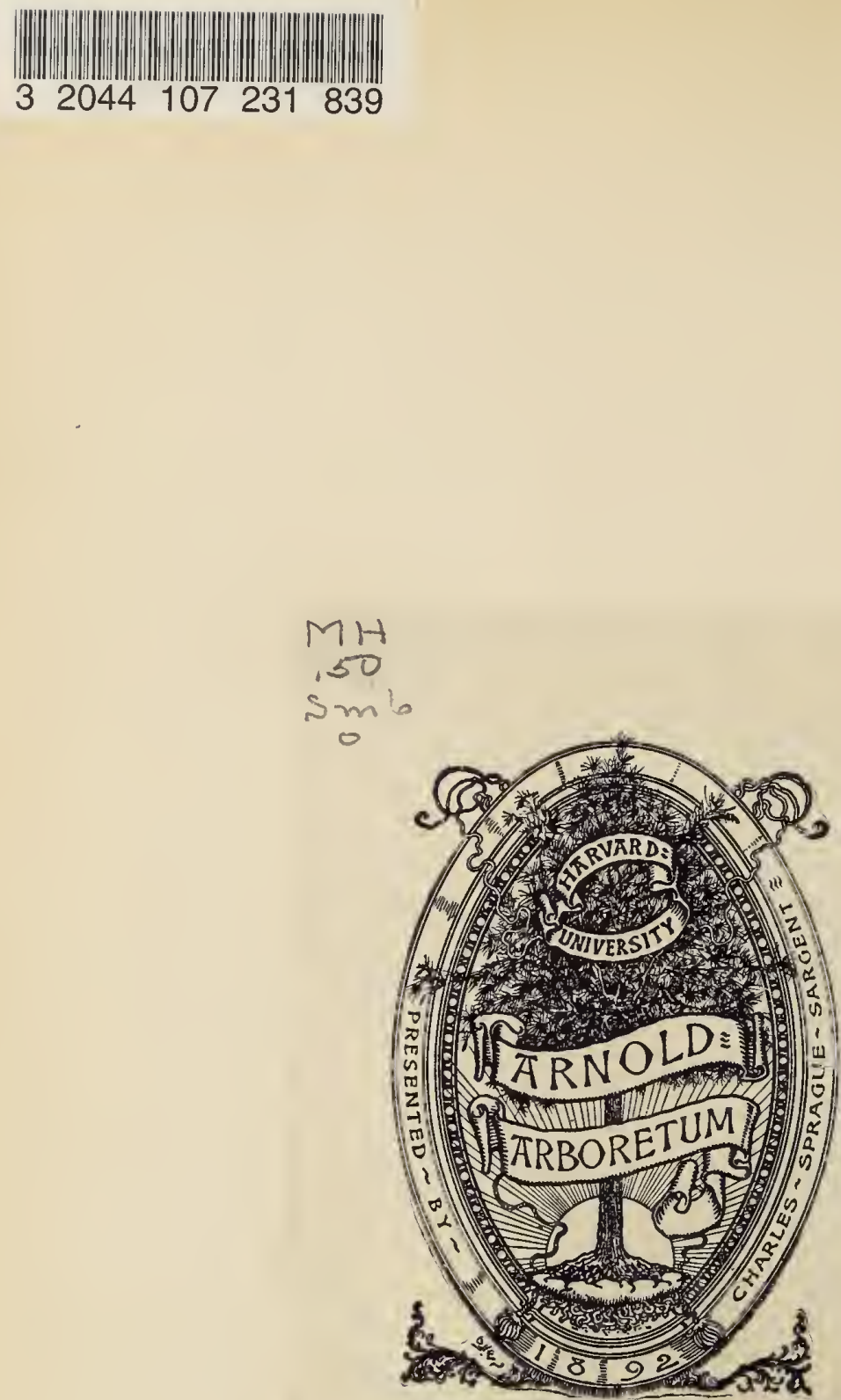


$$
\text { - }
$$


Digitized by the Internet Archive in 2014 


\title{
DIE ORCHIDEEN VON AMBON
}

VON

\author{
J. J. SMI'TH, \\ ASSISTENT AM HERBAR ZU BUITENZORG,
}

(HERAUSGEGEBEN VOM DEPARTEMENT FÜR LANDWIRTSCHAFT). 



\section{DIE ORCHIDEEN VON AMBON.}

Der Grund zu der jetzigen Kenntniss der Flora von Ambon wurde, wie bekannt, gelegt durch Rumphius in seinem "Herbarium Amboinense", das in der Mitte der $18^{\text {ten }}$ Jahrhundert ersch en. In diesem Werke wurde auch eine ziemlich grosse Anzahl Orchideen beschrieben und abgebildet, leider nicht stets in derartiger Weise, dass sie für spätere Forscher leicht erkennbar sind.

In Hasskarls Schlüssel zu diesen Bändern kommen, was die Orchideen betrifft, so viele falsche Angaben und Vermutungen vor und bleiben so viele Namen unaufgeklärt, das wohl nicht behauptet werden kann, die Kenntsiss der Orchideen sei dadurch viel gefördert worden.

Später besuchten mehrere Botaniker, wie Lesson, Zippelius, Doleschall, Forbes u. s. w. die Insel, aber die Zahl der von ihnen gesammelten Orchideen war nur sehr gering.

Nach Rumphius war Teysmann, der Ambon zweimal (in 1860 und 1876) besuchte, der erste, der sich mehr speziell für diese Familie interessierte. Viele Arten wurden von ihm in den Buitenzorger Garten eingeführt, von welchen einige im "Nat. Tijdschr. voor Ned.-Indie”" von ihm und Binnendijk beschrieben wurden. 
Herrn Prof. Dr. G. Karsten, welcher 1890 eine Reise nach den Molukken unternahm, verdankt der botanische Garten viele Arten, die zum Teil dort noch kultiviert werden.

Drei Jahre später sammelte Herr Prof. Dr. M. Treub auf einer Reise nach den Molukken und Neu-Guinea auf Ambon zahlreiche Pflanzen, wobei sich mehrere, zum Teil sehr interessante Orchideen befanden.

Zuletzt wurde mir selbst die Gelegenheit geboten in Gesellschaft des damaligen, auf dieser Reise verstorbenen Adjunct-Direktor des Buitenzorger Gartens Dr. J. G. Boerlage, Ambon zu besuchen, und die grosse Zahl der von mir dort gesammelten Orchideen, von denen mehrere neue Arten schon in den "Icones bogorienses", Vol. II beschrieben wurden, veranlasste mich die hier publizierte Liste zusammenzustellen.

Zwar giebt diese Arbeit bei weitem kein vollständiges Bild der ambonsche Orchideenflora, nicht nur weil es unmöglich ist, eine mit dichten Wäldeln bedeckte Insel wie Ambon innerhalb eines Monats gründlich zu durchforschen, aber auch weil viele der gesammelten und in Buitenzorg lebend eingeführten Arten noch nicht geblüht haben, doch vertraue ich, dass sie nicht völlig wertlos ist, um so mehr, da ich im Stande war einige der Rumpfschen Arten zur Klarheit zu bringen und einige Irrtümer nachzuweisen.

Die Zahl der hier angeführten Arten (und einiger Varietäten, von welchen die Typen nicht auf Ambon vorkommen) beträgt 104 und :3 unsichere. Die Arten, welche ich nicht blühend sah und also in der Regel nur 
bis auf die Gattung bestimmen konnte, sind hier, mit Ausmahme einiger wenigen, nicht aufgenommen. Diese nicht näher bestimmten Arten gehören hauptsächlich einigen im Archipel weit verbreiteten Gattungen an, wie Oberonia, Liparis, Ceratostylis, Dendrobium, Eria, Bulbophyllum, Appendicula etc.

Von diesen 104 Arten sind bis jetzt nicht weniger als 36 Arten und 6 Varietäten in Ambon endemisch, wiewohl es kaum zu bezweifeln ist, dass viele davon auch auf den benachbarten Inseln vorkommen. 23 Arten werden nur im östlichen Archipel gefunden. Dendrobium macrophyllum A. Rich, eine Art der typisch australischen Sektion Dendrocoryne Lndl., kommt bis in West-Java vor. D. superbum Rchb. f. ist von den Molukken, Borneo und den Philippinen bekannt. Phajus amboinensis Bl. ist ausser auf Ambon nur noch in Ost-Java angetroffen; Vandopsis lissochiloides Pfitz. auch auf den Philippinen. Microstylis ventilabrum Rchb. f. kommt wahrscheinlich auf Ambon und Borneo vor, während Habenaria Rumphii nicht nur in Ambon sondern auch in Celebes und Borneo einheimisch ist. Die übrigen Arten sind mehr oder weniger allgemein verbreitet im ganzen Archipel und einige davon kommen auch ausserhalb dieses Gebietes vor.

Im allgemeinen kann gesagt werden, dass die Orchideenflora von Ambon eine Mischung malaiischer und papuanischer Formen zeigt. Die letzteren sind besonders reich vertreten bei der Gattung Dendrobium Sw., und zwar durch die Sektionen Cadetia Bl., Longicollia J. J. S., Dendrocoryne Lindl., Antennata Rchb. f., Biloba J. J. S. und durch $D$. foliosum Brongn. 
Typisch australisch sind auch Cleisostoma cryptochilum F. v. Muell. und Sarcochilus Tacniophyllum J. J. S., welches der blattlosen Sektion dieser Gattung angehört. Bis jetzt ist nur eine endemische Gattung, Glossorhyncha Ridl., bekannt und diese bedürft noch näherer Untersuchung. Im von $D^{r}$. S. H. Koorders in der Minahasa gesammelten Herbarium befindet sich eine, leider blütenlose Pflanze, welche $G$. amboinensis Ridl. sehr ähnlich aussieht.

Merkwürdig ist das Vorkommen einer Art der Gattung Cryptochilus Wall. (C. bicolor J. J. S.) auf Ambon; diese Pflanze weicht jedoch in einigen Punkten von den beiden anderen, ostindischen Arten ab.

\section{Neuwiedia sp.}

Ambon: Zwischen dem Sirimau und Horiel ; Hoetoe Mortetoe; zwischen Alang und dem Latoea (J. J. Smith).

Weil es mir nicht gelungen ist auch nur eine einzige Blüte zu finden, muss ich leider auf eine Identifizierung dieser Pflanze verzichten.

Besonders in der Gegend zwischen Alang und dem Latoea, in den höher geliegenen Wäldern war diese Neuviedia so häufig, das Hunderte Exemplare den Boden mit ihren freudig grünen Blättern bedeckten; zum Teil waren sie mit halbreifen Früchten versehen, und die übrigen zeigten noch keine Spur eines Blütenstandes.

Die Blätter (ca. 9) sind schmal lanzettlich, lang und fein zugespitzt, längsfaltig, mit zahlreichen Längsnerven, glänzend dünkelgrün, mit dem $\pm 20 \mathrm{~cm}$. langen Stiel \pm $73 \mathrm{~cm}$. lang, $5.50 \mathrm{~cm}$. breit. Der Blütenstand ist \pm 
$80 \mathrm{~cm}$. lang, dicht und vielblütig, sehr kurz behart; der $\pm 56 \mathrm{~cm}$. lange Pedunculus mit zahlreichen blattartigen Schaftblättern bedeckt, die Rachis längsfurchig und dicht filzig. Bracteen lanzettlich, concav, viehnervig, aussen diclit und sehr kurz behaart, bis 3.10 cm. lang. Blüten wahrscheinlich klein. Frucht 3kantig, glünzend grün, schwach behaart, die Seiten $\pm 1.60 \mathrm{~cm}$. lang, $0.80 \mathrm{~cm}$. breit. Fruchtstiel $\pm 0.70 \mathrm{~cm}$. lang.

Paphiopedilum Mastersianum Pfitz. Engl. Bot. Jahrb. XIX (1894), 40; Pflanzenr. IV, 50 (1903) 84; Hallier Ann. Buit. XIV (1896) 36. - Cypripedium Matersianum Rchb. f. Gard. Chr. 1879, II, 102 ; Mast. l. c. 1894, I, 593, t. 74 ; Veitch, Man. IV, 39 ; Lindenia IV, t. 159; Rolfe, Orch. Rev. II, 17, f. 4 ; Curt. Bot. Mag. t. 7629 ; Krzl. Orch. I, 62 ; Desbois, Cypr. 333. - Paphiopedium Mastersianum Kerch. Liv. Orch. 455; Rolfe Orch Rev. IV (1896) 364.

Ambon: Salhoetoe ('Teysm.); Toena (Teysm., Micholitz); Hoetoe Mortetoe (J. J. Smith).

Diese nicht besonders schöne Art wurde ungefähr vor einem Dezennium von der Firma Sander, St. Albans, in grösserer Anzahl in England eingeführt, nachdem sie schon früher durch Sendungen des botanischen Gartens zu Buitenzorg in Europa bekannt geworden war.

Platanthera Susannae Lndl. Gen. et Sp. Orch. 295; Wight. Ic. t. 920 ; Dalz. et Gibs. Bomb. Fl. 269 ; Miq. Fl. Ind. Bat. III, 714; Kzll. Orch. Gen. et Sp. I, 601 ; J. J. S. Fl. Buit. Orch. 26. - P. gigantea Lndl. Wall. 
Cat. 7052. - P. robusta Lndl. 1. c. 7036 ; Gen. et Sp. Orch. 295. - Orchis Susannae L. Sp. Pl. n. 939. - 0. gigamtea Sm. Exot. Bot. t. 100. - Habenaria Susannae R. Br. Prodr. 312; Bl. Bijdr. 402 ; Hook. f. Fl. Br. Ind. VI, 137. - H. gigantea Don. Prodr. 24 ; Bot. Mag. t. 3374; Grah. Cat. Bomb. Pl. 201. - Flos Susannae Rumph. Herb. Amb. V, 286, t. 99.

Ambon: Ohne nähere Fundortsangabe (Rumph., Teysm.); Nona; Paso (J. J. Smith), an grasigen, sonnigen Stellen; auch Boeroe; Celebes; Timor; Java; Mal. Halbinsel; China; Ostindien.

Peristylus gracilis Bl. Bijdr. 404; Mus. II, 189; Lndl. Gen. et Sp. Orch. 300; Miq. Fl. Ind. Bat. III, 713 ; J. J. S. Fl. Buit. Orchid. 31. - Habenaria bambusetorum Krzl. Orch. Gen. et Sp. I, 384.

Ambon: Zwischen dem Sirimau und Horiel (J. J. Smith); auch Java; Sumatra.

Peristylus sp. - Orchis amboinica minor II Rumph. Herb. Amb. VI, 118, t. LIV, f. 3.

Ambon: Ohne nähere Fundortsangabe (Rumph.).

Rumphius Figur stellt sicher ein Peristylus vor, aber es ist nicht möglich die Pflanze zu bestimmen. $P$. gracilis Bl. kann es kaum sein, weil diese Art locker gestelte, nicht zusammengedrängte Blätter hat.

Peristylus candidus J. J. S. Fl. Buit. VI, Orch. 36. Ambon: Zwichen Alang und Hina Niwel (Boerlage, J. J. Smith); auch Java; ? Singapore. 
Wenn ich nicht irre, ist es diese Pflanze, welche Ridley in "The Orchideae and Apostasiaceae of the Malay Peninsula" und "The Flora of Singapore" als Habenaria lacertifera Btll. anführt.

Ich kann jedoch nicht annehmen, das Peristylus candidus J. J. S. und P. (Habenaria Rchb. f.) tentaculata J. J. S. zu einer und derselben Art gehören. Abgesehen von der Farbe sind die beiden Pflanzen noch verschieden durch die bei ersterer mit den Spitzen abstehenden oder mehr oder weniger zurückgekrümmten sepalen und Petalen, welche bei letzterer bis an die Spitze verklebt oder wenigstens zusammengeneigt sind; ferner hat. $P$. tentaculatus einen grossen Callus auf dem Lippengrund, welcher bei $P$. candidus fehlt, wiewohl der Nagel hier eine schwache Längsrippe zeigt. Auch sind bei $P$. candidus die Seitenlappen der Lippe bedeutend breiter als der Mittellappen, was bei $P$. tentaculatus nicht der Fall ist.

Dass diese Art nicht sehr variabel ist, wird sehr wahrscheinlich durch die Tatsache, das Exemplare so verschiedener Gegenden wie West-Java und Ambon einander vollkommen ähnlich sind.

Habenaria Rumphii Lndl. Gen. et Sp. Orch. 320; Mig. Fl. Ind. Bat. III. 713; Krzl. Engl. Bot. Jahrb. XVI, 156; Orch. Gen. et Sp. I, 383. - Platanthera Rumphii Brongn., Coquille 104, t. 38 A. - Orchis amboinica minor I Rumph., Herb. Amb. 118, t. 54, 2.

Ambon: Gemein an sonnigen, grasigen Stellen. (Rumphius, Lesson, Teysm.); Batoe Gadja (Boerlage, J. J. S.); Alang (J. J. S.) auch Celebes; Borneo. 
Pogonia flabelliformis Lindl. Wall. Cat. n. 7400; Gen. et Sp. Orch. 415; Mig. Fl. Ind. Bat. III, 715; J. J. S. Fl. Buit. VI, Orch. 57. - P. Nervilia Bl. Mus. Bot. Lugd. Bat. I, 32; Fl. Jav. Oreh. 130, t. 56. - Nervilia Aragoana Gaud. It. Freyc Bot. 422.

Ambon: Zwischen Larike und Alang (J. J. S.); auch Ternate; Timor; Java; mal. Halbinsel; Ostindien; Marianen.

Physurus herpysmoides King et Pantl. var. amboinensis J. J. S. n. var.

Folia circ. 4, oblique oblonga, acuminata, 3nervia, glaucescentia. Inflorescentia circ. $24 \mathrm{~cm}$. longa, laxe circ. 12flora. Flores circ. $1.25 \mathrm{~cm}$. lati, $0.95 \mathrm{~cm}$. longi. Sepala viridi-brunescentia, lateralia suberecta. Petala oblique linearia. Labelli lobus medius reflexus, subrotundus, acutus, albus; calcar brèviusculum, latum, profunde bilobatum, lobulis acutiusculis, brunescenti-album, circ. 0.25 $\mathrm{cm}$. longum, $0.30 \mathrm{~cm}$. latum.

Stengel niederliegend, aufstrebend, wurzelnd, stielrund, $\pm 6 \mathrm{~cm}$. lang, $0.30 \mathrm{~cm}$. dick, \pm blättrig. Blätter gestielt, abstehend, schief länglich, zugespitzt, spitz, am Rande wellig, mit 3 oben gefurchten, unten gekielten Nerven, graugrün, $\pm 6.50 \mathrm{~cm}$. lang, $2.50 \mathrm{~cm}$. breit; Stiel aufrecht, rinnig, mit der kürzeren, röhrigen Scheide $\pm 1.40 \mathrm{~cm}$. lang, hellgraugrün. 'Blütenstand aufrecht, abstehend behaart, $\pm 24 \mathrm{~cm}$. lang, locker, bis \pm 12 blütig. Pedunculus $\pm 15 \mathrm{~cm}$. lang, mit einigen röhrigen, lang zugespitzten, anliegenden, fast kahlen Schaftblättern, blass 
braungrün. Rachis blass braun. Bracteen lanzettliclı, fein zugespitzt, concav, anliegend drüsig behaart, braun, $\pm 0.90 \mathrm{~cm}$. lang. Blüten $\pm 1.25 \mathrm{~cm}$. breit, $0.95 \mathrm{~cm}$. lang. Unpaares Sepalum mit den Petalen helmbildend, lanzettlich, stumpflich, sehr concav, $0.80 \mathrm{~cm}$. lang, $0.25 \mathrm{~cm}$. breit. Paarige Sepalen flügelartig schräg aufrecht, mit dem unpaaren spitze Winkel bildend, schief, schwach Sförmig, stumpf, concav, $0.80 \mathrm{~cm}$. lang, $0.275 \mathrm{~cm}$. breit. Sepalen 3nervig, aussen abstehend drüsig behaart, grünbraünlich. Petalen mit dem unpaaren Sepalum verklebt, schief linear lanzettlich, gegen die Spitze etwas verbreitert, spitz, 1nervig, blass braun, an der Spitze weiss, $0.70 \mathrm{~cm}$. lang, $0.15 \mathrm{~cm}$. breit. Labellum vertikal, gespornt, ausgespreizt $\pm 0.83 \mathrm{~cm}$. lang, in der natürlichen Lage $0.33 \mathrm{~cm}$. breit; Platte schwach 3lappig, stark concav, mit am Grunde, der Säule fest anliegenden Rändern, innen mit einer Lüngsfurche, weiss, Seitenläppchen sehr klein, schwach abgerundet; Mittellappen stärk zurückgekrümmt, rundlich, spitz, oben mit einer tiefen Längsfurche, die beiden Hälften convex, wellig, $0.25 \mathrm{~cm}$. lang urd breit; Sporn abwärts gewandt, ziemlich kurz, gerade, breit, an der Spitze ziemlich tief 2lappig, mit spitzlichen Läppchen, hellbraun, $\pm 0.25 \mathrm{~cm}$. lang, $0.30 \mathrm{~cm}$. breit. Gynostemium aufrecht, bräunlich weiss, $\pm 0.53 \mathrm{~cm}$. lang, unten mit 2 Längsrippen; Clinandrium tief, länglich eirund. Anthera verlängert eirund, sehr spitz, hellbraun, $0.40 \mathrm{~cm}$. lang. Pollinien 2, gespalten, schmal keulig, gelblich weis, mit langen Caudiculae und kleiner Klebmasse.

Rostellum gross, 3 eckig, fein 2zähnig. Stigma dem 
Clinandrium ähnlich, gross, eirund. Ovarium aufrecht, abstehend drüsig behaart, braungrün, $\pm 0.80 \mathrm{~cm}$. lang.

Ambon: Zwichen Alang und Goenoeng Riboe (J. J. S.).

Diese Pflanze is $P$. herpysmoides $\mathrm{K}$. et $\mathrm{P}$. so ähnlich, dass es mir unerwünscht vorkam, sie als neue Art zu beschreiben. Die ambonsche Pflanze ist jedoch bedeutend kleiner, hat einen lockereren Blütenstand, kleinere Blüten und einen verhältnismässig kürzeren Sporn.

Anoectochilis Reinwardtii Bl. Fl. Jav. Orch. 40, t. 12, f. 2, t. 12 b, f. 14 ; Miq. Fl. Ind. Bat. III, 732 ; J. J. S. Fl. Buit. VI, Orch. 96. - Folium petolatum II femina s. vera Rumph. Herb. Amb. VI, 93, t. 41, f. 3.

Ambon: Ohne nähere Fundortsangabe (Rumph.); Toena (J. J. S.); auch Java; Sumatra; mal. Halbinsel.

Die Blüten dieser Pflanze habe ich nicht gesehen. Die Blătter sind denjenigen der javanischen Pflanze jedoch so ähnlich, dass man vorläufig die Bestimmung als richtig annehmen darf.

Fig. 2 der oben erwähnten 'lafel, Folium petolatum I, mas, stellt eine andere Art aus der Gruppe Physurinae da, vielleicht Zeuxine amboinensis J. J. S.

Zeuxine sulcata Lndl. Gen. et Sp. Orch. 485; Journ. Linn. Soc. I, 186; Griff. Not. III, 396 ; Ich. pl. Asiat. t. 349 ; Bl. Fl. Jav. Orch. 55 ; Miq. Fl. Ind. Bat. III, 723; Hook. f. Fl. Br. Ind. VI, 106; King et Pantl. Ann. Bot. Gard. Calc. VIII, 286, t. 381 ; J. J. S. Fl. Buit. VI, Orch. 108. - Z. bracteata, Z. brevifolia, Z. robusta Wght, Ic. 1724 bis, 1725, 1726. - Z. membranacea Lndl. 
Gen. et Sp. Orch. 486 ; Journ. Linn. Soc. I, 186 ; Bl. Fl. Jav. Orch. 56, t. 22, f. 2, t. 23 a.-Z. Tripleura Lndl. Journ. Linn. Soc. I, 186. - Z. integerrima Lndl. Gen. et Sp. Orch. 486 ; Bl. Fl. Jav. Orch. 55, t. 19 f. 1, t. 23 c; Miq. Fl. Ind. Bat. III, 723. - Z. cmarginata Lndl. Gen. et Sp. Orch. 185. - Z. procumbens Bl. Fl. Jav. Orch. 56, t. 22, f. 3, t. 23 b. - Tripleura pallida Lndl. Wall. Cat. 7291 ; Gen. et Sp. Orch. 452. - Adenostylis cmarginata, A. integerrima Bl. Bijdr. 414, t. 17. Pterygodium sulcatum Rxb. Fl. Ind. III, 452.

Ambon: Hila, am Strande zwischen Ipomoea biloba Forsk., Cassytha filiformis L. U. S. W. (J. J. Smith); auch Java; Philippinen; Assam; China; Ostindien.

Die Sepalen sind weiss, am Grunde hellgrün, das Labellum gelb, die Platte mit 3 grünen Längsnerven.

Zeuxine amboinensis J. J. S. Ic. bog. II, 259. Haplochitus amboinense J. J. S. Bull. Inst. bot. Buit. 7 ; Ic. bog. II, 19, t. c V A.

Ambon: Zwischen Alang und dem Latoea (J. J. S.) var. argentea J. J. S. I. c. - H. amboinense J. J. S. var. argentea J. J. S. 11. cc.

Mit der vorigen Art.

Cystopus muricatus J. J. S. n. sp.

Humilis. Folia circ. 6, petiolata, ovata, breviter acuminata, circ. $1.90 \mathrm{~cm}$. longa, $1.10 \mathrm{~cm}$. lata. Inflorescentia circ. $8.50 \mathrm{~cm}$. longa, circ. 8 flora, hirsuta. Bracteae a basi lata ciliata acuminatae, ovario multo longiores. Sepala parallela, acuminata, extus ad apicem muricata. 
Petala unilateralia, lanceolato-spathulata. Labelli unguis latus, integerrimus, utrinque infra laminam lobula parva; lamina porrecta, dilatata. Anthera longa, angusta. Caudicula lata.

Kleine Pflanze. Stengel niederliegend, aufstrebend, wurzelnd, stielrund, kahl, hellgrün, $\pm 10 \mathrm{~cm}$. lang, \pm 0.27 cm. dick. Blätter \pm 6 , abstehend, gestielt, eirund, kurz zugespitzt, sehr spitz, wellig, sammtartig grün, an der Spitze mit 3 weisslichen Adern, unten heller, \pm 1.90 $\mathrm{cm}$. lang, $1.10 \mathrm{~cm}$. breit; Stiel rinnig, mit der nahezu gleich langen, röhrigen Scheide $\pm 0.90 \mathrm{~cm}$. lang, kahl, hellgrün. Blütenstand aufrecht, ziemlich lang und grob abstehend behaart, $\pm 8.50 \mathrm{~cm}$. lang. Pedunculus stielrund, hellgrün, $\pm 6 \mathrm{~cm}$. lang, mit einigen $( \pm 4)$ locker anliegenden, lang zugespitzten, ausser der Spitze gewimperten, blassen Schaftblättern. Bracteen viel länger als das Ovarium, anliegend, aufrecht, aus eirund dreieckigem Grunde lang zugespitzt, concav, der breite Teil ziemlich lang gewimpert, blass grün, im ganzen $0.90 \mathrm{~cm}$. lang, $0.35 \mathrm{~cm}$. breit, die Spitze $0.40 \mathrm{~cm}$. lang. Blüten \pm 8 , nach einer Seite gekehrt, wenig geöffnet, $\pm 0.37 \mathrm{~cm}$. breit, $0.70 \mathrm{~cm}$. lang. Sepalen parallel, lanzettlich, zugespitzt, rinnig concav, aussen nahe der Spitze mit einigen ziemlich langen, locker anliegenden Weichstacheln, hellgrün mit weisser Spitze; das unpaare $\pm 0.60 \mathrm{~cm}$. lang, $0.17 \mathrm{~cm}$. breit; die paarigen schief, mit verbreitertem, concavem Grunde den Lippensack umfassend, $0.70 \mathrm{~cm}$. lang, an der Basis $0.23 \mathrm{~cm}$. breit. Petalen mit dem unpaaren Sepalum etwas verklebt, einseitig, lanzettlich spatelig, spitz, schwach 
concav und wellig, 1nervig, durchscheinend weiss, am Grunde blass grün, $0.53 \mathrm{~cm}$. lang, $0.13 \mathrm{~cm}$. breit. Labellum im ganzen $\pm 0.63 \mathrm{~cm}$. lang, weiss, am Grunde mit einem von den parrigen Sepalen umschlossenen, schräg nach hinten gekehrten, stumpfen, blass grünen, innen mit 2 Schwielen versehenen Sack; Nagel der Platte breit, rinnig, mit eingebogenen Rändern der Säule anliegend, vorn beiderseits mit einem kleinen, stumpfen, fleischigen Läppchen; Platte vorgestreckt, quer verbreitert, schwach 2lappig, mit einem kurzen Spitzchen, die beiden Hälften aufwärts gebogen, einen rechten Winkel bildend, $0.17 \mathrm{~cm}$. lang, $0.30 \mathrm{~cm}$. breit. Gynostemium blass grün, $0.37 \mathrm{~cm}$. lang; Clinandrium tief. Anthera lang und schmal, stumpf, am Grunde kurz herzförmig, weisslich, $0.25 \mathrm{~cm}$. lang. Pollinien 2, gelb, aus keuligen Massen zusammengestellt, auf einer breiten Caudicula mit spitzer Klebmasse. Rostellum tief geteilt, die Abschnitte durch eine dünne Membran verbunden. Stigma an der Unterseite der Säule, ungeteilt, dem Clinandrium ähnlich. Ovarium der Rachis parallel aufrecht, gedreht, hellgrün, nur an der Spitze etwas grob behaart, 0.60 $\mathrm{cm}$. lang.

Ambon: Toena (J. J. Smith).

Ich habe diese Pflanze vorläufig zu Cystopus gestellt, wiewohl der Nagel nicht gezähnt oder gefranst ist und ich keine Anhängsel an der Säule gefunden habe. Es ist immerhin möglich, ùass ich die letzteren, wenn sie sehr klein sind, ubersehen habe.

Bemerkenswert sind die ziemlich langen Weichstachel an der Spitze der Sepalen. 
Corymborchis veratrifolia Bl. Fl. Jav. Orch. 1C5, t. 42 E, t. 43, f. 1 ; J. J. S. Fl. Buit. VI Orch. 134. - C. assamica Bl. 1. c. 106, †. 43, f. 2. - Hysteria veratrifolia Reinw. Cat. Hort. Bog. 99; Bot. Zeit. Syll. Pl. nov. II, 5 ; Lndl. Gen. et Sp. 439; Hassk. Cat. Hort Bog. 47 ; Pl. Jav. rar. 131; De Vr. Ill. Orch. t. VII. - Corymbis veratrifolia Rchb. f. Flora XLVII (1865) 184; Hook. f. Fl. Br. Ind. VI, 91. - C. disticha Lndl. Fol. Orch. 1 (e. p.) - Macrostylis disticha Bred., Kuhl et v. Hass. Orch. jav. Fasc. I, t. 2. - Rhynchanthera paniculata Bl. Bijdr. f 78 .

Ambon: Hoetoemoeri ('Teysm.); Wai (Teysm., Treub.); Hitoe Lama (Treub); auch Molukken; N. Guinea; Borneo; Java; Sumatra; inal. Halbinsel; Ostindien.

Coelogyne Rumphii Lndl. Fol. Orch. n. 35 ; Miq. Fl. Ind. Bat. III, 668; Ridl. Journ. of Bot. XXIV (1886) 353. - C. psittacina Rehb. f. Xen. Orch. II, 141, t. 153. - Pleione Rumphii O. K. Rev. Gen. Pl. II, 680. Angraecum nervosum Rumph. Herb. Amb. VI, 106, t. 48.

Ambon: Ohne nähere Fundortsangabe (Rumphius, Doleschall); Hoetoemoeri ('Teysm.); Horiel ; Nona ; Hoetoe Mortetoe; zwischen Roema tiga und Hitoe; zwischen Alang und dem Latoea (J. J. Smith); auch Neu-Guinea.

Diese Art ist auf Ambon sehr allgemein an schattigen Stellen auf Bäumen, wird jedoch nie an der Küste angetroffen.

Sie ist nahe verwandt mit $C$. speciosa Lndl. von Java und kann gesagt werden diese Art auf Ambon $\mathrm{zu}$ ersetzen. 
In Buitenzorg wird ein Ex. kultiviert, das regelmässig 2blättrige Trugknollen hervorbringt, und grössere Blüten hat. Reichenbachs C. psittacina gehört sicher hierher; ich habe die Pflanze im Wiener Herbarium gesehen.

\section{Dendrochilum sp.}

Ambon: Salahoetoe (Teysmann).

Im Buitenzorger Herbarium befindet sich eine der Sektion Platyclinis angehörige Art, welche wahrscheinlich neu ist. Da die Blüten jedoch beschädigt sind, lasse ich die Pflanze unbeschrieben.

Tainia penangiana Hook. f. Fl. Br. Ind. V, 820; Ic. pl. XXI, t. 2089; Ridl. Journ. Limn. Soc. Bot. XXXII, 314 ; J. J. S. Fl. Buit. VI, Orch. 183.

Ambon: Toena (J. J. S.); auch Java; mal. Halbinsel.

Bei den von mir in Ambon und Java gefundenen Exemplaren bleiben die Blüten (in kultiviertem Zustande) stets halb geschlossen; das Rostellum fehlt und demgemäss findet Selbstbefruchtung statt. Bei einigen vom botanischen Garten zu Singapore erhaltenen und in Buitenzorg in genau derselben Weise behandelten Pflanzen dieser Art öffnen sich die Blüten regelmässig und haben stets ein gut ausgebildetes Rostellum.

Plocoglottis moluccana Bl. Mus. I, 47; Fl. Jav. Orch. 53, t. 16; Miq. Fl. Ind. Bat. III, 676.

Ambon: Ohne nähere Fundortsangabe (Zippel).

Blume's Angabe, dass diese Pflanze Rumphius' Angraecum terrestie alterum vorstellen sollte, ist sichel unrichtig. 
Die Figur gehört zu einer Phajus-art aus der LimatodisSektion.

Plocoglottis Lowii Rchb. f. Gard. Chr. 1865, 434; Xen. Orch. II, 142, t. 154 ; Hallier f. Ann. Buit. XIII, $2^{\circ}$ p. 318. - P. porphyrophylla Ridl. Trans. Linn. Soc. Ser. II, Bot. III, (1893) 368; Journ. Linn. Soc. Bot. XXXII, 317.

Ambon: Hoetoe Mortetoe (J. J. Smith); auch Borneo; mal. Halbinsel.

Ridley's Beschreibung von $P$. porphyrophylla passt so genau zu dieser Pflanze, dass sie ohne Zweifel dahin gehört.

Bemerkenswert ist die Asymmetrie, der Blüte. Das eine Petalum ist aufwärts, das andere mehr oder weniger abwärts gewandt; die parigen Sepalen sind naclı links, die Säule nach rechts gedreht.

Phajus callosus Lndl. var. ecalcaratus J. J. S. n. var. Folia circ. 4, erecta, petiolata, lanceolata, in totum circ. $1.15 \mathrm{~m}$. longa, $8-11 \mathrm{~cm}$. lata. Inflorescentia foliis aequilonga, multiflora. Sepala petalaque lanceolata, obtusa, intus cinnamomea, extus candida. Labellum ecalcaratum, gynostemium amplectens et basi eius adnatum, album, vino tinctum et maculatum. Gynostemium apicem versus valde alato•dilatatum.

Trugknollen genäher't, auf dem Querschnitt elliptisch, fast cylindrisch, 6gliedrig, grün, $\pm 8 \mathrm{~cm}$. lang, $2.80 \mathrm{~cm}$. breit, 上 4 blattrig, am Grunde mit Scheiden. Blätter aufrecht, 
gestielt, nur sehr wenig gebogen, lanzettlich, lang zugespitzt, mit 5--7 unten stark vorragenden Nerven, zwischen den Nerven convex, glänzend grün; Spreite bis t $82 \mathrm{~cm}$. lang, $9.70-11 \mathrm{~cm}$. breit; Stiel rinnig; 3rippig, hellgrün mit dunkleren Streifen, $\pm 33 \mathrm{~cm}$. lang. Blütenstände an den unteren Knoten, kräftig, aufrecht, den Blättern gleich lang, locker vielblütig. Pedunculus auf dem Querschnitt oval, oben stielrund, grün, $\pm 53 \mathrm{~cm}$. lang, $1.50 \mathrm{~cm}$. breit, mit mehreren am Grunde röhrigen, nach oben hin grösser werdenden, hellgrünen, mit 3-5 dunkleren, aussen vorragenden Nerven versehenen, bis $\pm 9 \mathrm{~cm}$. langen Scheiden. Rachis $\pm 72 \mathrm{~cm}$. lang. Bracteen gross, hinfällig, länglich 3 eckig, spitz, concav, aussen gekielt, hellgrün mit dunkleren, mehr oder weniger vorragenden Nerven, bis \pm 8 $\mathrm{cm}$. lang, $3 \mathrm{~cm}$. breit. Blüten \pm 20 , weit geöffnet, \pm $10 \mathrm{~cm}$. breit, die Sepalen und Petalen in einer mit dem Labellum einen spitzen Winkel bildenden Ebene ausge-breitet, bei Zerquetschung dunkelblau werdend, lange dauernd, fleischig. Sepalen lanzettlich, stumpf, innen mit einer Längsrinne, besonders die paarigen mit aussen vorragender Mittelrippe, aussen reinweiss, innen zimmtbraun, schwach heller und dunkler längsstreifig, mit kleinen, hellgelben Pünktchen, schmalem, blass gelbem Rande und gelblich weisser Spitze, $\pm 5.20 \mathrm{~cm}$. lang; das unpaare $1.30 \mathrm{~cm}$. breit; die paarigen etwas schief, etwas spitzer als das unpaare, $1.40 \mathrm{~cm}$. breit. Petalen lanzettlich, gegen die Spitze etwas verbreitert, stumpf, convex, ebenso wie die Sepalen an der Spitze concav, aussen mit einer Längsfurche und weiss, innen zimmt- 
braun, mit einer schmalen, hellgelben Mittellinie, hellgelben Pünktchen, schmalem weissem Rande und weisser Spitze, 5 cm. lang, $1.25 \mathrm{~cm}$. breit. Labellum um die Säule gerollt, mit einem \pm 1.25 langen, dick fleischigen, innen behaarten Nagel der Säule am Grunde angewachsen," nicht gespornt, am Grunde mit einem kurzen, abgerundeten, nicht zwischen 'den paarigen Sepalen hervorragenden Höcker; Platte 3lappig, unten mit einer Längsfurche, innen mit 2 breiten, flachen, fleischigen, durch eine schmale Furche getrennten, sich nach vorn zu einer viel schmäleren Längsrippe vereinigenden Längsleisten, ausgespreizt im ganzen $\pm 4.70 \mathrm{~cm}$. lang, 3.60 cm. breit, kahl, weiss, innen am Grunde weinrot gefleckt, die Lappen aussen und der Mittellappen innen zum grössten 'Teil, die Seitenlappen innen nur an der Spitze weinrot gefärbt; Seitenlappen gross, um die Säule gerollt, länger als die Säule, breit, abgerundet, mit auswärts gebogenem, welligem Rande; Mittellappen vorgestreckt, quer abgerundet 4eckig, an der Spitze rinnig, die beiden Hälften convex, am Rande wellig, $1 \mathrm{~cm}$. lang, $1.70 \mathrm{~cm}$. breit. Säule fast gerade, gegen die Spitze stark flügelig verbreitert und dort gekerbt; der mit dem Lippennagel verwachsene 'Teil unten behaart, blass weinrot, an der Spitze weiss berandet und beiderseits mit einem weinroten Fleck, unten weinrot, $\pm 2.60 \mathrm{~cm}$. lang, an der Spitze $0.80 \mathrm{~cm}$. breit; Clinandrium sehr tief. Anthera kappig, abgerundet, in ein eckiges Schnäbelchen zugespitzt, weiss, zerstreut behaart, $0.35 \mathrm{~cm}$. breit. Pollinien 8, wachsartig; verkehrt 3eckig, schief, abgerundet, seitlich zusamınengedrückt, matt gelb. Rostellum gross, 3eckig, 
spitz, zurückgeschlagen. Stigma verkehrt eirund. Ovarium $2.50 \mathrm{~cm}$. lang, gekrümmt; Stielchen $1.40 \mathrm{~cm}$. lang; beide glänzend weiss.

Ambon: Horiel (J. J. Smith).

Wiewohl sie in einigen Punkten bedeutend von $P$. callosis Lndl. abweicht, ist der Blütenbau beider Pflanzen im allgemeinen so ähnlich, dass ich sie nur als Varietät betrachtet habe. Die Hauptunterschiede sind das nahezu ungespornte Labellum und die Farbe, welche mit der von $P$. Incarvillei O. K. (P. Blumei Lndl.) auffallend übereinstimmt. Es muss jedoch gesagt werden, dass auch die Farbe von $P$. callosus in Java sehr variabel ist.

Die Beschreibung dieser stattlichen Pflanze wurde angefertigt nach einem im Buitenzorger Garten kultivierten Exemplar.

Phajus amboinensis Bl. Mus. II, 180; Fl. Jav. Orch. 8; Miq. Fl. Ind. Bat. III, 672 ; J. J. S. Fl. Buit. VI, Orch. 198. - P. Zollingeri Rchb. f. Xen. Orch. II, 201, t. 76 II ; Miq. I. c. 740. - Angraecum terrestre alterum Rumph. Herb. Amb. VI, 113, t, LII, f. 1.

Ambon: Ohne nähere Fundortsangabe (Rumphius, Zippel); zwischen dem Sirimau und Horiel (J. J. Smith); auch Java; Celebes.

Rumphius Figur (t. I, f. 3) welche als hierher gehörig angegeben wird, stellt eine kleinere Pflanze dar mit viel spitzeren Sepalen und Petalen. Wahrscheinlich gehört diese Figur zu P. gratus Bl.

Blume hat Rumphius' Angr. terrestre alterum sowohl als Phajus amboinensis Bl., wie auch als Plocoglottis 
moluccana Bl. gedeutet. Nur die erstere Angabe ist richtig.

Phajus gratus Bl. Mus. II. 181; Fl. Jav. Orch. II.Limatodis grata Miq. Fl. Ind. Bat. III, 672. - Angraccum tcrrestre primum album Rumph. Herb. Amb. VI, 113.

Ambon: An der Alf (Rumphius, Zippel).

Von dieser Art ist mir nichts bekannt.

Wahrscheinlich gehört die t. L, f. 3 zu diesęr Pflanze.

Calanthe tunensis J. J. S. Bull. Inst. Buit. n. 7; Ic. bog. II, 69, t. CXIII A. -

Ambon: Toena, auf und nahe der Spitze sehr häufig (J. J. Smith).

Die Pflanzen wachsen meistens am Boden; bisweilen findet man sie jedoch auch in der dicken Moosschicht ziemlich hoch an den Bäumen.

Calanthe saccata J. J. S. Bull. Inst. Buit. n. 7 ; Ic. bog, II, 70, t. CXIII B.

Ambon: Latoea, auf der Spitze (J. J. Smith).

Von dieser Art traf ich nur eine Pflanze blühend an.

Calanthe celebica Rolfe, Kew Bull. 1899, 129.

In der Umgebung des Latoea in Wäldern (J. J. Smith); auch Celebes.

Die von mir in Ambon gesammelte Pflanze ist sicher C. celcbica Rolfe, welche vielleicht als eine Varietät betrachtet werden könnte von $C$. cmarginata Lndl. Die letztere Pflanze ist im allgemeinen grösser, der Blütenstand 
verhältnissmässig kürzer und gedrängter, die Blüten sind grösser, der Sporn ist länger, nach hinten gekehrt und an der Spitze gegen das Ovarium aufwärts gekrümmt, kaum keulig, und bedeutend länger als die Platte; ausserdem sind die sehr kleinen Seitenlappen der Lippe sichclig auswärts gekrümmt und die Warzen rotbraun. Bei der ambonschen Pflanze ist der Sporn ausgesprochen keulig, der Platte gleich lang, mehr oder weniger volwärts gebogen und nach der Befruchtung der Platte angedrückt; die Seitenlappen sind gerade und die Warzen gelb.

Erwähnung verdient es, dass bei den wildwachsenden Exemplaren in Ambon das Ovarium schon bei den noch nicht geöffneten Blüten angeschwollen war, wiewohl ich auch in den geöffneten Blüten die weissen Pollinien stets trocken an ihrer Stelle antraf. Die Blüten sind violett.

Calanthe veratrifolia R. Br. Bot. Reg. sub t. 573 ; Lndl. Bot. Reg. t. 720; Gen. et Sp. Orch. 249; Fol. - Orch. 8; Bot. Mag. t. 2615; Griff. Ic. Pl. Asiat. t. 283, f. 4 ; Walp. Ann. VI. 917 ; Hook. f. Fl. Br. Ind. V, 851; J. J. S. Fl. Buit. VI, Orch. 211. - C. furcata Bat. Bot. Reg. 1838, Msc. n. 34 ; Miq. Fl. Ind. Bat. III, 711. - C. sumatrana Bl. ex. Boerl. Bijdr. Midd. Sum., 33. - ? C. catilligera Rchb. f. Bonpl. 1857, 37. - ? C. proboscidea Rchb. f. Gard. Chr. 1884, 476. - C. comosa Rchb. f. Linnaea, XIX, 374. - C. Perrotteti Rich. Ann. Sc. Nat. Ser. 2 XV, 68; Wight. Ic. t. 1664 ; Lndl. Fol. Orch. 7. - Limodorum veratrifolizm Wlld. 
Sp. Pl. IV, 122. - Amblyglottis veratrifolia Bl. Bijdr. 270. - Orchis triplicata Willem. Ust. Ann. 1852. Alismorchis veratrifolia O. K. Rev. Gen. Pl. II, 650. A. furcuta O. K. l. c. - Flos triplicatus Rumph. Herb. Amb. VI, 115, t. LII, f. 2.

Ambon: Ohne nähere Fundortsangabe (Rumphius); Hoetoemoeri (Teysm.); Sirimau; Horiel ; Toena ; zwischen Alang und dem Latoea; Hina Niwel (J. J. Smith); auch Ceram; Lombok; Borneo; Java; Sumatra; mal. Halbinsel; Philippinen; Ostindien; Neu-Guinea; Australien.

Was Rumphius mit seiner "Verandering” dieser Art meint, weiss ich nicht. Vielleicht nur eine Form dieser sehr varriabelen Calanthe.

\section{Acanthephippium sp.}

Ambon: Zwischen dem Sirimau und Horiel (J. J. Smith).

Ich traf die Pflanze ausser Blüte an und Exemplare im botanischen Garten kultiviert, habe ich noch nicht blühend gesehen.

Spathoglottis plicata Bl. Bijdr. 401, t. 76; Lndl. Gen. et Sp. Orch. 119; Wall. Cat. 3734 ; Rchb f. Walp. Ann. VI, 455; Hassk. Tijdschr. Nat. Gesch. IX, 139; Pl. Jav. rar. 126; De Vr. Ill. Orch.; Miq. Fl. Ind. Bat. III, 673 ; Hook. f. Fl. Br Ind. V. 813 ; J. J. S. Fl. Buit. VI, Orch. 219. - S. lilacina Griff. Not. IlI, 323 ; Ic. P]. Asiat. t. 311, f. 3.-Bletia angustifolia Gaud. Freyc. Vog. Bot. 421, t. 32. - Phajus Rumphii Bl. Mus. II, 
179; Fl. Jav. Orch. 6. - Angraecum terrestre primum. purpureum Rumph. Herb. Amb. VI, 112, (non fig.).

Ambon: An der Alf (Rumphius); in den Hügeln bei der Hauptstadt; Nona; zwischen Roemah tiga und Hitoe; zwischen Asiloeloe und Larike; zwischen Alang und dem Latoea (J. J. Smith); auch Molukken; Celebes; Borneo; Java; Sumatra; Singapore; mal. Halbinsel ; N.-Guinea; Salomon Inseln.

Diese Art ist auch in Ambon sehr häufig und kommt vor mit hell-und dunkelvioletten und mit weissen Blüten. In der Umgebung von Alang fand ich eine sehr schöne Form mit grossen, reinweissen, auf der Lippe citronengelb gezeichneten Blüten. Die weissblütige For'm in Java ist stets viel weniger schön als die violette; die Blüten sind dort klein, öffnen sich meistens nur wenig und die Farbe ist ziemlich schmutzig.

Rumphius hat mit der Beschreibung von seinen $A n$ yraecum terrestre primum purpureum bestimmt sicher Spathoglottis gemeint. Aus Versehen ist jedoch wohl die t. LII fig. 1 als hierher gehörig angegeben; die Beschreibung passt ja überhaupt nicht dazu. Blume hat dann aus der Kombination der Tafel, (welche Phajus (mboinensis Bl. vorstellt) mit der Beschreibung sein P. Rumphii zusammengestellt.

\section{Geodorum sp.}

Ambon: Batoe Gantoeng; Asiloeloe; Larike; Alang; (J. J. Smith), zwischen Gras wachsend.

Die Pflanzen waren leider alle ohne Blüten, so dass eine nähere Bestimmung unmöglich war. 
Oberonia (Sect. Caulescentes Lndl.) lucida J. J. S. n. sp. Caules elongati, circ. $23 \mathrm{~cm}$. longi. Folia lanceolato. 3angula, acuta, circ. $4 \mathrm{~cm}$. longa, superiora breviora. Bracteae parvae, suberosae. Flores plus minusve verticillati, verticilli circ. 10flori, apicem versus dissiti, minuti, flavo-virides. Sepala ovata, revoluta; petala linearia revoluta. Labellum lucidum, lobi laterales erecti, valde convexi; lobus medius porrectus, oblongus, bilobus, apice serratus.

Stengel genähert, herabhängend, $\pm 23 \mathrm{~cm}$. lang. Blätter \pm 23 , 2zeilig, stark seitlich zusammengedrückt, reitend, mit dem Stengel spitze Winkel bildend, fleischig, lanzettlich 3eckig, spitz, die Aussenseite scharfrandig, glänzend grün, die unteren $\pm 4 \mathrm{~cm}$. lang, $0.80 \mathrm{~cm}$. breit, nach oben hin kleiner werdend. Blütenstand terminal, hängend, $\pm 12 \mathrm{~cm}$. lang, vielblütig. Rachis längsrippig, hellgrün. Bracteen anliegend, klein, länglich, ziemlich spitz, etwas unregelmässig berandet, \pm 0.10 $\mathrm{cm}$. lang. Blüten mehr oder weniger deutlich in \pm 10 blütigen Quirlen, bisweilen spiralig, nach oben hin zerstreut, alleinstehend, die höchsten zuerst blühend, klein, gelbgrün, mit zurückgerollten Sepalen und Petalen, 土 0,10 cm. lang, $0.17 \mathrm{~cm}$. breit. Unpaares Sepalum länglich, schwach eirund, stumpf, mit breiter Basis, convex, fast $0.10 \mathrm{~cm}$. lang. Paarige Sepalen eirund. Petalen linear, fast $0.10 \mathrm{~cm}$. lang. Labellum ziemlich gross, 3 lappig, stark glänzend, am Grunde mit einer von einem halbkieisrunden Rande umgebenen Grube, Seitenlappen aufrecht, die Säule umfassend, breit länglich, stumpf, 
stark convex; Mittellappen vorgestreckt, nahezu flach, länglich, $0.10 \mathrm{~cm}$. lang, 2lappig, die Läppchen 3eckig, nahezu parallel, gesägt. Säule sehr kurz. Anthera quer oval, mit verdicktem, convexem, an der Spitze wie ein kurzes, stumpfes Schnäbelchen vorragendem Konnectiv. Pollinien orange. Ovarium + Stielchen $\pm 0.13 \mathrm{~cm}$. lang.

Ambon: In der Umgebung der Hauptstadt auf Bäumen (J. J. Smith).

Die Art is verwandt mit 0 . imbricata Lnd]. Der starke Glanz der Lippe ist sehr auffallend.

Microstylis moluccana J. J. S. Bull-Inst. Buit. n. T; Ic. bog. II, 28. t. CVII B.

Ambon: Ohne nähere Fundortsangabe ('Teysm.); zwischen Alang und Hina Niwel (J. J. Smith); auch Ternate (J. J. Smith).

? Microstylis ventilabrum Rchb. f. Gard. Chr. XVI (1881) 717 ; Ridl. Journ. Linn. Soc. Bot. XXIV (1888) 341.Malaxis ventilabrum O. K. Rev. Gen. Pl. II, 673.

Folia petiolata, oblique oblongo-lanceolata, acuta, undulata, supra cuprea, circ. $8 \mathrm{~cm}$. longa. Inflorescentia alata, apice nutans, multiflora. Flores parvi, viridilutei, marcescentes rubri. Sepala reflexa, ovalia, convexa. Petala lineari-oblonga. Labellum in circuitu rotundum, apice 8dendato, dentibus 2 intermediis se invicem tegentibus.

Stengel am Grunde niederliegend, wurzelnd, aufstrebend, 
fleischig, dunkelviolett, $\pm 11 \mathrm{~cm}$. hoch, beblättert. Blätter gestielt, länglich lanzettlich, schief, spitz, längsfaltig, am Rande wellig, mit 3 starken, oben gefurchten, unten gekielten Nerven, oben schimmernd kupferbraun, unten hellgraugrün, $\pm 8 \mathrm{~cm}$. lang; Stiel rinnig, 3 kantig, blass graugrün und violett gefärbt; Scheide kurz, röhrig, bisweilen aufreissend, violett. Blütenstand aufrecht, lange fortblühend, an der Spitze nickend, sehr vielblütig, 10 cm. und melrr lang. Pedunculus und Rachis ziemlich dümn, geflügelt, am Grunde violett, nach oben hin blass grün, der erstere $\pm 3-4 \mathrm{~cm}$. lang. Bracteen zurückgeschlagen, lanzettlich, spitz, violettlich, mit einem grünen Längsstreifchen. Blüten klein, $\pm 0.40 \mathrm{~cm}$. breit, 0.50 $\mathrm{cm}$. lang, blass grünlich gelb, beim Welken rotbraun werdend. Sepalen zurückgebogen, oval, stark convex, mit breiter Basis. Petalen etwas kürzer, linear länglich, convex, mit zurückgebogener Spitze. Lippe ziemlich flach, im Umriss nahezu rund, am Grunde mit einer hellgrünen Grube, die Säule mit 3eckigen, ziemlich spitzen, parallelen, blass grünlich gelben öhrchen umfassend; Mittellappen halbelliptisch, an der Spitze mit 2 übereinander liegenden Zähnen, etwas fleischig, glänzend goldgelb, beiderseits mit 3 ziemlich langen, nach aussen hin kleiner werdenden, pfriemlichen, sehr spitzen, gelben Zähnen. Gynostemium sehr kurz, blass grün, mit über die Anthera vorragenden öhrchen. Anthera hellgelb. Pollinien 4, gelb.

Ambon: Soja (Treub).

Diese Pflanze stimmt ziemlich gut mit Reichenbachs Beschreibung und mit den Exemplaren im Kew Herba- 
rium überein. Die (wahrscheinlich) gleiche Art sammelten Hallier und Nieuwenhuis in Borneo.

\section{Microstylis horielensis J. J. S. n. sp.}

Caulis erectus, crassus, multifolius. Folia lanceolata, 4nervia, margine undulata. Inflorescentia laxe multiflora, elongata. Flores $0.65 \mathrm{~cm}$. lati, atroviolacei. Sepala petalaque patentia, oblonga, obtusa. Labelli auriculae magnae, remotae, 3angulares; lobus medius latus, bilobus, incurvus, in utraque parte dentibus 2acutis brevioribus et lobula obtusa.

Stengel aufrecht, fleischig, fast cylindrisch, auf dem Querschnitt fast elliptisch, grün mit violettem Anflug, $\pm 12 \mathrm{~cm}$. lang, $1.20 \mathrm{~cm}$. breit, $15-20$ blättrig. Blätter 2zeilig, schräg aufrecht, umgebogen, gestielt, schief lanzettlich, zugespitzt, spitz, mit 4 oben gefurchten, unten scharf gekielten Nerven, oben zwischen den Nerven convex, am Rande wellig, glänzend grün, \pm 15.50 $\mathrm{cm}$. lang, $5.20 \mathrm{~cm}$. breit; Stiel breit, rinnig, mit der kurzen Scheide $\pm 5 \mathrm{~cm}$. lang, scharf 4 kantig, grün, die Ränder uud Kiele oft dunkelviolett. Blütenstand terminal, aufrecht, locker, vielblütig, dunkel rotviolett. Pedunculus vielflügelig-kantig, $\pm 6 \mathrm{~cm}$. lang, $0.35 \mathrm{~cm}$. breit. Rachis $\pm 16 \mathrm{~cm}$. lang. Bracteen zurückgeslagen, pfriemlich, spitz, $\pm 0.75 \mathrm{~cm}$. lang, dunkel rotviolett. Blüten $\pm 0.65 \mathrm{~cm}$. breit, $0.70 \mathrm{~cm}$. lang, mit abstehenden Sepalen und Petalen, dunkel rotviolett. Unpaares Sepalum länglich, stumpf, convex, $0.37 \mathrm{~cm}$. lang, $0.17 \mathrm{~cm}$. breit. Paarige Sepalen schief oval, stumpf, convex, 0.30 
cm. lang, $0.20 \mathrm{~cm}$. breit. Petalen länglich, etwas spatelig, stumpf, convex, $0.36 \mathrm{~cm}$. lang, $0.15 \mathrm{~cm}$. breit. Labellum hufeisentörmig, mit 2 grossen, 3 eckigen, nahezu parallelen, weit auseinander stehenden, stumpfen, ziemlich flachen ohrchen die Säule umfassend, die Platte vorn 3lappig, mit kurzen, stumpfen Seitenlappen und breitem, 2lappigem, stark vorwärts gekrümmtem, concavem Mittellappen und beiderseits davon 2 spitzen, schwach sicheligen, bedeutend kürzeren Zähnen, am Grunde mit einer grossen, von einem hufeisenförmigen Rande umgebenen Vertiefung, ausgespreizt im ganzen $\pm 0.45 \mathrm{~cm}$. lang und breit. Säule kurz, schwach gebogen, 土 0.12 lang, mit stumpfen, etwas rautenförmigen öhrchen. Anthera hellgelb. Pollinien gelb. Narbe eine Querspalte unterhalb der Narbe. Ovarium $\pm 0.25 \mathrm{~cm}$. lang, mit dem 0.35 langen Stielchen einen stumpfen Winkel bildend.

Ambon: Horiel (J. J. Smith).

Diese Pflanze ist wohl die meistblättrige Art, welche mir bekannt ist.

Sie gehört zu Blume's Crepedium und steht vielleicht M. obovata J. J. S. am nächsten. Die stark einwärts gekrümmte Spitze der Lippe ist charakteristisch für die Art und kommt auch vor bei $M$. Wallichii Lndl. aber nicht, für so viel mir bekannt ist, bei anderen Arten mit gezähntem Labellum.

Liparis odorata Lndl. Gen. et Sp. Orch. 26; Thw. Enum. Pl. Ceyl. 295; J. J. S. Fl. Buit. Orch. 263. L. paradoxa Rehb. f. Walp. Ann. VI, 218; Ridl. Jouln. Linn. Soc. Bot. XXXII, 261; Hook. f. Fl. Br. Ind. V, 
698; King et Pantl. Ann. Bot. Gard. Calc. VIII, 27, t. 34. - Malaxis odorata Wlld. Sp. Pl. IV, 91. - M. lancifolia Smith, Rees' Encycl. - Empusa paradoxa Lndl. Wall. Cat. 1937 A. (p. p.); Bot. Reg. sub. t. 825; Gen. et Sp. Orch. 17; Miq. Prol. Fl. Jap. 135; Thw. 1. c. 426. - Leptorchis odorata O. K. Rev. Gen. Pl. II, 671.

Ambon: Zwischen Alang und Hina. Niwel, in Grasebenen (J. J. Smith); auch Java; Sumatra; Siam; Kambodja; China; Japan; Ostindien.

Liparis (Sect. Mollifoliae Rchb. f.) amboinensis J. J. S. n. sp.

Terrestris. Pseudobulbi elongato-conici, paucifolii. Folia breviter petiolata, oblique oblonga, acuminata, circ. 6 nervia. Inflorescentia erecta, pauciflora. Bracteae parvae. Flores majusculi, viridi-violacei. Sepala lanceolata, lateralia sub labello porrecta, falcata. Petala reflexa, linearia. Labellum valde recurvum, orbiculare, crenulatum, ungue brevi lato, basi callis 2 parvis in costulas breves excurrentibus.

Erdpflanze. Trugknollen genähert, aufrecht, fleischig, lang kegelig, spitz, weniggliedrig, auf dem Querschnitt nahezu rautenförmig, $\pm 9 \mathrm{~cm}$. lang, $2.10 \mathrm{~cm}$. breit, mit am Grunde röhrigen, scharfkantigen Scheiden, \pm 3 blättrig. Blätter abstehend, kurz und breit gestielt, etwas schief länglich, zugespitzt, mit \pm 6 unten scharf gekielten Nerven, oben zwischen den Nerven etwas convex, nicht wellig, grün, bis $\pm 19 \mathrm{~cm}$. lang, $8 \mathrm{~cm}$. breit; Stiel + Scheide $\pm 3 \mathrm{~cm}$. lang, kantig. Blüten- 
stand aufrecht, wenigblütig. Penduculus 5 flügelig, hellgrün, $\pm 14 \mathrm{~cm}$. lang, $0.40 \mathrm{~cm}$. breit. Bracteen klein, abstehend, 3eckig, spitz, grün, $0.40 \mathrm{~cm}$. lang. Blüten ziemlich gross, $\pm 1.90 \mathrm{~cm}$. breit. Unpaares Sepalum zurückgeschlagen, linear lanzettlich, stumpf, stark convex, mit zurückgebogenen Rändern und Spitze, hellgrün, am Grunde etwas violett gefärbt, $1.40 \mathrm{~cm}$. lang, 0.35 $\mathrm{cm}$. breit. Paarige Sepalen unterhalb der Lippe vorgestreckt, schief nach hinten aufgerollt, lanzettlich, sichelig, stumpf, gefärbt wie das unpaare, $\pm 1.10 \mathrm{~cm}$. lang, $0.40 \mathrm{~cm}$. breit. Petalen zurückgeschlagen, linear, mit zurückgerollten Rändern, gegen die Spitze etwas verbreitert, stumpf, blassgrün und viollet gefärbt, \pm 1.35 cm. lang, $0.15 \mathrm{~cm}$. breit. Labellum stark gekrümmt, kreisrund, mi ${ }^{4}$ einen kurzen, breiten Nagel, gekerbt, oben mit einer Längsrinne, die beiden Hälften convex, am Grunde mit 2 kleinen, in 2 kurze Rippchen auslaufenden Calli, dunkelviolett, in der Mitte mit grünlichem Anflug, $\pm 1.10 \mathrm{~cm}$. lang und breit. Säule gekrummt, gegen die Spitze fleischig geflügelt und unten stark concav, am Grunde violett, an der Spitze blass grüngelb, $0.60 \mathrm{~cm}$. lang. Anthera nahezu kreisrund, lebhaft hellgrün. Pollinien 4, hellorange. Rostellum kurz und breit zugespitzt. Narbe tief, 4eckig. Ovarium aufwärts gebogen, hellgrün, mit dem violetten Stielchen \pm 1.40 cm. lang, schärf 6 rippig.

Ambon: Hatoe Lalikoel, zwischen Alang und dem Latoea (J. J. Smith).

Diesse Art steht $L$. bituberculata Lndl. sehr nahe.

Ich habe sie getrennt gehallten wegen des na- 
hezu kreisrunden Labellum und del anders gebauten Calli.

Liparis (Sect. Coriifoliae Rchb. f.) cleistogama J. J. S. n. sp.

Pseudobulbi ovati, 1folii. Folium anguste lanceolatum, acutum. Inflorescentia laxa, folio longior. Pedunculus compressus, ensiformis. Bracteae e basi lata subulatae. Flores cleistogami, virides. Sepala oblonga, extus costa valde incrassata. Petala linearia. Labellum late obovatum, emarginatum, apiculatum, basi bicallosum. Gynostemium curvatum, in utraque parte ala magna 3angulari.

Epiphyt. Trugknollen zusammengehäuft, eiförmig, auf dem Querschnitt elliptisch, grün, $\pm 1.70--2.10 \mathrm{~cm}$. lang, $0.80-1.20 \mathrm{~cm}$. breit, 1blättrig. Blatt schmall lanzettlich, spitz, am Grunde verschmälert, mit oben gefurchtem, unten scharf gekieltem Mittelnerv, \pm 5 nervig, glänzend grün, unten matt, $\pm 7-13.50 \mathrm{~cm}$. lang, $1.55-2 \mathrm{~cm}$. breit. Blätenstände an den jungen Trieben, aufrecht, länger als die Blätter, locker, ziemlich wenigblütig. Pedunculus zusammengedrückt, schwertförmig, scharfrandig, grün, $\pm 5.20 \mathrm{~cm}$. oder mehr lang, $0.20 \mathrm{~cm}$. breit, ohne Schaftblätter. Rachis zickzackig, 4 flügelig, $7 \mathrm{~cm}$. oder mehr lang. Bracteen 2zeilig, schräg abstehend, pfriemlich, mit breiter Basis, concav, gekielt, \pm 0.80 $\mathrm{cm}$. lang. Blüten sich nicht öffnend, nie Frucht ansetzend, hellgrün. Knospen länglich, 3kantig, $0.475 \mathrm{~cm}$. lang, $0.20 \mathrm{~cm}$. breit. Sepalen länglich, an der Spitze 
verschmälert, stumpflich, concav, mit aussen stark verdickter Mittelrippe; das unpaare $\pm 0.50 \mathrm{~cm}$. lang, 0.20 $\mathrm{cm}$. breit; die paarigen schwach sichelig, $0.45 \mathrm{~cm}$. lang, $0.20 \mathrm{~cm}$. breit. Petalen linear, schwach sichelig, stumpf, etwas convex, $0.475 \mathrm{~cm}$. lang, $0.05 \mathrm{~cm}$. breit. Lippe breit verkehrt eirund, vorn ausgerandet und mit einem kurzen, breiten, stumpfen Spitzchen in der Bucht, concav, am Rande ungefähr in mittlerer Höhe beiderseits mit einem stumpfen Zahn, am Grunde mit 2 fleischigen, glänzenden, nach vorn hin in 2 Längsrippchen auslaufenden Calli, $\pm 0.43 \mathrm{~cm}$. lang, $0.40 \mathrm{~cm}$. breit. Säule gekrümmt, mit breiter Spitze, weis, an der Spitze blass grün, beiderseits neben der Narbe mit einem grossen, 3eckigen, spitzen Flügelchen, $0.35 \mathrm{~cm}$. lang. Anthera eirund mit breiter Spitze, ziemlich gross. Pollinien gelblich weiss. Rostellum zurückgebogen, kurz, breit. Stigma gross, abgerundet. Ovarium + Stielchen \pm $0.95 \mathrm{~cm}$. lang, stark 6rippig, hellgrün.

Ambon: Zwischen dem Riboe und Latoea (J. J. Smith).

Diese Ar.t kultivierte ich während einiger Zeit in Buitenzorg und beobachtete sie mehrmals blühend; die Blüten öffneten sich jedoch nie.

Im Gegensatz zu den meisten anderen cleistogam blühenden Pflanzen scheint sie nie Frucht anzusetzen; im kultiviertem Zustande wenigstens fielen die Blüten stets nach einiger Zeit unbefruchtet $a b$.

Liparis cleistogama gehört zu den Arten mit zusammengedrücktem, schwertförmigem Pedunculus und meistens grünen Blüten, wie L. caespitosa Lndl., L. viridiflora Lndl., L. Forbesii Ridl. etc. Merkwürdig sind die sehr 
starken, stumpfen Kiele der Sepalen und die grossen, 3eckigen Flügelchen beiderseits der Säule; ähnliche Flügelchen kommen z. B. vor bei $L$. bootunensis Griff.

Liparis tunensis J. J. S. Ic. bog. II, 44, t. CIX B. Ambon: Toena (J. J. Smith).

Diese ist eine der wenigen zu der Gruppe der Coriifoliae gehörenden Arten, welche am Boden wachsen.

Liparis confusa J. J. S. val. amboinensis J. J. S. n. val.

Pseudobulbi e basi ovata attenuato-elongati, sectione transversa elliptici, basi circ. $2.30 \mathrm{~cm}$. lati. Inflorescentia gracilis, nutans, foliis longior. Flores iis L. confusae J. J. S. aequales.

Trugknollen aus eiförmigem Grunde lang und schmal ausgezogen, auf dem Querschnitt elliptisch, hellgrün, \pm 12 cm. lang, am Grunde $\pm 2.30 \mathrm{~cm}$, an der Spitze 0.60 cm: breit, 2 blättrig. Blätter schmal lanzettlich, spitzlich, am Grunde zusammengefaltet, mit oben gefurchtem, unten gekieltem Mittelnerv, ziemlich weich, hellgrün, $\pm 21 \mathrm{~cm}$. lang, $\pm 2.70-3.10 \mathrm{~cm}$. breit. Blütenstände am Grunde mit einer scharf zusammengefalteten, spitzen, $\pm 2 \mathrm{~cm}$. langen Scheide, zierlich überhängend, nahezu ungestielt, sehr vielblütig, $\pm 31 \mathrm{~cm}$. lang. Bracteen lanzettlich 3eckig, spitz, concav, $\pm 0.50 \mathrm{~cm}$. lang. Blüten weit abstehend, sehr klein, etwas riechend, sehr blass durchscheinend grün. Sepalen zurückgeschlagen, länglich, stark convex. Petalen zurückgeschlagen, linear, stumpf, convex. Labellun aufrecht, ungefähr in der 
Mitte abwärts gekrümmt, breit länglich, blass bräunlich gelb, der untere Teil rinnig, mit 2 einander gegenüberstehenden, spitzen, fleischigen Zähnen, die obere Hälfte etwas convex, kurz gewimpert, 2lappig, die Läppchen stumpf, schwach, gekerbt. Gynostemium schlank, gekrümmt, aufrecht, blass grün, $0.15 \mathrm{~cm}$. lang. Anthera rundlich, hellgrün. Pollinien 4, gelb. Stigma klein. Ovarium aufwärts gekrümmt, kaum $0.10 \mathrm{~cm}$. lang, mit dem weit abstehenden, $0.65 \mathrm{~cm}$. langen Stielchen einen rechten oder stumpfen Winkel bildend.

Ambon: Hila ('Treub).

Die Varietät unterscheidet sich vom Typus durch die dickeren, auf dem Querschnitt elliptischen Knollen, breiteren Blätter und den längeren, stärker umgebogenen Blütenstand. Sie stimmt ziemlich gut überein mit einer von Nieuwenhuis in Borneo gesammelten Pflanze.

L. confusa kommt weiter vor in Java und Sumatra, und ist verwechselt worden mit $L$. longipes Lndl, welche für so weit mir bekannt ist, noch nicht im malaiischen Archipel gesammelt wurde. Die beiden Arten zeigen im Habitus viele $\Lambda$ hnlichkeit. $L$. longipes lässt sich jedoch leicht unterscheiden durch das an der Spitze ungelappte Labellum. Die Varietät könnte man noch verwechseln mit L. parviflora Lndl. (L. flaccida Rchb. f.); letztere hat jedoch viel schlaffere, stark überhängende, meistens bedeutend längere, lockerere Blütenstände, lebhafter gefärbte Blüten und namentlich sind die Calli am Grunde der Lippe anders gebildet.

Cryptochilus bicolor J. J. S. Ic. bog. II, 65. t. CXII 
A. - Mediocalcar bicolor J. J. S. Bull. Inst. bot. Buit. n. 7.

Ambon: Spitze des Toena, auf mit einer dicken Moosschicht bedeckten Bäumen (J. J. Smith.).

Agrostophyllum longifolium Rehb. f. Bonpl. V, 41; J. J. S. Fl. Buit. VI, Orch. 290. - A. majus Hook. f. Ic. Pl. t. 2096 ; Fl. Br. Ind. V, 824. - Appendicula longifolia Bl. Bijdr. 304 ; Lndl. Gen. et Sp. Orch. 240; Miq. Fl. Ind. Bat. III, 704.

Einige von Karsten in Ambon gesammelten Exemplare werden im Buitenzorger Garten kultiviert. Weiter Celebes (?) ; Borneo; Java; Sumatra; Perak.

Agrostophyllum atrovirens J. J. S. Ic. bog. II, 59, t. CXI A.

Ambon: Latoea (J. J. Sinith).

Agrostophyllum amboinense J. J. S. Ic. bog. II, 60, t. CXI B.

Ambon: Latoea (J. J. Smith).

Glomera erythrosma Bl. Bijdr. 372, f. LXVIII; Lndl. Gen. et Sp. Orch. 253; Hassk. Cat. Bog. 46; Fl. Bot. Zeit. 1842, Beibl. II; Miq. Fl. Ind. Bat. III, 705; Rchb. f. Xen. Orch. II, 94, t. 128 ; J. J. S. Fl. Buit. Orch. 293. Ambon: Spitze des Toena (J. J. Smith); auch Java.

Ceratostylis (Sect. Caulescentes Rchb. f.) latuensis J. J. S. n. sp. 
hhizoma dependens, ramosum, vaginis fuscis tectun. Caules brevissimi. Folium fere lineare, rigidum, crasse carnosum, apice spinescenti-acuminatum. Pedunculus pilosus. Flos candidus, $0.70 \mathrm{~cm}$. latus. Sepala lanceolata, acuta, concava. Mentum breve. Petala linearia. Labellum latiuscule unguiculatum; lamina ovata, acuta, carnosa, basi concava et callis 2 violascentibus in unguem decurrentibus. Brachia gynostemii lata, acuta, anthera vix longiora.

Rhizom herabhängend, verzweigt, $\pm 7 \mathrm{~cm}$. lang; $0.10 \mathrm{~cm}$. dick, völlig bedeckt mit dunkelbraunen Scheiden. Stengelchen $\pm 1 \mathrm{~cm}$. entfernt, sehr klein, dünn, hellgrünn, $\pm 0.50 \mathrm{~cm}$. lang, 1blättrig. Blätter nahezu linear, dick fleischig, starr, unten convex, oben nahezu flach mit einer Längsfurche, in ein kurzes, dornähnliches Spitzchen zugespitzt; am Grunde kurz stielförmig verschmälert, glänzend grün, $\pm 4 \mathrm{~cm}$. lang, $0.40 \mathrm{~cm}$. breit; Scheide stielförmig, oben rinnig, $\pm 0.90 \mathrm{~cm}$. lang. Blütenstände zu 1 oder wenigen beisammen, terminal. Pedunculus dünn, grünlich weiss, lang behaart, \pm 0.90 cm. lang. Bractee röhrig, spitz, durchscheinend, hell grünbraun, $\pm 0.30 \mathrm{~cm}$. lang. Blüten weiss, \pm 0.70 $\mathrm{cm}$. breit. Sepalen lanzettlich, spitz, concav, aussen mit einigen zerstreuten Haaren; das unpaare $\pm 0.60 \mathrm{~cm}$. lang, $0.20 \mathrm{~cm}$. breit; die paarigen am Säulenfuss herablaufend, ein kurzes, stumpfes Mentum bildend, vorgestreckt, etwas sichelig, mit breiter Basis, $\pm 0.67 \mathrm{~cm}$. lang, $0.27 \mathrm{~cm}$. breit. Petalen abstehend, linear, 1nervig, $0.55 \mathrm{~cm}$. lang, $0.075 \mathrm{~cm}$. breit. Labellum vorgestreckt, 
genagelt; Nagel ziemlich breit, rinnig, $0.15 \mathrm{~cm}$. lang; Platte eirund, spitz, fleischig, am Grunde concav und mit 2 kurzen, ziemlich dicken, auf den Nagel herablaufenden, blass violetten Lüngsrippen, $0.35 \mathrm{~cm}$. lang, $0.25 \mathrm{~cm}$. breit, sehr kurz behaart. Gynostemium sehr kurz, stark verbreitert, weiss, $0.13 \mathrm{~cm}$. lang, $0.15 \mathrm{~cm}$. breit. Anthera kappig, nahezu vierkantig. Pollinien 8, keulig, gelblich weiss. Stigmaärmchen kaum länger als die Anthera, etwas divergierend, breit, aussen stark abgerundet, spitz, innen concav. Rostellum tief ausgerandet. Säulenfuss nach hinten gekehrt, mit dem Ovarium einen spitzen Winkel bildend, $0.07 \mathrm{~cm}$. lang. Ovarium grau, lang behaart, $\pm 0.35 \mathrm{~cm}$. lang.

Ambon: Spitze des Latoea. (J. J. Smith).

Eine Art aus der Sektion Caulescentes, mit verlängertem Rhizom und kurzen Stengelchen.

Glossorhyncha amboinensis Ridl. Journ. Linn. Soc. Bot. XXVIII, 341, t. XLIV.

Ambon: Salhoetoe (Tsm.).

Leider habe ich diese interessante Pflanze nicht wiedergefunden.

Dendrobium (Sect. Longgicollia J. J. S.) utile J. J. S. Ic. bog. II, 77, t. CXIV A.

Ambon: Ohne Angabe des Fundortes. ('Teysm., M. Weber).

Dendrobium (Sect. Logicollia J. J. S.). Dendrocolla J. J. S. Ic. bog. II, 78, t. CXIV B. 
Ambon: Ohne Angabe des Fundortes (Karsten); zwischen dem Riboe und dem Latoea (J. J. Smith).

Dendrobium (Sect. Longicollia J. J. S.) ecolle J. J. S. Ic. bog II, 82, t. CXV. A.

Ambon: Toena (J. J. Smith.)

Dendrobium (Sect. Cadetia Bl.) umbellatum Rehb. f. Walp. Ann. VI, 303. - Cadetia umbellata Gaud. Freye. Voy. Bot. 422, t. 33 ; Miq. Fl. Ind. Bat. III, 628.

Caules tenues, $4-5$ sulcati, 1 folii, circ. $3.50 \mathrm{~cm}$. longi. Folium lineari-lanceolatum, 2dentatum, crasse carnosum. Inflorescentiæ breves, fasciculatæ. Flores circ. $0.47 \mathrm{~cm}$. lati, albi. Sepalum dorsale oblongum, convexum ; lateralia lata, mentum calcariforme, obtusum formantia. Petala linearia, acuta, incurva. Labellum cuneato-spathulatum, concavum, ungue intus piloso; lobi laterales parvi, 3 angulares; lohus medius valde dilatatus, brevis, leviter retusus, carnosus. Ovarium muribus longis deflexis munitum; pedicellus nudus.

Stengel genähert, 1 gliedrig, dünn, an der Spitze etwas verdickt, mit 4-5 ziemlich tiefen Längsfurchen, grün, $\pm 3.50 \mathrm{~cm}$. lang, an der Spitze $0.20 \mathrm{~cm}$. breit, 1 blättrig, anfangs am Grunde mit röhrigen Scheiden. Blatt aufrecht, dick fleischig, starr, linear lanzettlich, an der Spitze ungleich und spitz 2zähnig, am Grunde verschmälert, convex, mit oben gefurchtem, unten stumpf vorragendem Mittelnerv, matt grün, unten blass punktiert. Blütenstände pseudoterminal, büschelig, sehr kurz, 1blütig, 
von trockenen Schuppen umgeben, nach cinander blühend. Pedunculus $\pm 0.20 \mathrm{~cm}$. lang. Bractee winzig, 3eckig. Blüten $\pm 0.47 \mathrm{~cm}$. breit, $0.60 \mathrm{~cm}$. lang, gelblich weiss. Unpaares Sepalum aufrecht, breit länglich, spitz, mit breiter Basis, convex, $0.35 \mathrm{~cm}$. lang, $0.23 \mathrm{~cm}$. breit. Paarige Sepalen mit einem mit den Vorderrändern verwachsenen Streifen am Säulenfuss herablaufend, ein nach hinten gekehrtes, dem Ovarium paralleles, spornförmiges, stumpfes, nicht ausgerandetes, $0.25 \mathrm{~cm}$. langes Mentum bildend, die freien Teile nahezu ehenso breit wie lang, concav, $0.30 \mathrm{~cm}$. hreit. Petalen linear, einwärts gehogen, schief spitz, 1nervig, $0.30 \mathrm{~cm}$. lang, $0.05 \mathrm{~cm}$. breit. Lahellum keilig spatelig, rinnig, 3lappig, ausgespreizt $0.40 \mathrm{~cm}$. lang, in der Höhe der Seitenlappen $0.30 \mathrm{~cm}$. breit; Nagel dünn, etwas keilig verbreitert, innen behaart; Seitenlappen neben der Säule aufrecht, klein, 3 eckig, spitz; Mittellappen stark verbreitert, kur'z, quer länglich, an der Spitze schwach eingedrückt, die beidlen Ecken aufwärts, gebogen und stumpf, fleischig, $0.125 \mathrm{~cm}$. lang, $0.40 \mathrm{~cm}$. breit. Gynostemium kurz, breit, vom Rücken zusammengedrückt, gelblich weiss, karminrot punktiert; Clinandrium wenig entwickelt, daher die Pollinien auf das Stigma fallend; Ohrchen gross, hreit, unregelmässig gezahnt. Anthera kappig, abgerundet viereckig, die breite Snitze hehaart, karminrot punktiert. Pollinien 4, gelblich weiss. Rostellum klein, 3eckig, Stigma halhrund, untief. Säulenfuss dem Ovarium angedrückt, innen behaart, $\pm 0.20 \mathrm{~cm}$. lang. Ovarium gelblich weiss, mit langen, fleischigen, abwärts gewandten Weichstacheln, $\pm 0.20 \mathrm{~cm}$. lang; Stielchen kahl, 
grünlich weiss, $\pm 0.20 \mathrm{~cm}$. lang. Frucht hängend, verkehrt eiförmig kugelig, 3 furchig, hell graugrün, mit starken, kegeligen, abstehenden Weichstacheln, in jeder Furche mit einer durch ähnliche Weichstachel kammförmigen Längsleiste, $\pm 0.70 \mathrm{~cm}$. lang, im ganzen 0.60 cm. breit; Stielchen umgebogen, hellgrün.

Ambon: Hoetoe Mortetoe (J. J. Smit); auch Rawak (Freycinet).

Diese Pflanze ist Cadetia umbellata Gaud. so ähnlich, dass ich sie als Gaudichaud's Art angehörig betrachtet habe. In einigen Punkten weicht sie jedoch von seiner Beschreibung und Figur ab. Das unpaare Sepalum ist bei der ambonschen Pflanze convex und nicht concav, das Mentum nicht ausgerandet und die Weichstachel des Ovarium länger und abwärts gewandt; erst später sind sie abstehend.

Dendrobium crumenatum Swartz, Act. Holm. 1800, 246; Lndl. Gen. et Sp. Orch. 88; Bot. Reg. 1839, t. 22 ; 'Trans. Hort. Soc. VII, 70; Griff. Not. III, 315; Bot. Mag. t. 4013; Miq. Fl. Ind. Bat. III, 638; Choix de pl. t. 22 ; Rchb. f. Walp. Ann. VI, 291; Hook. f. Fl. Br. Ind. V, 729; J. J. S. Fl. Buit. VI, Orch. 330. Onychium crumenatum B1. Bijdr. 326. - Callista crumenata O. K. Rev. Gen. Pl. 653.

Ambon: Ohne nähere Fundortsangabe (Karsten, J. J. Snith); auch Borneo; Java; Sumatra; Singapore; mal. Halbinsel; Cochinchina; Siam; Andaman Inseln; Tenasserim.

Dendrobium (Sect. Crumenata Pfitz.) papilioniferum J. 
J. S. n. sp. - D. crumenatum Sw. fl. lilec. Miq. Choix, t. XXII, f. 1. - Angraecum crumenatum Rumph. Herb. Amb. VI, t. XLVII, f. 2. - A. angustis crumenis Rumph. l. c. 107 .

Habitus D. crumenati Lndl. Flores circ. $4 \mathrm{~cm}$. lati, suaveolentes, plures dies tenentes. Sepala et petala oblonga, alba, apice acuto, dilute purpureo, reflexo. Mentum magnum, retroversum, conicum. Labellum basi pedi colomnae adnatum, cuneatum, 3 lobum, concavum, intus costis 3 approximatis, luteis, in lobo medio lacinulatis; lobi laterales late 3angulares, obtusi, purpureostriati; lobus medius porrectus, subrotundus, undulatus, crenatus, purpureus. Auriculae gynostemii obtusae. Pes gynostemii apice callo magno luteo instructus.

Habitus von $D$. crumenatum Lndl. Stengel verlängert, $1.10 \mathrm{~m}$. und mehr lang; am Gründe dünn, dann zu einer spindeligen, \pm 8 kantigen, später tief gefurchten, $\pm 15 \mathrm{~cm}$. langen, $1.25 \mathrm{~cm}$. dicken, nur mit bald vertrockneten Scheiden besetzten Knolle angeschwollen, der obere Teil wieder dünn, auf dem Querschnitt elliptisch, $\pm 0.43 \mathrm{~cm}$. breit, beblättert, der höchste Teil nur mit rudimentären Blättern; Internodien $\pm 2.50-3.50 \mathrm{~cm}$. lang, glänzend grün, später braun. Blätter abstehend, dick ledrig, starr, lanzettlich, stengelumfassend, stumpf, kurz und mehr oder weniger ungleich 2lappig, mit einem kleinen Spitzchen, mit oben schwach vorragenden Nerven, glänzend grün, $\pm 10 \mathrm{~cm}$. lang, $2.60 \mathrm{~cm}$. breit, nach oben hin kleiner werdend; Scheiden röhrig, auf dem Querschnitt elliptisch, hellgrün. Blütenstände an 
den Knoten des oberen, mit rudimentären Blättern besetzten Stengelteiles, sehr kurz, von einigen bald vertrockneten Schuppen umgeben, in Zwischenräumen einige Blüten entwickelnd; Schaftblätter durchscheinend, violettrot geadert. Blüten gross, \pm ' $4 \mathrm{~cm}$. breit, wohlriechend, einige Tage dauernd. Unpaars Sepalum länglich, spitz, mit einem kleinen Spitzchen, $\pm 2.85 \mathrm{~cm}$. lang, $1 \mathrm{~cm}$. breit. Paarige Sepalen am Süulenfuss herablaufend, ein grosses, nach hinten gekehrtes, kegeliges, stumpfes Mentum bildend, die Vorderränder völlig frei, länglich dreieckig, $\pm 2.70 \mathrm{~cm}$. lang, die Basis $1.85 \mathrm{~cm}$. breit. Petalen länglich, der obere 'T'eil etwas ausgefressen und wellig, am Grunde verschmälert. Sepalen und Petalen mit auswärts gebogener Spitze, spitz, weiss, an der Spitze hell viollettrot gefärbt. Labellum am Grunde dem Säulenfuss zu einem $\pm 0.55 \mathrm{~cm}$. langen, etwas vom Rücken zusammengedrückten, stumpfen Sporn angewachsen, keilig, vorn 3lappig, concav, unten etwas bauchig, innen mit 3 dicht beisammen stehenden, gelben oder grünlich gelben, auf dem Mittellappen geschlitzten, am Grunde am Sporneingang endenden Längsleisten, ausgespreizt $\pm 3,55 \mathrm{~cm}$. lang, $2.55 \mathrm{~cm}$. breit; Seitenlappen gloss, aufrecht, breit dreieckig, stumpf, concav, vorn gekerbt, weiss, innen violettrot geadert; Mittellappen vorgestreckt, rundlich, rinnig, wellig, stark gekerbt, violettrot, mit weisslichem Rande und Grunde, $\pm 1.10 \mathrm{~cm}$. lang, $1.30 \mathrm{~cm}$. breit. Gynostemium kurz, breit, weiss, $\pm 0.40 \mathrm{~cm}$. lang, $0.57 \mathrm{~cm}$. breit; Öhrchen gross, breit, stumpf. Anthera kappig, stumpf, violettrot oder weiss. Pollinien 4, schmal, gelb. Rostellum breit. Stigma untief, 
am oberen Rande mit 2 Läppchen. Säulenfuss mit dem Ovarium einen stumpfen Winkel bildend, schwach gebogen, gegen die Spitze verschmälert, stumpf, gegen die Spitze mit einer Längsrippe und im Sporn mit einem grossen, gelben Callus, $\pm 1.40 \mathrm{~cm}$. lang. Ovarium kurz, grünlich weiss, $\pm 0.30 \mathrm{~cm}$. lang; Stielchen weiss, 2.10 $\mathrm{cm}$. lang.

Ambon: Ohne nähere Fundortsangabe (Rumph.); zwischen Asiloeloe und Larike (J. J. Smith); auch Kei.

Eine von Kei stammende, im Buitenzorger Garten kultivierte Pflanze hat kleinere Blüten und ein an der Spitze mehr ausgerandetes Labellum als die ambonschen. Im allgemeinen sind sie einander ähnlich.

Die als Angr. angustis crumenis von Rumphius beschriebene Pflanze scheint die nämliche Art zu sein als die unter dem Namen $A$. crumenatum abgebildete, was auch Hasskarl in seinem "Schlüssel” annimt. Die Abbildung stellt jedoch keine typische Blüten des Dendrobium crumenatum Sw. dar, sondern des D. papilioniferum J. J. S.

Dendrobium papilioniferum J. J. S. var. ephemerum J. J. S. n. var. - Angraecum album minus Rumph. Herb. Amb. VI, 99, t. XLIV, f. 1.

Flores circ. 4 cm. lati, odorati, ephemeri, eburnei. Sepala petalaque oblonga, pars superior valde reflexa. Mentum magnum, retroversum, conicum. Labellum basi pedi columnae adnatum, magnum, cuneatum, 3lobum, intus costis 3 approximatis, saturate luteis, in lobo medio altioribus crenato-serratis vel verrucosis; lobi 
laterales lati, obtusi, purpureo-striati; lobus medius magnus, porrectus, subrotundus, valde canaliculatus, marginibus lateralibus valde reflexis, crenatus. Auriculae gynostemii latae, sinuatæ vel integræ. Pes gynostemii apice callo magno luteo instructus.

Habitus von D. crumenatum Sw. Stengel verlängert, $1.20 \mathrm{~m}$. und mehr lang, am Grunde dünn und stielrund, dann zu einer spindeligen, stark längsrippigen, \pm 13.50 cm. langen, $2 \mathrm{~cm}$. dicken, nur mit Scheiden besetzten Knolle angeschwollen, weiter wieder dünn, auf dem Querschnitt oval, beblättert, die Stengelspitze nur mit rudimentären Blättern besetzt. Blätter stengelumfassend, dick fleischig ledrig, lanzettlich, stumpf, ausgerandet, ungleich 2lappig, mit oben schwach gefurchtem, unten nicht vorragendem Mittelnerv, $\pm 11 \mathrm{~cm}$. lang, $3.50 \mathrm{~cm}$. breit, die höheren kleiner werdend. Blütenstände an den Knoten des oberen, mit rudimentären Blättern besetzten Stengelteiles, sehr kurz, von trocknen Schuppen umgeben, in Zwischenräumen einige Blüten entwickelnd. Schaftblätter röhrig, bauchig, spitz, durchscheinend blass grün, mit etwas dunkleren, nach oben hin violettbraunen, vorragenden Nerven. Blüten gross, $\pm 4 \mathrm{~cm}$. breit, nur 1 Tag dauernd, riechend, milchweiss. Unpaares Sepalum länglich, mit breiter Basis, gegen die Spitze verschmälert, mit einem stumpfen Spitzehen, convex, der obere Teil zurückgekrümmt und mit vorwärts gebogenen Rändern, $\pm 3 \mathrm{~cm}$. lang, $1.10 \mathrm{~cm}$. breit. Paarige Sepalen am Säulenfuss herablaufend, abstehend, der obere Teil zurückgekrümmt und mit einwärts gebogenen Rändern, 
spitz, länglich dreieckig, $\pm 3 \mathrm{~cm}$. lang, die Basis $2 \mathrm{~cm}$. breit. Petalen länglich, die oberen $2 / 5$ zuräckgekrümmt, spitzlich, etwas wellig, am Grunde verschmälert, \pm 3 cm. lang, $1.40 \mathrm{~cm}$. breit. Labellum am Grunde dem Säulenfuss zu einem $\pm 0.50 \mathrm{~cm}$. langen Sporn ạgewachsen, gross, 3lappig; der mittlere Teil unten concav, innen convex und mit 3 dicht beisammen stehenden, dunkelgelben, auf dem Mittellappen stärker vorragenden und gekerbten (bei einer Pflanze niedrigen, fleischigen, warzigen) Längsleisten, von denen die beiden seitlichen sich am Grunde seitwärts abbiegen und die Spornhöhlung abschliessen, ausgespreizt $\pm 3.85 \mathrm{~cm}$. lang, $2.55 \mathrm{~cm}$. breit; Seitenlappen aufrecht, die Säule locker umfassend, breit, stumpf, weit wellig, weiss, innen mit violettroten, gegabelten Adern; Mittellappen gross, vorgestreckt, vorn stark rinnig und mit stark zurückgebogenen Seitenrändern, unregelmässig gekerbt, am Grunde violettrot geadert, ausgespreizt $\pm 1.40 \mathrm{~cm}$. lang, $1.65 \mathrm{~cm}$. breit. Säule kurz, breit, weiss, $0.40 \mathrm{~cm}$. lang, $0.60 \mathrm{~cm}$. breit; Ohrchen breit, gekerbt (bei einer Pflanze ganz). Anthera kappig; stumpf, weiss, am Grunde mit 2 schmalen, abstehenden Zipfeln. Pollinien 4, schmal, gelb. Stigma untief. Säulenfuss mit dem Ovarium einen spitzen Winkel bildend, etwas gebogen, concav, mit verdickten Ründern und gegen die Spitze mit einer Längsrippe, weiss, im Sporn mit einem grossen, dunkelgelben Callus, $\pm 1.70 \mathrm{~cm}$. lang. Ovarium kurz, blass grün, $0.35 \mathrm{~cm}$. lang; Stielchen weiss, $\pm 1.80 \mathrm{~cm}$. lang.

Ambon: Ohne nähere Fundortsangabe (Rumph.); Hila (Treub); zwischen Asiloeloe und Larike (J. J. Smith). 
Die Varietät ist von dem Typus hauptsächlich verschieden durch die Farbe, den weniger angenehmen Geruch, die viel stärker zurückgekrümmten Sepalen und Petalen. Merkwürdig ist es jedoch, dass die Blüten, ebenso wie bei D. crumenatum Sw., nur einen Tag dauern, auch wenn sie nicht befruchtet werden, wăhrend diejenigen des Typus einige Tage frisch bleiben.

D. crumenatum Sw. kommt in denselben Gegenden vor, wie D. papilioniferum. Kann D. papilioniferum var. ephemerum J. J. S. vielleicht eine Hybride zwischen den beiden Arten sein?

Rumphius' Angraecum album minus, Herb. Amb. VI, 100, t. XLIV, f. 1, und wahrscheinlich auch t. XLVII, f. 2, welche nicht beschrieben wird, haben wohl Beziehung auf diese Pflanze.

D. bursigerum Lndl. welchen Namen Hasskarl für diese Pflanze angiebt, ist etwas anderes.

Die von Rumphius beschriebene „Form” dieser Pflanze ist wahrscheinlich eine andere Dendrobium-Art; sicher nicht Hysteria veratrifolia Rnwdt., wie Hasskarl meint, welcher Pflanze Rumphius' "dicke, starre Blättchen" wohl nicht angehören können.

Der Typus und die Varietät sind D. crumenatum Sw. so ähnlich, dass sie ohne Blüten wohl kaum zu unterscheiden sind; sie sind dann auch mit dieser Art verwechselt oder als eine rosenrote Varietät betrachtet worden.

Die Beschreibung von D. Papilio Loher passt einigermaassen zu ihr; Verwechselung der Arten scheint mir jedoch ausgeschlossen. Loher's Beschreibung der Lippe: 
"labellum longe unguiculatum, stipite canaliculato flavo, limbo rotundato crenulato undulato, striis 3 et nervis lateralibus purpureis" passt wenigstens'nicht zu meiner Pflanze.

Dendrobium Iobulatum Rolfe et J. J. S. Fl. Buit. VI, Urch. 336.

Ambon: Ohne nähere Fundortsangabe (Karsten); auch Borneo; Java.

Karsten sammelte diese Art auf Ambon und führte sie lebend in Buitenzorg ein.

Eine Beschreibung dieser ziemlich weit verbreiteten Art konnte ich nicht finden und da auch Herr Rolfe, nach Zusendung einer Skizze mir schrieb, die Art sei ihm unbekannt, wiewohl er meinte, dass sie schon einen Namen haben sollte, sind wir gezwungen sie als neu zu betrachten.

Dendrobium calceolum Rxb. Hort. Beng. 63; Fl. Ind. III, 488; Miq. Fl. Ind. Bat. III, 630. - D. Roxburghii Lndl. Journ. Linn. Soc. III, 4. - Aporum Roxburghii Griff. Calc. Journ. N. Hist. V, 370. - Callista calceola O. K. Rev. Gen. Pl. II, 654. - Herba supplex quinta Rumph. Herb. Amb. VI, 111, t. LI, f. 2.

Ambon: Auf Bäumen in der Nähe der Küste gemein (Kumph., Teysm.); Ambon (Hauptstadt); Galela; Wai ; Asiloeloe; etc. (J. J. Smith); Neu-Guinea?

Die Pflanze ist nicht Herba supplex femina Rumph. VI, 110, t. LI, f. 1, wie oft angegeben wird, jedoch das oben zitierte $H$. s. quinta.

Die Stengel werden $1.25 \mathrm{~m}$. und mehr lang, sind 
zusammengedrückt und am Grunde nicht angeschwollen. Die Blüten sind $\pm 1.45 \mathrm{~cm}$. breit und $2.40 \mathrm{~cm}$. lang. Eine von Niederl. Neu-Guinea eingeführte Pflanze ist I. calceolum sehr ähnlich, unterscheidet sich jedoch durch die kleineren ( $\pm 1 \mathrm{~cm}$. breit, $1.40 \mathrm{~cm}$. lang) Blüten mit viel stärker gekrümmtem Säulenfuss und die stark verzweigten, einige $\mathrm{cm}$. über die Basis angeschwollenen Stengel (auch die $\boldsymbol{\Lambda}$ ste). Vielleicht ist diese Pflanze $D$. Goldfinchii F. Muell.

Dendrobium (Sect. Aporum Bl.) concavum J. J. S. n. sp. Caules elongati, compressi, pars inferior foliis 7 normalibus, pars superior foliis rudimentaribus munita. Folia valde lateraliter compressa, lanceolata, acuta. Inflorescentiae ad caulium partem superiorem, fasciculatae. Flores albi, $0.87 \mathrm{~cm}$. lati. Sepala ovata; mentum magnum, conicum. Petala lanceolata. Labellum margini antico pedis gynostemii apicis calcariformis insertum, unguiculatum, 3lobum, intus fascia incrassata antice 3costata; lobi laterales lineares, falcati; lobus medius valde concavus, multo latior quam longus, profunde 2lobatus. Pes gynostemii fere rectus, apice breviter (alcariformi, intus callo luteo.

Stengel dicht beisammen, dünn, zusammengedrückt, schwach zickzackig, $\pm 33 \mathrm{~cm}$. lang, der untere Teil normale, der obere rudimentäre Blätter tragend. Blätter \pm 7 , 2zeilig, stark seitlich zusammengedrückt, lanzettlich, spitz, fleischig, \pm 3 cm. lang; Scheiden röhrig, stark seitlich zusammengedrückt, $\pm 1 \mathrm{~cm}$. lang. Blütenstände am 
oberen Stengelteil, sehr kurz büschelig, in Zwischenräumen einige Blüten entwickelnd, von trocknen Schuppen umgeben. Blüten einige Tage dauernd, weiss, \pm 0.87 $\mathrm{cm}$. breit, $1.15 \mathrm{~cm}$. lang. Unpaares Sepalum nach vorn gekehrt, eirund, mit einem sehr kleinen Spitzchen, stark convex, $\pm 0.50 \mathrm{~cm}$. lang, $0.40 \mathrm{~cm}$. breit. Paarige Sepalen am Säulenfuss herablaufend, ein grosses, kegeliges, stumpfes Mentum bildend, die Vorderseiten etwas höckerig aufgetrieben, 3eckig, spitzlich, mit aussen vorragender Mittelrippe, $0.60 \mathrm{~cm}$. lang, die Basis $\pm 0.70 \mathrm{~cm}$. breit. Petalen lanzettlich, am Grunde verbreitert, stumpf, convex, $0.60 \mathrm{~cm}$. lang, $0.20 \mathrm{~cm}$. breit. Labellum am Vorderande der spornförmigen Säulenfussspitze inseriert, aufrecht, 3lappig, genagelt, innen mit einem verdickten, nach vorn hin 3rippigen und am Grunde des Mittellappens in 3 Zähne endenden, blass gelblich und schwach rötlich gefärbten Längsbande, ausgespreizt $\pm 0.95 \mathrm{~cm}$. lang, $1.30 \mathrm{~cm}$. breit; Seitenlappen aufrecht, über die Säule gebogen, linear sichelig, stumpf, concav; Mittellappen vorwärts gebogen, stark concav, viel breiter als lang, $0.40 \mathrm{~cm}$. lang, $0.85 \mathrm{~cm}$. breit, 2lappig, die beiden Läppchen abgerundet, etwas ausgerandet, etwas wellig. Gynostemium kurz, $0.20 \mathrm{~cm}$. lang; Ohrchen 3eckig, Anthera kappig, weiss, mit abgestützter Spitze. Pollinien 4, gelb. Stigma abgerundet. Säulenfuss mit dem Ovarium einen rechten Winkel bildend, nahezu gerade, concav, an der Spitze kurz kegelig spornförmig und mit einem gelben Callus, $0.70 \mathrm{~cm}$. lang. Ovarium $\pm 0.25 \mathrm{~cm}$. lang, hellgelb, fein rot punktiert; Stielchen gelblich weiss, 0.40 cm. lang. 
Ambon: Ohne nähere Fundortsangabe (Karsten).

Die Beschreibung dieser Pflanze ist angefertigt nach einem in Buitenzorg kultivierten Exemplar. Sie ist nicht mit anderen Arten der Aporum-Sektion zu verwechseln und hat zarte Blüten, welche sich jedoch einige Tage halten, wie sie öfters bei der Sektion Crumenata gefunden werden.

Bemerkenswert ist der an der Spitze spornförmige, mit einem Callus versehene Säulenfuss und das auf dem Vorderrande dieses Sporns inserierte Labellum.

Dendrobium (Sect. Strongyle Lndl.) salicornioides T. et B. Nat. Tijdschr. Ned. Ind. XXIV (1862) 315.

Caules elongati, flexuosi. Folia remota, teretia, sectione transversa ovalia, c. $3 \mathrm{~cm}$. longa. Inflorescentiae pseudoterminales, brevissimae, pauciflorae. Flores majusculi, albi, extus violaceo tincti, circ. $1.75 \mathrm{~cm}$. lati. Mentum magnum, conicum, curvatum, obtusum, sepalis duplo longius. Petala oblonga, acuta, basi attenuata, extus medio paulum incrassata. Labellum oblongo-cuneatum, apice dilatatum, sublobatum, emarginatum, undulatum, macula lutea, intus costae 2 paulum elevatae.

Stengel dicht beisammen, geschlängelt, etwas verzweigt, $\pm \quad 30-40 \mathrm{~cm}$. lang; die Internodien $\pm 2 \mathrm{~cm}$. lang; von der Basis gegen die Spitze verdickt. Blätter fleischig, auf dem Quersehnitt oval, etwas gebogen, gegen die Spitze verschmälert, spitz, grün, $\pm 3 \mathrm{~cm}$. lang, 0.30 und $0.35 \mathrm{~cm}$. dick. Blüten allein oder zu 2 beisammen an den Stengelspitzen, hängend, zart, weiss, aussen oft 
etwas violett angehaucht, riechend, $\pm 1.60-1.90 \mathrm{~cm}$. breit. Unparres Sepalum lïnglich eirund, spitz, convex, $+0.90 \mathrm{~cm}$. lang; $0.50 \mathrm{~cm}$. breit. Paarige Sepalen am Sïulenfuss herablaufend, ein grosses, gekrümmtes, kegeliges, stumpfes Mentum bildend, 3eckig, $0.90 \mathrm{~cm}$. lang. Petalen länglich, am Grunde verschmälert, etwas convex, aussen mit einer Längsverdickung, $0.85 \mathrm{~cm}$. lang, 0.35 cm. breit. Labellum dem Säulenfuss parallel aufrecht, gekrümmt, mit grossem, länglich keiligem, breit rinnigem Nagel, vorn in die verhältnismässig kurze, vorwärts gebogene, schwach 3lappige, in der Mitte ausgerandete, im Sinus mit einem gelben Fleckchen gezeichnete, \pm 1.40 cm. breite Platte verbreitert, innen mit 2 dichtbeisammen stehenden, an der Spitze etwas scharfen Längsleisten, ausgespreizt $\pm 2.40 \mathrm{~cm}$. lang. Gynostemium \pm 0.25 cm. lang, $0.50 \mathrm{~cm}$. breit; Öhrchen fleischig. Anthera kappig, weiss. Pollinien 4, gelb. Säulenfuss mit dem Ovarium einen spitzen oder fast rechten Winkel bildend, lang, gekrümmt, mit etwas verdickten Rändern, an der Spitze mit einem blass gelblichen Fleckchen, \pm 1.80 cm. lang. Ovarium hellgrün, $0.40 \mathrm{~cm}$. lang; Stielchen weiss, ziemlich schlaff, $1.50 \mathrm{~cm}$. lang.

Ambon: Ohne nähere Fundortsangabe (Teysm. in Herb. Bog.): auch Celebes: Krakataoe; Pinang.

Die Beschreibung ist angefertigt nach von Dr. Koorder's in der Minahasa gesammelten, in Buitenzorg kultivierten Exemplaren. Eine schon sehr lange mit der Nummer: D. salicornioides T. et B., Krakatau, Tsm., zu Buitenzorg kultivierte Pflanze ist völlig identisch damit und ebenso einige von Pinang unter dem falschen Namen $D$. terminale Par. et 
Rchb. f. erhaltenen Pflanzen. Die Beschreibnng im Nat. 'Tijdschr. passt ziemlich gut auf die Art, nur ist die Länge der Blätter bedeutend kürzer angegeben (1 cm.), aber dieser Unterschied mag vielleicht daran zugeschrieben werden, dass die Pflanzen in Buitenzorg im starken Schatten kultiviert werden. Auch sagen Teysmann und Binnendijk bestimmt: „labello calloso trilineato," während ich nur 2 Rippen habe nachweisen können.

Die Arten der Sektion Strongyle zeigen in den Blüten nur sehr wenig charakteristisches, so dass sehr genaue und vollständige Beschreibungen erforderlich sind um sie richtig bestimmen zu können.

D. albicolor Ridl. scheint dieser Art sehr ähnlich zu sein, aber Ridley sagt: „mentum cum sepalis aequilongum," während es bei der von mir beschriebenen Art doppelt so lang ist als die Sepalen.

Dendrobium atropurpureum Miq. Fl. Ind. Bat. III, 644. Oxystophyllum atropurpureum Bl. Rumphia IV, 41, t. 193, f. 4, t. 198G. - Herba supplex minor Rumph. Herb. Amb. VI, 110 , t. I, f. 2.

Ambon: Auf Bäumen an der Küste (Rumph., Teysm.); Ambon; Galela; Wai ; Asiloeloe; etc. (J. J. Smith); auch Neu-Guinea.

Wiewohl Blume's Figuren von Oxystophyllum carnosum und 0 . atropurpureum einander sehr ähnlich sind, bin ich noch nicht völlig davon überzeugt, dass sie wirklich nur einer Art angehören. Schon die Tatsache, dass die erstere in Java im Gebirge, die letztere in Ambon und 
Neu-Guinea mur an der Küste wächst, macht die Sache ziemlich unsicher.

Dendrobium amboinense Hook. Bot. Mag. t. 49:37: Miq. F'l. Ind. Bat. III, 634. -- Callista amboinensis O. K. Rèv. Gen. Pl. II, 654.

Ambon: Olrne nähere Fundortsangabe (Karsten), Hoetoe Mortetoe und Toena (J. J. Smith).

Diese interessante Pflanze had 1- oder 2-, selten 3blütigen Blütenstände in Aushöhlungen der auf dem Querschmitt rautenförmigen, an der Spitze meistens 2 blättrigen, keuligen Stengel. Die grossen, aber zarten, kaum 1 Tag dauernden, eigentümlich riechenden Blüten haben $\pm 10 \mathrm{~cm}$. lange, lineare Sepalen und ähnliche Petalen. Die Lippe ist viel kürzer, beweglich, 3lappig; innen mit einem fleischigen Callus und 2 kurzen, hohen Längsplätchen versehen; die Farbe ist grössenteils blass gelb, zwischen den Seitenlappen citronengelb mit einem eirunden, dunkelbraun punktierten Fleck; der fein pfriemlich zugespitzte Mittellappen ist weisslich mit gelben Rändern und Spitze, während die Ränder in den Buchten zwischen den Lappen schwarzbraun sind.

Im botanischen Garten zu Buitenzorg blülnt die Art regelmässig.

Dendrobium macrophyllum A. Rich. Sert. Astrol. 22, t. 6; Ill. hort. 1888, 59, t. LVII; Rchb. f. Walp. Ann. VI, 30. - J. J. S. Fl. Buit. VI, Orch. 347. - D. m. var. Veitchianum Lndl. Bot. Mag. 1867, t. 5649. - D. Veilchianum Lndl. Bot. Reg. 1847, sub. t. 25; De Vriese 
Ill. t. 5; t. 11, fig. 3; Miq. Fl. Ind. Bat. III, 632. D. ferox Hassk. Retzia I, 1. - Callista Veitchiana O. K. Rev. Gen. Pl. II, 655.

Ambon: Sirimau (J. J. Smith); auch Ternate; N. Guinea; Java.

Von dieser Pflanze fand ich ein riesiges Exemplar mit $\pm 55 \mathrm{~cm}$. langen Stengeln, bis $33 \mathrm{~cm}$. langen und 12 $\mathrm{cm}$. breiten Blättern, 35--40 blütigen, $\pm 52 \mathrm{~cm}$. langen Blütenständen. Die Blüten waren $6 \mathrm{~cm}$. breit und hatten schwarzviolett punktierte Sepalen und Petalen, die letzteren jedoch nur für $2 / 3$.

Dendrobium Mirbelianum Gaud. Voy. Freyc. Bot. 423, t. XXXVIII. - D. Rosenbergii T. et B. Nat. Tijdschr. Ned. Ind. XXIV (1862), 317. - D. calophyllum Rchb. f. Xen. Orch. II, 167. - Callista Mirbeliana O. K. Rev. Gen. Pl. II, 655. - D. calophylla O. K. 1. c. - Angraccum flavum septimum Rumph. Herb. Amb. VI, 102, t. XLV; ? t. XLVI, f. 2.

Ambon: Ohne nähere Fundortsangabe (Rumphius, Rosenberg, Teysm.); zwischen Toelehoe und Soeli; Hila: Asiloeloe; zwischen Alang und Hina Niwel, u. s. w. (J. J. Smith); Neu-Guinea.

Eine auf Ambon, wo sie meistens auf alleinstehenden Bäumen wächst, sehr gemeine Art.

Ruinphius' Tafel XLVI, f. 2, zu Angraecum flavum nonum gehörend, ist eigentlich nicht von seiner t. XLV zu unterscheiden. Wahrscheinlich gehören auch noch 1 oder mehrere Reichenbachsche Arten hierzu; z. B. scheint mir D. polycarpum Rchb. f. sehr ähnlich zu sein. Auch der 
Name polycarpum passt vorzüglich zu dieser Art, da alle Blüten stets sehr regelmässig Frucht ansetzen

Die Blüten sind ziemlich schmutzig gelb, mehr oder weniger violettbraun gefürbt; das Labellum ist blassgelb mit braunvioletten Adern. Die Petalen sind nicht sehr viel länger als die Sepalen, wenig gedreht, und glänzend.

Dendrobium Rumphianum T. et B. Nat. Tijdschr. Ned. Ind. XXIV (1862) 317. - D. minax Rchb. f. Xen. Orch. II, 129, t. 145. - Angraecum flavum sextum moschatum sive odoratum Rumph. Herb. Amb. VI, 102.

Ambon: Ohne nähere Fundortsangabe (Rumphius, Doleschall, Teysm.); Hila (Treub); auch Molukken; Celebes.

Die Blütenstände sind ziemlich kurz und sehr armblütig. Die Sepalen und die bedeutend längeren Petalen sind melır oder weniger blass grün und violett gefärbt; das Labellum grünlich weiss mit rotvioletten Adern.

D. Burbidgci Rchb. f. ist vielleicht auch diese Art.

Dendrobium taurinum Lndl. var. amboinense Rolfe. Orch. Rev. (1897), 304.

Ambon: Ohne nähere Fundortsangabe.

Dendrobium (Sect. Grastidium Bl.) pruinosum T. et B. Nat. Tijdschr. Ned. Ind. XXIV (1862), 314. - Angraecum jumbu Rumph. l. c. 108.

Caules validi, elongati. Folia hifaria, rigida, semiam. plexicaulia, oblonga, obtusa, emarginata. Inflorescentiae numerosae, brevissimae, 2florae, basi bracteis brevibus obtusis, lateraliter valde compressis. Flores ephemeri, 
lutescentes, c. $2.80 \mathrm{~cm}$. lati. Sepala petalaque linearilanceolata; sepala lateralia falcata incurva. Mentum brevissimum, bilobum. Labellum parvum, 3 lobum, intus costa miniata; lobi laterales oblongo-3angulares, basi verrucosi; lobus medius revolutus, ovatus, acutus, crenulatus, verrucosus, medio pilosus. Pes gynostemii brevis.

Stengel kräftig, überhängend, verlängert, auf dem Querschnitt oval-elliptisch, glänzend grün, $\pm 1.25 \mathrm{~cm}$. lang, $0.80 \mathrm{~cm}$. breit; Internodien $2.50-3 \mathrm{~cm}$. lang, die höhe. ren kleiner. Blätter abstehend, 2zeilig, dick ledrig, starr, länglich, halbstengelumfassend, an der Spitze etwas ungleich 2lappig, oben mit einer Längsrinne, $\pm 10 \mathrm{~cm}$. lang, $4.30 \mathrm{~cm}$. breit, nach oben hin kleiner werdend. Blütenstände zahlreich, 2 Scheiden durchbohrend, abwärts gewandt, unter den Blättern versteckt, sehr kurz, 2blütig, am Grunde mit einigen einander umfassenden, kurzen, röhrigen, stark seitlich zusammengedrückten, abgerunde. ten Schaftblättern, von denen die äusseren bald vertrocknen. Pedunculus $1 \mathrm{~cm}$. lang, zusammengedrückt. Blüten zart, 1 Tag dauernd, blass gelb, $\pm 2.80 \mathrm{~cm}$. breit. Sepalen linear lanzettlich, spitz, concav, das unpare $\pm 2.30 \mathrm{~cm}$. lang, $0.55 \mathrm{~cm}$. breit; die paarigen mit den Spitzen einander zugebogen, sichelig, aussen gekielt, mit dem Säulenfuss ein sehr kurzes, 2lappiges Mentum bildend. Petalen abstehend, linear lanzettlich, gegen die Spitze etwas verbreitert und concav, mit aussen vorragendem Mittelnerv, $2 \mathrm{~cm}$. lang, $0.50 \mathrm{~cm}$. hreit. Labellum klein, beweglich, 3lappig, innen mit einer körnigen, hell mennigroten Längsrippe, ausgespreizt $\pm 1 \mathrm{~cm}$. lang und 
breit; Seitenlappen aufrecht, länglich dreieckig, an der Spitze gekerbt, die untere Hälfte innen init hellbraunen Warzen; Mittellappen eirund 3eckig, spitz, zurückgerollt, convex, unregelmässig gekerbt und wellig, braunwarzig, in der Mitte dicht abstehend hellgelb behaart, $0.50 \mathrm{~cm}$. lang und breit. Gynostemium weiss, $\pm 0.55 \mathrm{~cm}$. lang; Orchen abgerundet. Anthera kappig. Pollinien 4, länglich, gelb. Stigma jeckig, tief. Säulenfuss mit dem Ovarium einen nahezu rechten Winkel bildend, kurz, gelblich weiss, an der Spitze mit einem mennigroten Fleckchen, $0.40 \mathrm{~cm}$. lang. Ovarium $\pm 0.70 \mathrm{~cm}$., Stielchen $\pm 0.80 \mathrm{~cm}$. lang, grünlich weiss.

Ambon: Hila (Treub); zwischen Asiloeloe und Alang (J. J. Smith) : auch Molukken; Kei.

Die Pflanze blüht nur ungefähr einmal in einem Jahre, die Blüten dauern nur 1 Tag, also wird man sie nur zufälligerweise blühend antreffen. Die Beschreibung ist angefertigt nach in Buitenzorg kultivierten, kräftig wachsenden Exemplaren.

D. pruinosum ist vielleicht die grösste der bekannten, der Sektion Grastidium angehörigen Arten. Die Blütenstände sind alle abwärts gewandt und befinden sich also unterhalb der Blätter. Eine blühende Pflanze zieht des grossen Blütenreichtums wegen die Aufmerksamheit sofort an sich, aber nur wenn man die Stengel von unten sieht.

Dendrobium (Sect. Distichophylla) angustipetalum .J. J. S. n. sp.

Caules elongati. Folia lanceolata, valde inaequaliter 
2loba. Inflorescentiae numerosae, laxe c. 7 florae. Flores viridi-albi, c. $1.45 \mathrm{~cm}$. lati. Sepalum dorsale oratoovale; lateralia late 3angularia. Petala lanceolata. Labellum margini antico pedis columnae apicis calcariformis insertum, erectum, minute unguiculatum, 3lobum, album, intus carinis 2 altis lamellaeformibus, apice in dentem excurrentibus, utrinque costa minore apice dentata: lobi laterales minuti ad basin labelli dentiformes; lobus medius magnus, pars inferior fere quadrata, apice valde dilatata, rotundata, emarginata, reflexa. Gynostemium latum atroviolaceum.

Wurzeln warzig, braun, mit lebhaft grünen Spitzen. Stengel genähert, uberhängend, auf dem Querschnitt elliptisch, gegen die Spitze verdünnt, später tief längsfurchig, glänzend grün, an den Knoten mit einem gelben Querstreifen, beblättert, $\pm 90 \mathrm{~cm}$. lang, $\pm 0.90 \mathrm{~cm}$. breit; Internodien $\pm 2-2.50 \mathrm{~cm}$. lang. Blätter lanzettlich, gegen die Spitze verschmälert, sehr ungleich 2lappig, mit oben gefurchtem, unten schwach vorragendem Mittelnerv und zurückgebogenem Rande, heiderseits sehr glänzend grün, dünn ledrig, $\pm 10 \mathrm{~cm}$. lang, $2.20 \mathrm{~cm}$. breit; Scheiden röhrig, kürzer als die Internodien, schwach gekielt, hellgrün. Blütenstände an den Knoten, zahlreich, abstehend, die Scheiden am Grunde durchbohrend, locker, 7blütig, $\pm 5-6 \mathrm{~cm}$. lang. Pedunculus grün, $1.40-2.50 \mathrm{~cm}$. lang. Rachis zickzackig. Bracteen klein, anliegend, 3eckig, $\pm 0.22 \mathrm{~cm}$. lang. Blüten weit geoffnet, $\pm 1.45 \mathrm{~cm}$. breit, grünlich weiss. Unpaares Sepalum eirund oval, etwas zugespitzt, stumpf, mit brei- 
ter Basis und zurückgebogenen Rändern, 5nervig, 0.60 cm. lang, $0.50 \mathrm{~cm}$. breit. Paarige Sepalen am Säulenfuss herablaufend, 3eckig, spitz, mit zurückgebogener Spitze, weit wellig, 5nervig, an der Spitze dunkelviolettbraun, $\pm 0.60 \mathrm{~cm}$. lang, $0.87 \mathrm{~cm}$. breit. Petalen lanzettlich, spitz, mit schiefer Basis etvas an säulenfuss herablaufend, convex, 1nervig, $0.55 \mathrm{~cm}$. lang, $0.20 \mathrm{~cm}$. breit. Lippe mit sehr kurzem und schmalem, rinnigem Nagel dem Vorderrand des spornförmigen Säulenfusses angeheftet, dem Säulenfuss parallel aufrecht, 3lappig, weiss, ausgespreizt $\pm 1 \mathrm{~cm}$. lang, in der Höhe der Seitenlappen $0.60 \mathrm{~cm}$, an der Spitze $0.85 \mathrm{~cm}$. breit, innen mit 2 dicht beisammen stehenden, hohen, etwas über die Mitte der Lippe in ein Paar spitzer, unregelmässiger, aufstrebender Zähne endenden, violett punktierten und berandeten Längsleisten und beiderseits noch einer viel schwächeren, unregelmässig berandeten, in mehrere unregelmässige Zähne auslaufenden Leiste; Seitenlappen am Grunde der Lippe, sehr klein, abstehend, zahnförmig, 3eckig, spitz; Mittellappen gross, aufrecht, der untere Teil nahezu vierkant und unten etwas convex, der obere Teil stark verbreitert, ausgerandet, 2lappig, zurückgebogen, mit einer Längsrinne, die beiden Hälften stark convex, mit oben vorragenden Nerven, am Rande klein gekerbt und blass gelblich, der ganze Mittellappen $\pm 0.80 \mathrm{~cm}$. lang. Gynostemium sehr kurz, breit, dunkelviolett, $0.20 \mathrm{~cm}$. lang. Anthera kappig, breiter als hoch, blass grün. Pollinien 4, schmal, ziemlich dunkelgelb. Rostellum breit dreieckig, blass grün. Stigma sehr gross, 5eckig, unten zugespitzt, blass grün. Säulenfuss mit dem Ovarium 
einen rechten Winkel bildend, gross, gerade, $0.85 \mathrm{~cm}$. lang, die unteren $0.55 \mathrm{~cm}$. breit, concav, grünlich weiss, dunkelviolett punktiert und berandet, am Rande dunkelviolett gewimpert, $0.35 \mathrm{~cm}$. breit, die oberen $0.35 \mathrm{~cm}$. verschmälert, kegelig spornförmig, seitlich zusammengedrückt, stumpf, am Eingang verdickt, innen und am Eingang behaart. Ovarium grün, $0.30 \mathrm{~cm}$. lang; Stielchen rechtwinkelig umgebogen, blass grünlich, $1.20 \mathrm{~cm}$. lang.

Ambon: Hoetoe Mortetoe (J. J. Smith); Ternate: Piek (J. J. Smith).

Diese interessante Art gehört wohl der Sektion Distichophylla an, welche überhaupt nur sehr charakteristische Arten zählt.

Die Lippe, welche zum grössten. Teil nur aus dem stark entwickelten Mittellappen besteht, ist mittelst eines sehr kleinen, rinnigen Nägelchens dem Vorderande der spornförmigen Säulenfussspitze angeheftet. Dieser spornförmige Teil ist am Eingang verengert durch Verdickung der Wand und ausserdem innen behaart. Eine ähnliche Spornbildung des Säulenfusses kommt, ausser bei einigen anderen Dendrobien, auch bei Chrysoglossum $\mathrm{Bl}$. vor.

Dendrobium bifarium Lndl. Wal. Cat. 2002; Gen. et Sp. Orch. 81; Miq. Fl. Ind. Bat. III, 640. -- Callista bifaria O. K. Rev. Gen. Pl. II, 654. - Angraecum purpureum I litoreum s. nudum Rumph. l. c. 109, t. $\mathrm{XL}$, f. 2.

Ambon: An der Küste (Rumph.).

Lindley hat diese Pflanze als $D$. bifarium bestimmt 
ohne Blüten gesehen zu haben. Etwas Zweifel an der Richtigkeit der Benennung scheint mir nicht überflüssig.

Der Habitus der Pflanze erinnert an Appendicula Bl.

Dendrobium purpureum Rxb. Fl. Ind. III, 484; Miq. Fl. Ind. Bat. III, 640. - D. viridirosenm Rchb. f. Bonpl. III, 226; Walp. Ann. VI, 295. - Cullista purpurea O. K. Rev. Gen. Pl. II, 655. - Anyraecum purpuresm II silvestre Rumph. Herb. Amb. VI, 109, t. L, f. 1.

Ambon: Ohne nähere Fundortsangabe (Rumph.); Hila (Treub): auch Ternate.

Dendrobium gemellum Lndl. (p. p., non Ridl.) Gen. et sp. Orch. 81 ; J. J. S. Fl. Buit. VI, Orch. 362. Pedilonium biflorum Bl. Bijdr. 322. - Callista biflora O. K. Rev. Gen. Pl. II, 653.

Ambon? (Karsten); auch Java; Sumatra.

Das einzige Exemplar aus Ambon, das ich gesehen habe, ist im botanischen Garten zu Buitenzorg kultiviert; ich bin jedoch nicht vollkommen sicher davon, dass die Nummer nicht einmal verwechselt worden ist. Man hat diese Art, wie es scheint, hüufig mit $L$. salaccense Lndl. verwechselt.

Die Blütenstände sind kurz, 2--3blütig. Die Blüten dauern einige Tage, sind gelblich-weiss mit einem blassroten Fleck auf der Lippe, und $\pm 3.30 \mathrm{~cm}$. breit. Die Petalen sind etwas breiter als die Sepalen. Die Lippe ist mit einem $\pm 0.60 \mathrm{~cm}$. langen Nagel dem Säulenfuss zu einem dünnen Sporn angewachsen; die Platte schwach 3lappig, eirund 3eckig, zugespitst, mit welligem Rande, 
innen mit einer convexen Längsverdickung, $\pm 2.15 \mathrm{~cm}$. lang, $1.47 \mathrm{~cm}$. breit. Der Säulenfuss bildet mit dem Ovarium einen spitzen Winkel, ist schmal und 0.90 cm. lang.

Dendrobium lancifolium A. Rich. Sert. Astrol. 20, t. 8; Bot. Reg. 1844, misc. 59. - D. lilacinum 'T. et B. Nat. Tijdschr. Ned. Ind. XXVII (1864), 18. - Callista lancifolia O. K. Rev. Gen. Pl. II, 655.

Ambon: Batoe Gantoeng; wahrscheinlich auch Sirimau; Hoetoe Mortetoe; Toena; Latoea (J. J. Smith); auch Boeroe (d'Urville).

Ein Exemplar, von Batoe Gantoeng stammend, erhielt ich vom Leutenant der Chinesen in Ambon; dasselbe blühte später in Buitenzorg, und war dann leicht als L. lancifolium A. Rich. $\mathrm{zu}$ bestimmen.

Unter den von mir selbst an sehr verschiedenen stellen gesammelten Pflanzen, welche wahrscheinlich zu dieser Art gehören, war leider keine einzige blühend und die in Buitenzorg eingeführten Pflanzen haben ebenfalls noch nicht geblüht.

Diese Pflanze ist in Ambon sehr häufig und kriecht mit verlängertem, dünnem Rhizom weit hinauf in die Bäume; die abstehenden, dünnen stengel tragen lanzettliche, krautartige Blätter.

D. lilacinum $\mathrm{T}$. et $\mathrm{B}$. ist, wie aus dem Original im Leidener Herbar klar hervorgeht, nichts anderes als $D$. lancifolium A. Rich. Die Angabe, dass die Pflanze aus Java stammen soll, ist nicht unwahrseinlich auf eine Nummerverwechselung zurückzufülıren. 
Dendrobium (Sect. Eudendrobium Lndl.) Treubii J. J. S. n. sp.

Caules e basi tenui valde dilatati et compressi, usque ad $3.50 \mathrm{~cm}$. lati. Folia decidua, oblonga. Inflorescentiae ad nodos superiores, pendulae, laxe 5 --6florae. Flores circ. $6 \mathrm{~cm}$. lati, eburnei. Sepalum dorsale ovato-lanceolatum, lateralia 3angularia; mentum magnum, anguste conicum, obtusum. Petala lanceolata. Labellum erectum, unguiculatum, 3lobum, intus purpureum, costulis 7-9 exiguis: unguis late linearis; loli laterales erecti, late 3angulares, obtusi; lobus medius oblongus obtusus, marginibus parallelis, basi pallide luteus. Pes gynostemii longus, fere rectus, ad apicem costa flavescenti.

Stengel am Grunde dünn, auf dem Querschnitt elliptisch und nur mit Scheiden besetzt, nach oben hin stark verbreitert und zusammengedrückt, schwertförmig, etwas zickzackig, schwach längsrippig, beblättert, spitz, im ganzen $\pm 45 \mathrm{~cm}$. lang, bis $3.50 \mathrm{~cm}$. breit, glänzend gelblich grün, später braunrot; Internodien $\pm 3-4 \mathrm{~cm}$. lang. Blätter abfallend, länglich, weit wellig, 7-9nervig, mit oben gefurchter, unten schmal gekielter Mittelrippe, ziemlich hellgrün, $\pm 5 \mathrm{~cm}$. breit; Scheiden kurz, breit, vorn aufreissend, hellgrün mit helleren Nerven. Blütenstände an den höchsten Knoten, hängend, locker, 5 -6blüttig, $\pm 6 \mathrm{~cm}$. lang. Bracteen 3eckig, grüngelb. lich, $0.30 \mathrm{~cm}$. lang. Blüten weit geöffnet, $\pm 6 \mathrm{~cm}$. breit, einige Tage dauernd. Unpaares Sepalum eirund lanzettlieh, schwach convex, $\pm 2.90 \mathrm{~cm}$. lang, $1 \mathrm{~cm}$. breit. Paarige sepalen am Säulenfuss herablaufend, die 
Vorderränder etwas verwachsen, ein grosses, schmal kegeliges, vom Rücken zusammengedrücktes, stumpfes Mentum bildend, stumpfwinkelig 3eckig, spitz, aussen gekielt, $3.10 \mathrm{~cm}$. lang. Sepalen gelblich weiss, beiderseits glänzend. Petalen lanzettlich, ziemlich spitz, weiss, am Grunde glänzend, \pm 2.90 lang, $0.90 \mathrm{~cm}$. breit, aussen mit einer Längsfurche. Lippe dem Säulenfuss parallel aufrecht, vorwärts gebogen, genagelt, 3lappig; breit rinnig, 'zwischen den Seitenlappen violettrot mit 7 -9 schwachen, dunkler gefärbten Längsrippen, ausgespreizt $\pm 4.50 \mathrm{~cm}$. lang, $2.10 \mathrm{~cm}$. breit, unten mit einer Längsfurche; Nagel vom Säulenfuss abgebogen concav, gelblich weiss, breit linear, $0.55 \mathrm{~cm}$. breit; Seitenlappen aufrecht, breit 3eckig, stumpf, concar, weiss, innen mehr oder weniger violettrot gefürbt; Mittellappen länglich, mit parałlelen Rändern, stumpf, wellig, weiss, am Grunde blass gelb, $\pm 1.70 \mathrm{~cm}$. lang, $1.10 \mathrm{~cm}$. breit. Säule kurz, dick, glänzend weiss, \pm $0.40 \mathrm{~cm}$. lang; Ohrchen gross, stumpf, etwas unregelmissig berandet. Anthera kappig, weiss; Filament lang. P'ollinien 4, länglich, gelb. Rostellum breit. Stigma algerundet 4kantig. Säulenfuss mit dem Ovarium einen rechten Winkel bildend, lang, nahezu gerade, schwach concav, stumpf, an der Spitze mit einer gelblichen Längsrippe und dem Labellumnagel etwas angewachsen, gelblich weiss, etwas blass violett angestrichen, \pm 2.60 $\mathrm{cm}$. lang, $0.55 \mathrm{~cm}$. breit. Ovarium blass grünlich, glänzend, $0.90 \mathrm{~cm}$. lang; Stielchen gelblich weiss, 2 $\mathrm{cm}$. lang.

Ambon: Ohne nähere Fundortsangabe (Warburg); auf 
dem Hoetoe Mortetoe (J. J. Smith); Ceram; Wahaai (Treub).

Eine leicht zu erkennen de Art mit der Tracht des $D$. lamellatum Lndl., aber viel grösser. Die Blüten sind ziemlich gross und hübsch gefärbt. In Buitenzorg wurde die Pflanze zuerst von Herrn Prof. Treub eingeführt aus der Insel Ceram und zwar im Jahre 1893; ich sammelte die nämliche Art 1900 auf Ambon und sah Exemplare aus der letztgenannten Insel stammend, auch im Herbar des Herrn Prof. Warburg zu Berlin. Sie wächst und blüht in Buitenzorg sehr gut.

Dendrobium superbum Rchb. f. Walp. Ann. VI, 282.

D. macronhyllum Lndl. Bot. Reg. 1834, misc. 46; Sert. Orch. t. 35: Hook. Cent. Orch. t. 12. - D. macranthum Miq. Fl. Ind. Bat. III. 642. - D. anosmum Lndl. Bot. Reg. XXI (1844), misc. 41. - ? D. Scorlechinii Hook. f. Fl. Br. Br. Ind. V, 741. - Callista anosma O. K. Rev. Gen. Pl. II, 653. - ? C. Scortechinii O. K. 1. c. 655. Angraecum caninum sive undecimum Rumph. Herb. Amb. VI, 105, t. XLVII, f. 1.

Ambon: Ohne nähere Fundortsangabe (Pumph.); Hila (Treub); zwischen Toelehoe und Soeli (.J. J. Smith); auch Ceram; Boeı oe; Borneo; Philippinen.

Eine sehr variabele Art. Die ambonschen Exemplare haben starke, dicke Stengel und 2-4 blütige Blütenstände.

Dendrobium (Sect. Biloba J. J. S.) Koordersii J. J. S. n. sp.

Caules aggregati, tenues, multifolii. Folia linearia 
graminea, plus minusve inaequaliter biloba; vaginae rugulosae. Inflorescentiae paucae, 1 florae. Flos $1 \mathrm{~cm}$. latus, pallide viridis. Sepalum dorsale ovatum, lateralia late 3angularia; mentum magnum, retusum. Petala lanceolata obtusa. Labellum carnosum, oblongum, 3lobum, atropurpureum, nitidissimum, intus medio incrassatum: lobi laterales brevissimi, rotundati; lobus medius subrotundus, convexus, opacus. Pes gynostemii paulum curvatum.

Stengel zahlreich, dicht beisammen, dünn, auf dem Querschnitt elliptisch, glänzend grün, $\pm 30 \mathrm{~cm}$. lang, $0.10 \mathrm{~cm}$. breit, vielblättrig; Internodien $\pm 2.50 \mathrm{~cm}$. lang. Blätter linear, an der Spitze mehr oder weniger ungleich 2lappig, oben mit einer Längsfurche, glänzend grün, $\pm 8 \mathrm{~cm}$. lang, $0.40 \mathrm{~cm}$. breit: Scheiden röhrig, länger als die Internodien, auf dem Querschnitt elliptisch, fein runzelig, dunkel grauviolett, $0.15 \mathrm{~cm}$. breit. Blütenstände sehr wenig zahlreich, 2 Scheiden durchbohrend, sehr kurz, 1blütig. Pedunculus $\pm 0.20 \mathrm{~cm}$. lang. Bracteen klein, 3eckig. Blüten einige Tage dauernd, \pm 1 $\mathrm{cm}$. breit und lang. Unpaares Sepalum länglich eirund, spitzlich, etwas convex, 5nervig, $0.55 \mathrm{~cm}$. lang, 0.33 $\mathrm{cm}$. breit. Paarige Sepalen am Säulenfuss herablaufend, ein grosses, stumpfes, etwas ausgerandetes Mentum bildend, stumpfwinkelig 3eckig, stumpf, $0.60 \mathrm{~cm}$. lang und an der Basis ebenso breit. Petalen lanzettlich, stumpf, $0.55 \mathrm{~cm}$. lang, $0.175 \mathrm{~cm}$. breit. Sepalen und Petalen blass grün, glänzend, etwas fleischig. Labellum fleischig, schwach gebogen, länglich, 3lappig, breit rinnig, stark 
glänzend, $\pm 0.67 \mathrm{~cm}$. lang, $0.375 \mathrm{~cm}$ breit, innen mit einem breiten, etwas verdickten dunkelroten, glänzenden Lăngsbande; Seitenlappen sehr kurz, abgerundet, vom Mittellappen durch Buchten getrennt, durchscheinend weisslich mit dunkelrotem Rande, etwas rot gefleckt; Mittellappen rundlich, dick fleischig, convex, undeutlich dunkelrot gefleckt, ziemlich matt, $\pm 0.20 \mathrm{~cm}$. lang, 0.25 cm. breit. Gynostemium kurz, blass grün, $0.20 \mathrm{~cm}$. lang; Ohrchen 3eckig, gezähnelt. Anthera kappig, stumpf, rot, mit dunkler Spitze. Pollinien 4, gelb. Rostellum breit, ausgerandet. Stigma quer länglich, dunkelrot berandet. Säulenfuss etwas gebogen, $0.40 \mathrm{~cm}$. lang, blass grün, an der Spitze dunkelrot. Ovarium + Stielchen $\pm 0.33 \mathrm{~cm}$. lang, hellgrün.

Ambon: Hoetoe Mortetoe (J. J. Smith); auch Celebes (S. H. Koorders).

Diese Art ist mit $D$. bilobum Lndl. sehr verwandt; hier sollen jedoch die Petalen bedeutend kleiner, die Lippe deutlicher 3lappig und der Mittellappen derselben warzig sein.

D. Koordersii J. J. S. bildet mit D. bilobum Lndl. und wenigen anderen Arten eine gut charakterisierte Sektion, welche vielleicht unter dem Namen Biloba unterschieden werden kann. Sie ist charakterisiert durch die verlängerten, dünnen, glänzenden, vielblättrigen Stengel, die linearen, mehr oder weniger ungleich 2lappigen, dünnen, papierartigen Blätter und die sehr kurzen, 1 blütigen, am Grunde nicht von kurzen, stumpfen, seitlich zusammengedrückten Schuppen umgebenen Blütenstände.

Sie sehen einigen Arten der Sektion Grastidium sehr 
ăhnlich aus, aber sind leicht zu unterscheiden durch die Blütenstände.

D. Koordersii wächst seln gut in Buitenzorg, abel die kleinen, wenig in die Augen fallenden Blüten sind ausserdem sehr wenig zahlreich.

Dendrobium (? Sect. Biloba J. J. S.) orientale J. J. S. 11. sp.

Caules elongati, tenues. Folia bifaria, late linearia, apicem versus attenuata, valde inaequaliter obtuse 2 lobata. Inflorescentiae numerosae, brevissimae. Flores pallide lutei, $1.40 \mathrm{~cm}$. lati. Sepalum dorsale ovatum, lateralia 3angularia, carinata, apiculo conico. Petala oblonga, subspathulata. Labellum mobiliter affixum, 3lobum, dilute viride, intus costa simplici; lobi laterales patentes, minusculi, convexi; lobus medius porrectus, dilatatus, subbilobus, in sinu apiculo obtuso. Gynostemium longius. culum. Pes gynostemii rectus, apice libero rectangulo incurvo, carneo.

Rhixom kurz. Wurzeln dicker als die Stengel. Stengel dünn, hart, auf dem Querschnitt elliptisch, beblättert, glänzend grün, $\pm 1 \mathrm{~m}$. lang, $0,30 \mathrm{~cm}$. breit; Internodien $\pm 2-2.50 \mathrm{~cm}$. lang, die höheren kleiner. Blätter 2zeilig, breit linear, gegen die Spitze verschmälert, sehr ungleich stumpf 2lappig, mit oben kaum gefurchtem, unten schwach vorragendem Mittelnerv, dünn ledrig, glänzend grün, $\pm 11 \mathrm{~cm}$. lang, $1.20 \mathrm{~cm}$. breit; Scheiden röhrig, länger als die Internodien. Blütenstände an den Knoten, zachlreich, 2 Scheiden durchbohrend, sehr kurz. 
Bracteen sehr klein, 3eckig. Blüten blass gelb, \pm 1.40 cin. breit. Unpares sepalum eirund, spitz, mit breiter Basis, etwas convex, 7nervig, $\pm 0.85 \mathrm{~cm}$. lang, 0.45 cm. breit. Paarige Sepalen am Säulenfuss herablaufend, abstehend, 3eckig, mit einem fleischigen, kegeligen Spitzchen, aussen gekielt und ebenso wie das unpaare etwas warzig, $\pm 0.85 \mathrm{~cm}$. lang, am Grunde $0.60 \mathrm{~cm}$. breit. Petalen länglich, etwas spatelig, stumpf, 3nervig, + $0.70 \mathrm{~cm}$. lang, $0.30 \mathrm{~cm}$. breit. Labellum dem Säulenfuss beweglich angeheftet, gebogen, 3lappig, breit rinnig, innen mit einer einfachen Längsrippe, hellgrün, mit grünlich weissem Rande, ausgespreizt $\pm 0.70 \mathrm{~cm}$. lang, $0.40 \mathrm{~cm}$. breit; Seitenlappen schräg abstehend, ziemlich klein, 3eckig, ziemlich stumpf, mit nach vorn gekehrter Spitze, convex; Mittellappen vorgestreckt, verbreitert, etwas 2lappig, mit einem kurzen, stumpfen Läppchen vorn in der Bucht, eckig, $0.50 \mathrm{~cm}$. breit, die beiden Läppchen convex. Gynostemium verhältnissmässig lang, gerade, hellgrün, $\pm 0.47 \mathrm{~cm}$. lang, mit breiter, etwas ausgerandeter Spitze und kurzen, stumpfen Öhrchen. Anthera kappig, breiter als lang, mit ausgebogenem Rande, hellgrün. Stigma ziemlich gross, birnförmig; spitz. Säulenfuss mit dem Ovarium einen spitzen oder fast rechten Winkel bildend, der untere, mit den paarigen Sepalen verwachsene Teil gerade, $0.35 \mathrm{~cm}$. lang, mit einer Längsrippe, grünlich weiss, die $0.20 \mathrm{~cm}$. lange Spitze frei, rechtwinkelig vorwärts gebogen, abgestutzt, dunkel fleischfarbig. Ovarium verkehrt kegelig, seegrün, $0.30 \mathrm{~cm}$. lang; Stielchen blass grün, $1.40 \mathrm{~cm}$. lang.

Ambon. 
Diese Art erhielt ich vom Leutenant der Chinesen zu Ambon, ohne nähere Fundortsangabe. Ich möchte sie in die Sektion Grastidium unterbringen, wenn nicht die typischen, seitlich zusammengedrückten Scheiden am Grunde der Blütenstände fehlten (?). Der habituellen Merkmale wegen gehört sie vielleicht am besten in die Verwandtschaft von D. bilobum Lndl.

Dendrobium foliosum Brongn. Voy. Coq.. 203, t. XLI. D. spinescens Lndl. Journ. Linn. Soc. III (1859), 14; Miq. Fl. Ind. Bat. III, 638. - Eria foliosa Ridl. Journ. of Bot. XXIV (1886) 326. - Callista foliusa O. K. Kev. Gen. Pl. II, 654.-C. spinescens O. K. l. c. 655.

Ambon: Hoetoemoeri (Teysm.); Toena (Teysm., Treub); Soja (Treub); auch Neu-Guinea.

Diese interessante Pflanze, welche kaum mehr zu Dendrobium zu rechnen ist, hat ein kriechendes, dünnes, verzweigtes Rhizom, und zahlreiche, aufrechte, dünne, etwas verzweigte, vielblättrige Stengel. Die Blätter sind lanzettlich, spitz, wellig, ledrig, 5nervig, $\pm 9.50 \mathrm{~cm}$. lang, $2.30 \mathrm{~cm}$. breit, und besonders merkwürdig wegen der convolutiven Knospenlage. Die zahlreichen Blütenstände erscheinen an den Knoten, sind kurz und 2-4. blütig. Die Blüten sind $\pm 1.50 \mathrm{~cm}$. breit, hellgelb. Die schmalen Sepalen sind in einer Ebene ausgebreitet, die paarigen stark sichelig. Die Petalen, Lippe und Säule stehen einander parallel in der Mitte der Blüte. Die Lippe ist dem nur $0.10 \mathrm{~cm}$. langen Säulenfuss beweglich angeheftet, stark gekrümmt, länglich, ungeteilt, mit 2 glatten, sich vorn vereinigenden Längsrippen und beson- 
ders gegen die Spitze kuř und dicht behaart. Die Säule ist schlank und stark gekrümmt, $\pm 0.70 \mathrm{~cm}$. lang. Das Konnektiv der kappigen Anthera ist in eine grosse zusammengedrinckte Leiste ausgedehnt und läuft an der Spitze in einen spitzen Zaln aus. Pollinien 4, linear, olme Anhängsel. Die reife Frucht ist gekrönt durch die etwas vergrösserte, grüne Blüte, welche ihre Form nicht im wenigsten verliert.

Dendrobium glaucum T. et B. Cat. Hort. Bog. 43 .

Dendrobium rorulentum T. et B. Cat. Hort. Bog. 44.

Von diesen beiden Arten sind nur die Namen publiziert worden.

Eria rugosa Lndl. Gen. et Sp. Orch. 66; Miq. Fl. Ind. Bat. IIl, 661; J. J. S. Fl. Buit. VI, Orch. 378. - E. stellata Lindl. I. c. 67 ; Bot. Reg. t. 904; Bot. Mag. t. 3605 ; Miq. 1. c. - E. striolata Rchb. f. 111. Hort. 1888, 35, t. 48. - E. vaginata Bth. Journ. Linn. Soc. XVIII, (1881) 303. - Dendrolirium rugosum Bl. Bijdr. 345.--? Dendrobium jacanicum Sw. Act. Holm. 1800, 247. Octomeria stellata Spr. Syst. IV, 2, 310. - 0. vaginata Bredá, Orch. t. õ. - Pinalia rugosa O. K. Rev. Gen. Pl. II, 679. - P. stellata O. K. 1. c. - P. striolata U. K. l. c.

Ambon: Ohne nähere Fundortsangabe (Doleschall); Hoetoe Mortetoe (J. J. Smith); auch Ceram; Noesa laoet; Celebes; Borneo; Java; Sumatra; Singapore; mal. Halbinsel; Philippinen.

Eine weit verbreitete Art mit gelblich weissen oder 
mehr oder weniger runkelıübenrot gestreiften Blüten. Die Pflanze ist merkwürdig wegen der convolutiven Blätter.

Eria bractescens Lndll. Bot. Reg. 1841, Misc. 18: 1844, t. 29 ; Relib. f. Walp. Am. VI, 277; Hook. f. Fl. Br. Ind. V, 796; King et Pantl. Ann. Bot. Gard. Calc. VIII, 120, t. 166. - E. Dillwynii Hook. Bot. All. 4163; Bot. Reg. 1845, Misc. 67. - E. littoralis 'T. ot B. Nat. Tijdschr. Ned. Ind. XXIV (1862) 312. - Pinalia bractescens O. K. Rev. Gen. Pl. II, 679.

Ambon: Sehr gemein auf Bäumen an der Küste ('Teysm., Treub, J. J. Smith); auch Kei; Singapore; Tenasserim ; Ostindien.

Die Blüten sind weiss oder gelblich, die Seitenlappen der Lippe heller oder dunkler braunrot, die Bracteen hellgelb.

Eria (Sect. Hymenaria Lndl.) moluccana Schlechter et .J. J. Smith n. sp.

Pseudobulbi. approximati, magni, carnosi, oblongi, cilc. śfoliati. Folia carnosa, lanceulata, acuta, basi attenuata. Inflorescentiae apicem bulborum versus, erectae, foliis aequilongae, valde multiflorae, tomentosae. Flores parvi, pallide flavi. Sepalum dorsale oblongum; lateralia triangularia, mentum obtusum formantia. Petala oblonga. Labellum unguiculatum, 3lobum, lobi laterales 3anguli, acuti, callo nitido; lobus medius rotundatus, convexus, costa carnosa.

Trugknollen dicht beisammen, gross, länglich, dick, 
weniggliedrig, auf dem Querschnitt oval, $\pm 15 \mathrm{~cm}$. lang (bei einem schwachen Exemplar), \pm 4 und $3.40 \mathrm{~cm}$. dick, mit grossen, dreieckigen, bald trocknenden Scheiden, an der Spitze \pm oblättrig. Blätter schräg aufrecht, fleischig ledrig, schmal lanzettlich, spitz, am Grunde stielförmig verschmälert, rinnig, mit zurückgebogenem Rande, oben mit einer Iängsfurche, die stärkeren Nerven unten vorragend, schwach glänzend, grün, $\pm 32-48$ cın. lang, 3.80-- 5.60 cm. breit. Blütenstände an deı höchsten Knoten, aufrecht, den Blättern gleich lang, sehr vielblütig, kurz wollig behaart. Pedunculus bis \pm 14 cm. lang, hellgrün, stielrund, mit mehreren lanzettlichen, zugespitzten, $\pm 1 \mathrm{~cm}$. langen Schaftblättern. Bracteen zurückgeschlagen, länglich, concav, blass grün, aussen behaart, $\pm 0.70 \mathrm{~cm}$. lang. Blüten abstehend, klein, $\pm 0.60 \mathrm{~cm}$. breit, geruchlos, blass gelb, mit halbabstehenden Sepalen, aussen kurz behaart. Unpaares Sepalum länglich, stumpf, concav, $\pm 0.60 \mathrm{~cm}$. lang, $0.40 \mathrm{~cm}$. breit. Paarige Sepalen am Säulenfuss herablaufend, ein grosses, stumpfes Mentum bildend, 3eckig, stumpf, 5nervig, $\pm 0.55 \mathrm{~cm}$. lang, Basis $0.50 \mathrm{~cm}$. breit. Petalen länglich, stumpf, $\pm 0.47 \mathrm{~cm}$. lang, $0,27 \mathrm{~cm}$. breit. Labellum aufrecht, 3lappig, mit breitem, concavem, blass gelbem Nagel; Seitenlappen aufrecht, 3eckig, stumpf, vorn spitz, stark convex, mit einer glänzenden Verdickung, blass gelb; Mittellappen umgebogen, abgerundet, convex, fleischig, mit einer fleischigen Längsleiste, kadmiumgelb. Gynostemium kurz, gelblich weiss, 0.25 cm. lang; Öhrchen stumpf. Anthera breiter als lang, ausgerandet, blass gelb, mehr oder weniger braunrot 
gefärbt. Pollinien 8, kurz keulig, weiss. Stigma gross. Säulenfuss mit dem Ovarium einen spitzen Winkel bildend, an der Spitze etwas vorwärts gebogen, weisslich, \pm C.50 cm. lang. Ovarium + Stielchen $\pm 1 \mathrm{~cm}$. lang, hellgrün, kurz wollig behaart.

Ambon: Sehr gemein; Hila (Treub); zwischen 'Toelehoe und Soeli; Larike; Alang; u. s. w. (J. J. Smith); auch Ceram; Kei; Celebes.

Die Beschreibung ist angefertigt nach einem aus Ambon stammenden, in Buitenzorg kultivierten, nicht sehr starken Exemplar; die hinzugefügten grösseren Maasse haben Beziehung auf dem Exemplar aus Ceram im Leidener Herbar, welches sich noch unterscheidet durch den ziemlich bedeutend kürzeren, nur $0.30 \mathrm{~cm}$. langen Säulenfuss.

Eria (Sect. Hymenaria Lndl.) quinquangularis J. J. S. n. sp. Rhizoma patens, ramosum, validum. Pseudobulbi remonti, carnosi, fusiformes, apice 6 - 7folii. Folia linearilanceolata. Inflorescentiae in parte superiore caulium, foliis breviores, laxe multiflorae. Flores parvi, lutescente albi, extus paulum tomentosi. Sepalum dorsale et petala lanceolata, 3nervia. Sepala lateralia oblongo3angularia, falcata. Labellum fere integrum, quinquangulare, acutum, basi profunde canaliculatum, atrorubrum. Gynostemium gracile. Pes gynostemii breviusculus, reetus.

Wurzeln dünn, braun, dicht abstehend behaart, mit dunkelpurpurner Spitze. Rhizom nicht kriechend, abstehend, kräftig, verzweigt, stielrund, $\pm 0.70 \mathrm{~cm}$. dick. 
Trugknollen in die Verlängerung des Rhizoms, $2-4 \mathrm{~cm}$. entfernt, spindelig, fleischig, weniggliedrig, hellgrün, \pm 7-9 cm. lang, $1.60 \mathrm{~cm}$. breit, an der Spitze 6-7blättrig. Blätter abstehend, linear lanzettlich, spitz, \pm 13nervig, mit oben gefurchtem, unten (ausser bei den unteren Blättern) vorlagendem Mittelnerv, dünn ledrig, hellgrün, oben schwach glänzend, bis $\pm 17.50 \mathrm{~cm}$. lang, 2.40 cm. breit; Scheiden kurz, die Knolle umfassend, vorn bald rertrocknend. Blütenstände den Stengelspitzen genähert, in kleinen Aushöhlungen, kürzer als die Blätter, locker, vielblütig, hellbraun wollig behaart. Penduculus \pm 2 cm. lang, mit mehreren abstehenden, länglichen, mehr ader weniger eirunden, zugespitzten, spitzen, schwach convexen, hellgrünen, $0.50 \mathrm{~cm}$. langen Schaftblättern. Rachis $\pm 6.50 \mathrm{~cm}$. lang. Bracteen abstehend, länglich, zugespitzt, spitz, etwas concav, hellgrün, \pm $0.40 \mathrm{~cm}$. lang, $0.20 \mathrm{~cm}$. breit. Blüten $\pm 0.63 \mathrm{~cm}$. breit, durchscheinend gelblich weiss, schwach richend. Unpaares Sepalum lanzettlich, spitz, 3nervig, $0.56 \mathrm{~cm}$. lang, $0.175 \mathrm{~cm}$. breit. Paarige Sepalen am Säulenfuss herablaufend, abstehend, länglich dreieckig, sichelig, spitz, etwas concar, 3nerrig, $\pm 0.50 \mathrm{~cm}$. lang, $0.23 \mathrm{~cm}$. breit, ebenso wie das unpaare aussen, besonders am Grunde, etwas hellbraun wollig hehaart. Petalen lanzettlich, spitz, schwach concav, 1nervig, $0.50 \mathrm{~cm}$. lang, 0.13 cm. breit. Lippe nahezu ungeteilt, am Grunde tief rinnig, mit etwas auswärts gebogenen Rändern, vorn ziemlich flach, etwas convex, spitz, ausgespreizt .jeckig, $0.26 \mathrm{~cm}$. lang, $0.25 \mathrm{~cm}$. breit, am Grunde breit und schwach ausgerandet, innen mit 3 undeutlichen Verdic- 
kungen, dunkelrot mit blassen Rändern und blass gelber Spitze. Gynostemium schlank, schwach gebogen, am Grunde blass, an der Spitze dunkelrot, $0.10 \mathrm{~cm}$. lang. Pollinien 8, birnförmig, blass gelb. Rostellum kurz. Stigma eine untiefe Querspalte mit vorragendem Unterrande. Säulenfuss mit dem Ovarium einen rechten Winkel bildend, gerade, weiss, $0.175 \mathrm{~cm}$ lang. Ovarium + Stielchen $0.40 \mathrm{~cm}$. lang, dunkelrot, hellbraun wollig behaart.

Ambon: Zwischen der Hauptstadt und Paso; Wai (J. J. Smith).

Eine kleinblütige Art, welche man auf dem ersten Anblick zur Sekt. Urostachya rechnen möchte, wiewohl sie zur Sekt. Hymenaria gehört.

Bemerkenswert sind die weit abstehenden Rhizomäste und Trugknollen. Das ungelappte, ausgespreizt 5eckige, mit 3 Verdickungen versehene Labellum sieht in der natürlichen Lage demjenigen eines Bulbophyllum sehr ähnlich aus; der untere Teil ist tief rinnenförmig zusammengelegt, während der obere Teil etwas umgebogen und convex ist.

Bulbophyllum infundibuliforme J. J. S. Ic. bog. II, 103, t. CXX A.

Ambon: Ohne nähere Fundortsangabe (J. J. Smith); auch Misool (Teysm.)

Ich bin nicht ganz sicher davon, das diese Pflanze auf Ambon vorkommt, weil die Nummer leider verloren ging.

Bulbophyllum crassinervium J. J. S. Ic. bog. II, 95, t. CXVIII A. 
Ambon: Toena (J. J. Sinith).

Bulbophyllum recurviflorum J. J. S. Ic. bog. II. !f;, t. CXVIII B.

Ambon: Hoetoe Mortetoe (J. J. Smith).

Bulbophyllum Epicrianthes Hook. f. Fl. Br. Ind. V, 753 ; J. J. S. Fl. Buit. VI, Orch. 447. - Epicrianthes javanica Bl. Bijdr. 306, f. VIII; Fl. Jav. Praef. VI; Lndl. Gen. et Sp. Orch 61; Miq. Fl. Ind. Bat. III, 654. Phyllorchis javanica O. K. Rev. Gen. Pl. II, 676.

Ambon: Ohne nähere Fundortsangabe (Karsten); auch Java; Tenasserim.

Bulbophyllum (Sect. Oxysepalum Wight.) Teysmannii J. J. S. n. sp.

Rhizoma elongatum, pendulum, ramosum, geniculatum. Pseudobulbi remoti, fere cylindrici, rhizomati adpressi, c. 1,10 cm. longi. Folium lanceolatum, crassum, obtusum, c. $8 \mathrm{~cm}$. longum. Inflorescentiae ad nodos rhizomatis, numerosae, 1 florae, brevissimae. Sepala e basi oblongo triangulari longe aristata, c. $1.25 \mathrm{~cm}$. longa. Petala parva, oblonga, retuso-bidentata. Labellum parvum, 3angulariligulatum, curvatum. Auriculae gynostemii breviusculae. Anthera medio valde incrassata, apice incurva acuta.

Rhizom lang, herabhängend, verzweigt, kniebeugig, stielrund, hellgrün, $\pm 40 \mathrm{~cm}$. lang, $0.15 \mathrm{~cm}$. dick, mit angedrückten Wurzeln und trocknen, gelbbraunen Scheiden; Zweige abstehend; Internodien $\pm 0.50 \mathrm{~cm}$. lang. 
Trugknollen $\pm 4 \mathrm{~cm}$. entfernt, dem Rhizom aufliegend, fast cylindrisch, grüll, $\pm 1.10 \mathrm{~cm}$ lang, $0.275 \mathrm{~cm}$. dick, 1 blättrig. Blatt dick fleischig, lanzettlich, gegen die Spitze verschmälert, stumpf, mit einem Spitzchen, am Grunde stielförmig verschmälert, oben mit einer Längsrinne, die beiden Hälften convex, beiderseits stark glänzend grün, $\pm 8 \mathrm{~cm}$. lang, $2.50 \mathrm{~cm}$. breit; Stiel rinnig; $1.20 \mathrm{~cm}$. lang. Blütenstände an den Knoten des Rhizoms, sehr zahlreich, 1blütig, sehr kurz. Pedunculus kurz, weiss, \pm 0.20 . cm. lang, mit wenigen langen, häutigen, durchscheinenden Scheiden. Sepalen länglich 3eckig, concar, 3nervig, sehr lang und fein begrannt, ockergelb, am Grunde blasser, im ganzen $\pm 1.20-1.30 \mathrm{~cm}$. lang, der verbreiterte Teil $\pm 0.35 \mathrm{~cm}$. lang; $0.15-0.20 \mathrm{~cm}$. breit; die paarigen am Säulenfuss herablaufend. Petalen klein, lïnglich, an der Spitze ausgerandet, durchscheinend gelblich, glänzend, $0.20 \mathrm{~cm}$. lang, $0.07 \mathrm{~cm}$. breit. Lippe dem Säulenfuss beweglich angeheftet, klein, 3eckig, zungig, gubogen, am Grunde rinnig und plötzlich zusammengezogen blass gelb, $0.275 \mathrm{~cm}$. lang, $0.075 \mathrm{~cm}$. breit. Säule kurz, gelblich weiss, $0.10 \mathrm{~cm}$. lang; 0hrchen ziemlich kurz. Anthera kappig, mit stark verdicktem Konnektiv und spitzer, gekrümmter Spitze. Pollinien 2, blass gelb. Säulenfuss init dem Ovarium einen stumpfen Winkel bildend, stumpf, convex, hellgelb, $0.13 \mathrm{~cm}$. lang. Ovarium weiss, $0.15 \mathrm{~cm}$. lang.

Ambon (Teysmann).

Diese Art steht B. sessile J. J. S. (B. clandestinum Lndl.) sehr nahe, ist jedoch leicht zu unterscheiden durch die viel grösseren Dimensionen und die sehr lang begrannten 
Sepalen. Die Petalen waren bei allen von mir gesehenen Blüten an der Spitze ausgerandet, 2zähnig.

Wie bei mehreren anderen Arten mit herabhängendem Rhizom scheint die Pflanze nur am Grunde bewurzelt zu sein. Bei näherer Untersuchung stellt es sich dann jedoch heraus, dass auch die frei herabhängenden Äste Wurzeln bilden; dieselben kriechen jedoch unterhalb der Scheiden und dem Rhizom fest angedrückt weiter. Beispiele sind u. m. B. sessile J. J. S., B. mutabile Lndl., B. capitatum Lndl., B. angustifolium Lndl. u. S. .w Auch bei anderen Gattungen, wie Ceratostylis Bl. § Caulescentes, Pholidota gibbosa Lndl. kommt diese Eigentümlichkeit vor.

Bulbophyllum macranthum Lndl. var. albescens J. J.S. n. var.

Flores majusculi, flavescenti albi. Sepala petalaque erecto-conniventia, intus (sepalum dorsale ad basim tantum) laxe violaceo-maculata, nitida. Labellum opacum, dilute luteum, antice violaceo-punctatum.

Rhizom lang, kriechend, $\pm 0.40 \mathrm{~cm}$. dick, an den Knoten mit Trichter bildenden Fasern der bald verwitternden Scheiden. Trugknollen $\pm 4-5 \mathrm{~cm}$. entfernt, mehr oder weniger eiförmig, stumpfkantig, an der Vorderseite mit einer breiten Längsrinṇe, matt grün, \pm 2 cm. lang, $1.50 \mathrm{~cm}$. dick, 1blüttrig. Blatt dick fleischig; starr, länglich, an der Spitze ausgerandet und zurückgebogen, am Grunde stielförmig verschmälert, scharfrandig, oben mit einer Längsfurche, ziemlich glänzend grün, 
$\pm 16.50 \mathrm{~cm}$. lang, $6.50 \mathrm{~cm}$. breit; Stiel tief gefurcht, $\pm 1.50 \mathrm{~cm}$. lang. Blütenstände an den Knoten des Rhizoms, aufrecht, kurz, 1blüttig. Peduculus sehr kurz, mit einigen ziemlich weit röhrigen, in ein eingebogenes Spitzchen endenden, blass gelbgrünlichen, violletgrau punktierten Scheiden. Blüten aufrecht, ziemlich gross, wenig geöffnet, fleischig; glïnzend, gelblich weiss, riechend. Unpaares Sepalum aufrecht, länglich, mit breiter Basis, sehr spitz, concav, vielnervig, am Grunde mit einigen dunkelvioletten Punkten, $\pm 2.50 \mathrm{~cm}$. lang; $0.85 \mathrm{~cm}$. breit. Paarige Sepalen am kurzen Sïulenfuss herablaufend, aufrecht, lïnglich, mit breiter Basis, sehr spitz, concav, die benachbarten Ränder, ausser an der Basis, aneinander schliessend und in der Mitte dunkelrotviolett gefürbt, gegen die Spitze gefleckt, am Grunde der dem unpaaren Sepalum zugewandten Ränder zerstreut dunkelviolett punktiert, $2.50 \mathrm{~cm}$. lang, $0.90 \mathrm{~cm}$. breit. Petalen aufrecht, lanzettlich, spitz, concav, dunkelviolett gefleckt, $\pm 2.20 \mathrm{~cm}$. lang, $0.55 \mathrm{~cm}$. breit. Lippe dem Säulenfuss sehr beweglich angegliedert, klein, mit der Spitze zwischen den paarigen Sepalen hervortretend, fleischig, 3lappig, am Grunde rinnig, gekrümmt, matt hellgelb, vorn violett punktiert, $\pm 0.70 \mathrm{~cm}$. lang; $0.55 \mathrm{~cm}$. breit; Seitenlappen schräg abstehend, abgerundet, convex; Mittellappen stark seitlich zusammengedrückt, sichelig gekrünmt, sehr spitz, am Grunde mit 2 Längsrippen, $\pm 0.10 \mathrm{~cm}$. breit. Säule gerade, von der Seite zusammengedrückt, glïnzend hellgelb; Öhrchen stumpf. Anthera wenig gewölbt, mit stark kammförmig verdicktem Konnektiv, dunkel braunviolett. Pollinien 4, lïng. 
lich, gelb. Stigma gross, concav. Säulenfuss mit dem Ovarium einen stumpfen Winkel bildend, kuř, vorwärts gekrümmt, mit freier Spitze, stumpf, glänzend hellgelb, $0.60 \mathrm{~cm}$. lang. Ovarium blass graugelb, $1 \mathrm{~cm}$. lang; Stielchen blass gelb, $3.50 \mathrm{~cm}$. lang.

Ambon (Karsten); Hoetoe Mortetoe (J. J. S.).

Diese Pflanze hatte ich anfangs als eine eigene Art betrachtet. Sowie in den vegetativen Teilen wie auch in den Blüten ist sie jedoch $B$. macranthum Lndl so ähnlich, dass diese Meinung bei genauerer Untersuchung nicht bestïtigt wurde. Die Varietiit unterscheidet sich vom Typus nur durch die Farbe und die aufrechten, nicht weit abstehenden Sepalen und Petalen. In der Umgebung von Alang fand ich ein leider nicht blühendes Bulbophyllum, welches vielleicht die hier beschriebene Pflanze sein dürfte. Sie ist B. macranthoides Krzl. sehr ähnlich.

Bulbophyllum virescens J. J. S. Bull. Inst. Buit. n. 7; Ic. bog. II, 99, t. CXIX A.

Ambon; Spitze des Toena (J. J. Smith).

Diese Pflanze scheint Cirrhopetalum maximum Ridl., besonders auch was die Farbe anbelangt, sehr ähnlich $\mathrm{zu}$ sein; letztere hat jedoch bedeutend grössere Blüten (Sepalen $12.50 \mathrm{~cm}$. lang).

Bulbophyllum elegans J. J. S. - Cirrhopetalum elegans 'T. et B. Nat. Tijdschr. Ned. Ind. XXIV (1862) 310.

Ambon: Hila (Treub); auch Molukken (Teysm.); Bangka.

Die schon lange mit der Fundortsangabe "Bangka" im Buitenzorger Garten kultivierten Pflanzen sind den. 
jenigen, welche Treub bei Hila sammelte, vollkommen gleich. Die Beschreibung von Teysmann und Binnendijk ist sehr gut.

Das Rhizom ist sehr lang; die Trugknollen sind 上 5-10 cm. von einander entfernt. Die Blüten sind zwar ziemlich gross, aber nicht schön, die Grundfarbe ist blass gelb, mehr oder weniger violettbraun gefleckt und punktiert. Ausserdem haben sie einen schwachen, aber ziemlich unangenehmen, fischähnlichen Geruch. Das unpaare Sepalum ist nicht gewimpert, sondern in einen aufrechten, dünnen, an der Spitze verdickten, schwarzvioletten, \pm $0.60 \mathrm{~cm}$. langen Faden verlïngert. Die paarigen Sepalen sind gerade vorgestreckt, nicht gebogen. Die Petalen haben an der Spitze einige grosse, durchscheinende, warzig verdickte Punkte. Die Säulenöhrchen sind sehr lang und dünn, in der Mitte knieartig gebogen und von einem Zahn versehen. Die Anthera ist an der Spitze gezähnelt.

Bulbophyllum psittacoides J. J. S. - Cirrhopeialum psittacoides Ridl. Journ. Limn. Soc. Bot. XXXII, 280.

Ambon: Hoetoe Mortetoe (J. J. Smith); auch Biliton; mal. Halbinsel.

Wie aus den angegebenen Fundorten hervorgeht, hat diese zierliche und sehr leicht zu kennende Art ein ziemlich grosses Verbreitungsgebiet.

Grammatophyllum scriptum Bl. Mus. I, 47; Rumphia IV, 48; Miq. Fl. Ind. Bat. III, 708; T. et B. Nat. Tijdschr. Ned. Ind. XXVII (1864) 21. - G. Rumphianum 
Miq. Ann. Mus. Bot. Lugd. Bat. IV, 219. t. 819; Rolfe Orch. Rev. III (1895); Bot. Mag. LII (1896) t.7507. G. Speciosum Lndl. Gen. et Sp. Orch. 173 (p. p.) - G. Fonzliamum Rchb. f. Xen. Orch. II. 16. - G. leopardinum Rchb. f. Flora, 1888, 151. - G. Guilclmi II Krzl. Gartenfl. XLIJI (1894) 114. - Gabertia scripta Gaud. Freyc. Voy. Bot. 425. - Vanda scripta Spr. Syst. Veg. III, 719, 2. - Cymbidium scriptum Sw. Schrad. Journ. 1799, 218; Wlld. Sp. Pl. IV, 100 ; Pers. Syn. Pl. II, 515. - - Epidendrum scriptum L. Sp. Pl. 1351; Lam. Enc. bot. I, 185. - Angraccum scriptum Rumph. Herb. Amb. VI, 95, t. 42 .

Ambon: Ohne nähere Fundortsangabe (Rumph.); Wai (J. J. Smith); auch Boeroe; Ternate; Neu-Guinea; Minahasa (Celebes).

Exemplare dieser stattlichen Pflanze, aus verschiedenen Gegenden stammend, werden im Buitenzorger Garten kultiviert, aber weder an den lebenden Pflanzen noch in den Beschreibungen und Figuren sind Unterschiede zul entdecken, welche das Aufstellen mehrerer Arten rechtfertigen können. Es wurde mich nicht wundern, als auch $G$. multiflorum Lndl. aus den Philippinen nur eine Form des $G$. scriptum Bl. wäre.

Es ist sehr merkwürdig, dass diese Pflanze für eine kräftige Entwickelung so wenig Bedürfnisse hat. In der Orchideenabteilung des botanischen Gartens zu Buitenzorg wächst ein Exemplar auf einem c. 2 m. hohen und nur wenige $\mathrm{cm}$. dicken Stämmchen von Plumicra acutifolia Poir. Zwar hat sie ein dichtes Gewebe von Fangwurzeln gebildet, aber der sundanesische Gärtner 
sucht, der Reinlichkeit wegen, sorgfailtig die darauf fallenden Blätter u. s. w. hinab. Nichtsdestoweniger wächst die Pflanze kräftig und bildet bei jeder neuen Knolle meistens 2 starke Blütenstände.

Rumphius beschreibt noch 2 Formen, welche ich nach der Beschreibung nicht für spezifisch verschieden halte. Hasskarl giebt dafür die Namen Cymbidium Wallichii Lndl.? ? und Arachnitis moschifera $\mathrm{Bl}$.

\section{Dipodium sp.}

Ambon: Nona; Hoetoe Mortetoe; Toena; Riboe (zwischen Alang und dem Latoea) (J. J. Smith).

Diese auf Ambon weit verbreitete Pflanze habe ich leider nicht blühend gesehen. Die in Buitenzorg eingeführten Exemplare, wiewohl gut wachsend, haben ebenfalls noch nicht geblüht.

Thelasis elongata Bl. var. amboinensis J. J. S. n. var.

Pusilla, caespitosa. Bracteae patentes non reflexae, 3angulares, subacuminatae, acutae. Flores parvi, vix aperti, horizontaliter compressi, circ. $0.35 \mathrm{~cm}$. longi, 0.20 cm. lati.

Rasig. Rhizom stark verzweigt. Trugknollen klein, stark und schief niedergedrückt, fleischig, hellgrün, \pm $1 \mathrm{~cm}$. breit, $0.40 \mathrm{~cm}$. hoch, an der Spitze 1blättrig, am Grunde mit einigen fleischigen, hellgrünen Scheiden, von denen 1 oder 2 eine kleine Spreite tragen und die höchste die ganze Knolle und die Blattbasis eng umschliesst, also an ihre Spitze stark verengert ist. Blatt 
aufrecht, fleischig, linear lanzettlich, 'an der Spitze etwas zurückgekrümnt, etwas ungleich stumpf und mit einem Spitzchen, am Grunde verschinälert und zusammengefaltet, mit einer schwachen Längsfurche, die beiden Hällften etwas convex, $\pm 4 \mathrm{~cm}$. lang, $0.70 \mathrm{~cm}$. breit; Scheide fleischig, auf dem Querschnitt oval, $\pm 0.35 \mathrm{~cm}$. lang. Blütenstände aufrecht, sehr dicht und vielblütig. Pedunculus stielrund, warzig, $\pm 2.30 \mathrm{~cm}$. lang, mit wenigen röhrigen Schaftblättern. Rachis bis $\pm 3 \mathrm{~cm}$. lang, lange fortblühend, die blühende Spitze aufrecht, pyramidalisch, $\pm 0.60-0.70 \mathrm{~cm}$. lang. Bracteen abstehend, 3eckig, etwas zugespitzt, spitz, bald vertrocknend, $0.15 \mathrm{~cm}$. lang. Blüten weit abstehend, klein, kaum geöffnet, horizontal zusammengedrückt, nicht umgedreht, blass grün mit weisslichen Spitzen, mit dem Ovarium $\pm 0.35 \mathrm{~cm}$. lang, $0.20 \mathrm{~cm}$. breit. Unpaares Sepalum länglich, spitz, concav, den paarigen parallel, $\pm 0.20 \mathrm{~cm}$. lang, $0.075 \mathrm{~cm}$. breit. Paarige Sepalen viel breiter, dem Mittelnerv entlang scharf zusammengefaltet, scharf gekielt, spitz, $0.20 \mathrm{~cm}$. lang. Petalen länglich, nur mit der Spitze zwischen den Sepalen vorragend, stumpf, $0.15 \mathrm{~cm}$. lang, $0.075 \mathrm{~cm}$. breit. Labellum stark concav, mit am Grunde einwärts gebogenen Rändern, eirund, weiss, am Grunde blass grün, $0.13 \mathrm{~cm}$. lang. Gynostemium sehr kurz; Clinandrium eirund, spitz. Anthera aus breitem, quer ovalem, an der Basis mit 2 kurzen Lüppchen versehenem Grunde plötzlich lang und spitz zugespitzt, warzig, hellgrün. Pollinien 8, birnförmig; gelb, auf einem langen, dünnen, gelben Stielchen auf einer langen, schmalen Klebmasse. Rostellum über die Anthera vorragend, sehr spitz 2zäh- 
nig. Ovarium 3kantig, horizontal zusammengedrückt, mit scharfen Seitenrändern, hellgrün, $\pm 0.17 \mathrm{~cm}$. lang. Ambon: Hila (Treub).

Eine stark wachsende, dichte Rasen bildende Pflanze, welche von $T$. elongata $B$. verschieden ist durch die kleineren Dimensionen, die verhältnissmässig breiten Blüten, die weniger zugespitzten, nicht zurückgebogenen Bracteen. Man könnte jedoch diese Pflanze mit fast gleichem Rechte als eine Varietait der T. capituta Bl., oder als eine neue Art betrachten.

\section{Phreatia sp.}

Ambon: Ohne nähere Fundortsangabe (Karsten).

Eine kleine Art mit kurzem Stengel, linearen, fleischigen Blättern und kleinen grünlichen Blüten, welche noch näher zu untersuchen sind.

Podochilus appendiculatus J. J. S. Bull. Inst. Buit. n. 7 ; Ic. bog. II, 50, t. CIX F.

Ambon: Latoea (J. J. Smith).

Appendicula reflexa Bl. Bijdr. 301; Lndl. Gen. et Sp. Orch., 229 ; Miq. Fl. Ind. Bat. III, 703; Ridl. Journ. Linn. Soc. Bot. XXXII, 390 ; J. J. S. Fl. Buit. VI, Orch. 523. - A. cordata Hook. f. Fl. Br. Ind. VI, 83; Ic. pl. XXII, t. 2148. - A. viridiflora T. et B. Nat. Tijdschr. Ned. Ind. XXIV, 321. - Podochilus reflexus Schltr. Mém. Herb. Boiss. 1900, n. 21, 31.

Ambon: Latoea (J. J. Smith); auch Nell-Guinea; Celebes; Borneo; Java; mal. Halbinsel. 
Eine der meist verhreiteten Arten dieser (Gattung, mit lateralen, seln kurzon, dichten, \pm (j -12blütigen, abwärts gebogenen Blütenstïnden kleiner, blass grüner Blüten.

\section{Appendicula latilabium J. J. S. n. sp.}

Caules elongati, teretes. Folia membranacea, lanceolata, apice 2dentata cum mucrone aequilongo. Inflorescentiae ad apicem caulium, paulum ramosae, deflexae, multiflorae. Bracteae reflexae et flores majusculi extus verrucosa. Sepala ovato-3angularia; mentum breve, latissimum. Petala oblongo-spathulata. Labellum recurvatum, late oblongum, intus lamellis 2 carnosis, in ungue appendicem brevem, obtusum, non concavum formantibus, arl apicem costa parva. Pes gynostemii curvatus, sulcis 2 profundis.

Stengel dicht beisammen, am Grunde stielrund, nach oben hin elliptisch, hellgrün, $\pm 50 \mathrm{~cm}$. lang, $0.30 \mathrm{~cm}$. dick; Internodien $\pm 1.60 \mathrm{~cm}$. lang. Blätter dünn, am Grunde gedreht, lanzettlich, spitz 2zähnig und mit einem gleich langen Spitzchen, mit oben gefurchtem, unten gekieltem Mittelnerv und einigen unten schwach vorra genden Nerven, glänzend grün, unten matt, $\pm 8 \mathrm{~cm}$. lang, $1.60 \mathrm{~cm}$. breit; Scheiden röhrig, kürzer als die Internodien, mehr oder weniger violett gefärbt. Blütenstände der Stengelspitze genähert, etwas verzweigt am Grunde abwärts gebogen, vielblütig, dicht. Bracteen zurückgeslagen, länglich, etwas eirund, spitz, concav, mit 5 aussen vorragenden, warzigen Nerven, graugrün, \pm 
$0.65 \mathrm{~cm}$. lang, $0.35 \mathrm{~cm}$. breit. Blüten ziemlich gross, $\pm 0.80 \mathrm{~cm}$. breit. Unpaares Sepalum länglich eirund, stumpf, mit einem kurzen, dicken Spitzchen, sehr concav, mit 3 aussen rorragenden Nerven, aussen sehr warzig, dunkelviolett, am Grunde grünlich, $\pm 0.75 \mathrm{~cm}$. lang, $0.35 \mathrm{~cm}$. breit. Parige Sepalen am Säulenfuss herab. laufend, ein kurzes, sehr breites, stumpfes, $\pm 0.30 \mathrm{~cm}$. langes, $0.40 \mathrm{~cm}$. breites Mentum bildend; 3eckig; spitzlich mit einem kurzen, stumpfen Spitzchen, aussen warzig und mit 5 aussen vorragenden Nerven, violett, am Grunde blass grün, $\pm 0.70 \mathrm{~cm}$. lang. Petalen dem unpaaren Sepalum parallel, länglich spatelig, stumpf, sehr blass grün, $\pm 0.60 \mathrm{~cm}$. lang; $0.27 \mathrm{~cm}$. breit. Lippe am Grunde dem Süulenfuss parallel und angedrückt, in $1 / 3$ vom Grunde rechtwinkelig vorwärts und in $2 / 3$ rechtwinkelig abwärts gebogen, sehr breit länglich, am Grunde verschmälert, an der Spitze breit abgerundet, innen mit 2 fleischigen, durch eine Längsfurche getrennten, auf dem Nagel sich vereinigenden und ein kurzes, stumpfes Anhängsel bildenden Längsleisten, an der Spitze mit einem kleinen Längsrippchen, weiss, ausgespreizt $\pm 0.70 \mathrm{~cm}$. lang, $0.55 \mathrm{~cm}$. breit. Säule kurz, dick, grün, am Rande violett, $0.27 \mathrm{~cm}$. lang, an der Spitze 3lappig; die Öhrchen abgestutzt. Anthera kappig, herzförmig, dunkelviolett mit hellem Rande und Spitze. Pollinien 6, keulig, gelb. Rostellum kurz und spitz 2zähnig, dunkelviolett. Narbe halbrund. Säulenfuss gebogen, concav, mit 2 tiefen Längsfurchen, am Grunde grün mit, 2 violetten Längsstreifchen, an der Spitze weisslich, $\pm 0.30 \mathrm{~cm}$. lang. Ovarium grün und violett gefürbt, $\pm 0.70 \mathrm{~cm}$. lang. 
Ambon: Zwischen dem Latoea und Riboc, an Bäumen und Steinen wachsend (.J. J. Smith).

Eine Art aus der Verwandtschaft der A. pendula Bl. und A. philippinensis J. J. S. (Schl.), von welchen sie sich durch die bedeutend grösseren Blüten, das breite Labellum und namentlich durch das fleischige, nicht concave, gegen sein Ende verschmälerte Anhängsel des Lippennagels unterscheidet.

\section{Acriopsis sp.}

Ambon: Zwischen Toelehoe und Soeli in einem Leucadendronwäldchen.

Wahrscheinlich ist diese Art 1. javanica Reinw; leider habe ich keine Blüten gesehen.

Luisia teretifolia Gaud. Bot. Freyc. Voy. 427, t. 37 ; Bl. Rumphia, IV, t. 194, f. 3; t. 197 D; Mus. Bot. I, 63; Lndl. Fol. Orch. 2 (excl. syn. Epidendrum triste); Mip. Fl. Ind. Bat. III, 683; Hook. f. Fl. Br. Ind. VI, 22 ; King et Pantl. Ann. Bot. Gard. Cale. VIII, 203, t. 271 ; J. J. S. Fl. Buit. VI, Orch. 545. - L. brachystachys Bl. var. flaveola Par. et Rchb. f. Trans. Linn. Soc. XXX, 144. - L. burmanica Lndl. Fol. Orch. 3. - L. platyglossa Richb. f. Walp. Ann. VI, 622. - L. zeylanica Lndl. 1. c. - Cymbidium triste Rxb. Fl. Ind. III, 461; Bot. Mag. t. 3648; Wight Ic. 911 (excl. Fig.); Griff. Not. III, 340. - C. tenuifolium Wight, l. c. t. 1689 (excl. Text.) - Angraccum flavum decimum sive angustifolium Rumph. Herb. Amb. VI, 104.

Ambon: Ohne nähere Fundortsangabe (Rumphius); 
Ambon; Galela; Wai (.I. J. Smith); auch Molukken; Mariannen; Neu-Caledonien; Java; Ostindien; Ceylon.

Phalaenopsis amabilis Bl. Bijdr. 294, f XLIV; Rumhia IV, 52, t. 194, 199 A; Lndl. Gen. et Sp. Orch. 213 ; Horsf. Pl. Jav. rar. 28, t. 8; Bot. Mag. t. 4297 ; Miq. Fl. Ind. Bat. III, 690 ; J. J. S. Fl. Buit. VI Orch. 549. - P. grandiflora Indl. Gard. Chr. 1848, 39; Bot. Mag. t. 5184 ; Miq. 1. c.-- Epidendrum amabile L. Spec. pl. 1351. - Cymbidium amabile Rxb. Fl. Ind. III, 457. Angraecum album majus Rumph. Herb. Amb. VI, 99, t. 33.

Ambon: Ohne nähere Fundortsangabe (Rumphius, 'T'eysm.); zwischen Toelehoe und Soeli; Hila; Larike; zwischen Alang und dem Latoea; Hina Niwel (J. J. Smith); auch Boeroe; Celebes; Borneo; Java; Philippinen.

Rumphius vermeldet 2 Formen, welche wohl noch zu vermehren wären. Hasskarl's Meinung, dass eine davon $P$. violacea T. et $B$. sein dürfte, ist sicher irrig.

Sarcochilus pallidus Rchb. f. Walp. Ann. VI, 500; J. J. S. Fl. Buit. VI, Oreh. 559. - S. unguiculatus Lndl. Bot. Reg. 1840, Misc. 67. - S. aureus Hook. f. Fl. Br. Ind. VI, 35; Ann. Bot. Gard. Calc. V, 42, t. 64. - S. cladostachys Hook. f. l. 1. c. c. 35 et 43 , t. 65. -- Dendrocolla pallida Bl. Bijdr. 290. - Acrides pallidum Lndl. Gen. et Sp. Orch. 241; Miq. Fl. Ind. Bat. III, 697. - A. diurnum T. et B. Nat. Tijdschr. Ned. Ind. XXVII (1864) 19. - Thrixspermum pallidum Rchb. f. Xen. Orch. II, 122. - T. unguiculatum Rchb. f. l. c. - T. aureum O. K. Rev. Gen. Pl. II, 682. -- 
T. cladostachyum O. K. I. c. - Phalaenopsis fugax Krzl. Gard. Chr. 1893, II, 360.

Ambon: Ohne nähere Fundortsangabe (Karsten); auch Celebes; Borneo; Java; mal. Halbinsel; Philippinen.

Eine weit verbreitete und daher ziemlich variabele Art, mit längeren oder kürzeren, dickeren oder dünneren, grünen oder grau und violett gefärbten Blättern und lüngeren order kürzeren Blütenständen. Die Blüten, welche für ein Sarcochilus ziemlich gross sind, zeigen in der Form nur kleine Abweichungen; die Sepalen und Petalen sind mehr oder weniger spitz, der callusartige Mittellappen der Lippe ist ganz oder mehr oder weniger ausgerandet; die Farbe wechselt von weiss zu blass gelb, und die Zeichnungen auf der Lippe sind heller oder dunkler violett oder violettbraun.

Blume hat die Art zuerst beschrieben; das Original befindet sich im Leidener Herbarium.

Sarcochilus Taeniophyllum J. J. S. n. sp.

Caulis brevissimus, aphyllus. Radices complanati, lati. Inflorescentiae erectae, elongatae, laxe multiflorae. Penduculus tenuis. Flores probabiliter ephemeri, minusculi. Sepala petalaque oblonga, obtusa, petala basi angustata. Labellum parvum; lobi laterales majusculi, erecti, oblongi; lobus medius deflexus, parvus, crassus, pilosus; calcar incurvum, breviter crasse conicum, apice attenuatum, obtusum, intus dorso callo instructum. Pes gynostemii tenuis.

Stengel sehr kurz, blattlos. Wurzeln stark entwickelt, 
flach, oben mit scharfen Pünktchen, $\pm 20 \mathrm{~cm}$. lang, $0.65 \mathrm{~cm}$. breit. Blütenstände aufrecht, verlängert, locker, viel- ( \pm 15 -)blütig. Penduculus dünn, stielrund, \pm 13 cm. lang, $0.075 \mathrm{~cm}$. dick; mit einigen ( \pm 8) kurzen, zugespitzten Schaftblättern. Rachis dünn, $\pm 8 \mathrm{~cm}$. lang. Bracteen klein, 3eckig, spitz, concav, $0.175 \mathrm{~cm}$. lang. Blüten allseitswendig, wahrscheinlich in Zwischenräumen eine Anzahl zugleich blühend, wahrscheinlich 1 Tag dauernd. Sepalen länglich, stumpf, 3nervig, das unpaare $\pm 0.65 \mathrm{~cm}$. lang; $0.25 \mathrm{~cm}$. breit, die paarigen etwas scliief, nicht am Säulenfuss herablaufend, 0.70 cm. lang, $0.27 \mathrm{~cm}$. breit. Petalen länglich, stumpf, am Grunde verschmälert, 3nervig, $0.65 \mathrm{~cm}$. lang, $0.25 \mathrm{~cm}$. breit. Lippe der Spitze des Säulenfusses angeheftet, klein, im ganzen $0.30 \mathrm{~cm}$. lang, gespornt, 3lappig; Seitenlappen aufrecht, schräg nach hinten gekehrt, verhältnissmässig gross, länglich, stumpf, etwas eingebogen, convex, $0.17 \mathrm{~cm}$. lang; Mittellappen klein, abwärts gebogen, dick, polsterig, stumpf, convex, abstehend behaart; Sporn schräg nach vorn gekehrt, kurz und dick kegelig, mit schmaler, stumpfer, melır oder weniger znrückgekrümmter Spitze, dickwandig, innen am Hinterwand mit einem Callus. Gynostemium sehr kurz, dick. Säulenfuss vorgestreckt, gerade, linear, dünn, $0.175 \mathrm{~cm}$. lang.

? Ambon: Ohne nähere Fundortsangabe (Teysmann); Banda (Treub).

Diese Art steht S. phyllorhizus F. Muell. von Queensland und einer neuen Art ron Aroe sehr nahe; die erstere hat jedoch kleinere Blüten und kleine, schmal 
längliche, keulige Seitenlappen an der Lippe. Sie sehen alle Taeniophyllum Bl. sehr ähnlich aus, den Blüten nach sind sie jedoch echte Sarcochilus-arten. Die ebenfalls (wenigstens nahezu) blattlose Gattung Chiloschista unterscheidet sich durch länger dauernde, sich allmählig und nicht in Zwischenräumen entwickelnde Blüten, auf der Säulenfussspitze inserierte, paarige Sepalen und am Säulenfuss herablaufende Petalen.

Prof. Dr. M. Treub sammelte diese Pflanze im Jahre 1893 auf der Insel Banda, nnd stellte das in Alkohol aufbewahrte Material freundlichst zu meiner Verfügung. Teysmann sammelte die vielleicht gleiche Art nach einem Zettel im Buitenzorger Herbar auf Ambon; seine Exemplare sind leider blütenlos.

Sarcochilus Zollingeri Richb. f. Walp. Ann. VI, 500; J. J. S. Fl. Buit. VI, Orch. 563. - Dendrocolla Zollingeri Rchb. f. Bonpl. 1857, 40; Xen. Orch. II, 213, t. 86, I; Miq. Fl. Ind. Bat. III, 743. - Grossourdya Zollingeri Rchb. f. Xen. Orch. I, 123.

Ambon: Halong und Toena (J. J. Smith); auch Java.

Diese Pflanze gehört zu den wenigen Sarcochilus-arten mit weichstacheligen Blütenständen, welche Ridley, wiewohl ohne Grund, unter den Namen Ascochilus abtrennt. Ascochilus Ridl. könnte jedoch als Sektion bei Sarcochilus beibehalten werden. Andere Unterschiede als der genannte giebt es nicht.

Die paarigen Sepalen sind bei S. appendiculatus J. J. S. (Dendrocolla Bl. und vielleicht identisch mit S. hirtulus Hook. f.) und S. emarginatus Rclsb. f., welche beide 
zur Sekt. Ascochilus gehören, nicht bedeutend breiter als das unpaare; dagegen sind sie z. B. bei S. Teysmannii J. J. S. (Aerides Miq.) und auch bei S. compressus Rchb. f. mit nicht behaarten Blütenständen, deutlich breiter. Die Säule ist nicht nur verlängert bei $S$. appendiculatus J. J. S. und S. Zollingeri Rchb. f. (Sekt. Ascochilus), sondern auch Z. B. bei S. Teysmannii J. J. S. und S. sigmoideus Ridl. (syn. S. stenoglottis Hook. f.). Dagegen ist dieselbe sehr kurz bei $S$. emarginatus Rchb. f.

Auch was die Entwickelung des Blütenstandes anbelangt, stimmen Ridley's Angaben nicht mit meinen Erfahrungen überein. Wie bei den anderen Arten der Gattung entwickeln die 3 mir bekannten und viele Jahre lebend im botanischen Garten zu Buitenzorg beobachteten Arten mit behaartem Blütenstand 1 oder wenige Blüten zu gleicher Zeit, um das nach einer gewissen Ruheperiode $\mathrm{zu}$ wiederholen.

Thrixspermum amplexicaule Rchb. f. Xen. Orch. II, 121 ; J. J. S. Fl. Buit. VI Orch. 573. - T. lilacinum Rchb. f. 1.c. - Dendrocolla amplexicaulis Bl. Bijdr. 288. Aerides amplexicaule Lndl. Gen. et Sp. Orch. 239; Miq. Fl. Ind. Bat. III, 696. - Sarcochilus amplexicaulis Rchb. f. Walp. Ann. VI, 499. - S. lilacinus Griff. Not. III, 334 ; Ic. Pl. Asiat. t. 320, f. 11 ; Rehb. f. Walp. Ann. l.c.; Hook. f. Fl. Br. Ind. VI, 40. Orsidice amplexicaule Rchb. f. Bonpl. II, 93.

Ambon: Ema (Teysm.); Hauptstadt; Nona (J. J. Smith), meistens in Grasfeldern; auch Banda; Celebes; Borneo; Java; Sumatra; Singapore; mal. Halbinsel. 
Thrixspermum subteres J. J. Smith, Bull. Inst. Buit. n. 7 ; Ic. bog. II, 119, t. CXXIII C.

Ambon: Hoetoe Mortetoe und Toena (J. J. Smith).

Thrixspermum subulatum Rehb. f. Xenia Orch. II, 122 ; J. J. S. Fl. Buit. VI, Orch. 578. - Dendrocolla subulata Bl. Bijdr. 291. - Aerides subulatum Lndl. 'Gen. et Sp. Orch. 241; Miq. Fl. Ind. Bat. III, 698. - Sarcochilus subulatus Rchb. f. Walp. Ann. VI, 500.

Ambon: Hila (Treub); auch Tenimber Inseln; Java; Sumatra.

Eine sehr distinkte Art mit langen, schlaffen, herabhängenden, stark zusammengedrückten, verzweigten Stengeln, linear lanzettlichen, plötzlich zugespitzten Blättern und sehr kurzen, armblütigen Blütenständen. Die Blüten sind zart, $1.60 \mathrm{~cm}$. breit, wohlriechend, mehr oder weniger gelblich weiss, die aufrechten, sichelig 3eckigen, spitzen Seitenlappen der Lippe mit einem orangefarbigen Fleck gezeichnet; der Mittellappen ist kurz und callusförmig.

Renanthera moluccana Bl. Rumphia IV, 54, t. 193, f. 2 ; t. 197 E; Mus. I, 60; Miq. Fl. Ind. Bat. III, 699. - Angraecum rubrum Rumph. Herb. Amb. VI, 101, t. 44, f. 2.

Ambon: Ohne nähere Fundortsangabe (Rumph.): Hoetoe Moeri (Teysm.); Paso.

Eine mit $R$. elongata Lndl. sehr verwandte Art, durch die bedeutend grösseren Blüten jedoch leicht zu unterscheiden. Was Rumphius mit seiner "Verandering" dieser Art gemeint hat, kann ich nicht sagen. 
Vanda furva Lndl. (non Bl.) Gen. et Sp. Orch. 215. -Cymbidium furvum Wlld. Spec. Pl. IV, 103. - Epidendrum furvum L. Spec. Pl. 1348. - Angraecum furvum Rumph. Herb. Amb. VI, 104, t. XLVI, f. 1.

Folia lorata apice inaequaliter obtusa, non dentata, mucrone dentiformi. Inflorescentiae foliis breviores laxe circ. 11florae. Flores $3.50 \mathrm{~cm}$. lati. Sepala petalaque spathulata, undulata, intus fusca, extus pallide lutea. Labelli lobi laterales parvi, rotundati, lobus medius porrectus, late panduratus, lobulo antico basilaribus multo majore subrotundo, convexo, late obtuso, dilute flavus; calcar retroversum, breve, lateraliter compressum rotundatum.

Stengel am Grunde meistens verzweigt. Blätter zahlreich, riemenförmig, an der Spitze ungleich, mit einem zahnförmigen Spitzchen, die längste Hälfte abgerundet, nicht gezähnt, oben mit einer Längsfurche, unten scharf gekielt, ziemlich hellgrün, viel weniger starr als bei $V$. tricolor Lndl., $\pm 32 \mathrm{~cm}$. lang, $3.20 \mathrm{~cm}$. breit. Blütenstände $\pm 20 \mathrm{~cm}$. lang, locker, \pm 11 blütig. Pedunculus $\pm 5 \mathrm{~cm}$. lang, ebenso wie die kantige Rachis blass grün, etwas rot gefleckt. Bracteen 3eckig, stumpf, $0.45 \mathrm{~cm}$. lang. Blüten weit geöffnet, $3.50 \mathrm{~cm}$. breit. Sepalen und Petalen fleischig, spatelig, mit stark convexem Nagel und unregelmassig rundlicher, stark weit welliger Platte, innen glänzend braun, am Grunde etwas rot, auf dem Nagel blass gelb streifig, mit blass gelbem Rande, aussen blass gelb, die Sepalen mit einem braunen Längsstreifen, resp. 1.70 und $1.83 \mathrm{~cm}$. lang, 1.25 und 
$1.13 \mathrm{~cm}$. breit. Labellum vorgestreckt, gespornt, 3lappig; Sporn nach hinten gekehrt, kurz, stark seitlich zusammengedrückt, abgerundet, gelblich weiss, $0.40 \mathrm{~cm}$. lang, am Eingang mit 2 durch eine Längsfurche getrennten, polsterigen, gelben, behaarten Verdickungen; Seitenlappen klein, vertikal, zwischen Säule und Mittellappen vorgestreckt, viel kürzer als die Säule, abgerundet, etwas concav, die oberen Ränder divergierend, blass gelb; Mittellappen vorgestreckt, gerade, breit geigenförmig, convex, ziemlich hellgelb, am Grunde mit 3 Längsrippchen und 6 braunen Streifchen, $\pm 1.40 \mathrm{~cm}$. lang, $1 \mathrm{~cm}$. breit, die Fussläppchen klein, abgerundet, convex, das Mittelläppchen viel grösser, rundlich, mit breiter, stumpfer, nicht ausgerandeter Spitze. Gynostemium kurz, an der Basis stark verbreitert, gelblich weiss, $0.50 \mathrm{~cm}$. lang, $\pm 0.80 \mathrm{~cm}$. breit. Anthera rundlich mit einem breiten, stumpfen Schnäbelchen, weiss. Pollinien 4, zusammengedrückt, gelb, auf einem mässigen, breiten, weissen Stielchen und grosser, quer ovaler Klebmasse. Rostellum stumpf 2 zähnig. Stigma nahe der Säulenspitze eine breite Querspalte bildend. Ovarium + Stielchen $\pm 4.70 \mathrm{~cm}$. lang, gelblich weiss, nach oben hin stark 6rippig.

Ambon: Ohne nähere Fundortsangabe (Rumphius); Hatiwi ketjil und Toelehoe (J. J. Smith).

Diese Art scheint mehrmals mit anderen verwechselt $\mathrm{zu}$ sein. Blume's Figur in Rumphia stellt eine andere Art, wenigstens was die Farbe und die Form der Lippe anbelangt, da.

Vanda crassiloba T. et B. Cat. Hort. Bog. 48. - ? V. 
hastifera Rehb. f. Linnaea, 1876, 30 ; Gard. Chr. 1883, II, 556. - ? Angraecm saxatile Rumph. Herb. Amb. VI, 107, t. XLIX, f. 1.

Folia lorata, inaequaliter biloba, mucronata, lobis intus denticulatis. Inflorescentiae foliis breviores pauci- (?) florae. Flores $3.70 \mathrm{~cm}$. lati. Sepala petalaque oblongospathulata, reflexa, paulum undulata, pallide viridiflava, fusce maculata. Labelli lobi laterales porrecti, rhombei, obtusi, con'avi, albi; lobus medius porrectus, hastatus, flavescenti-albus, hirtus, çasse carnosus; lobulis basilaribus patentibus, acutis; lobulo antico apicem versus attenuato, breviter obtuse 2 lobulato, apice glabro; calcar retroversum, lateraliter compressum, subconicum. Gynostemium medio constrictum, basi vale dilatatum.

Stengel verlängert, stielrund, $+0.65 \mathrm{~cm}$. dick. Blätter 2zeilig, riemenförmig, umgebogen, am Grunde rinnig; mit oben gefurchter, unten gegen die Spitze gekielter Mittelrippe, an der Spitze ungleich 2lappig mit eckigen, am inneren Rande gezähnelten Läppchen und einem Spitzchen dazwischen, dick ledrig, ziemlich hellgrün, \pm $23 \mathrm{~cm}$. lang, $2 \mathrm{~cm}$. breit; Scheiden röhrig, länger als die Internodien, vorn aufreissend. Blütenstände viel kürzer als die Blätter, arm-(土 2-)blütig, aufrecht. Pedunculus blass grün, $\pm 2.50 \mathrm{~cm}$. lang, mit einigen kurzen, röhrigen, gekielten, blass grrinen Schaftblättchen. Rachis kantig, blass grün. Bracteen klein, 3eckig. Blüten weit geöffnet, fleischig, $\pm 3.70 \mathrm{~cm}$. breit, schwach wohlriechend, lange dauernd. Sepalen länglich, ziemlich schwach spatelig, stumpf, etwas weit wellig, blass grünlich gelb, 
unregelmässig braun gefleckt; das umpaare vorwärts gebogen, $\pm 2.30 \mathrm{~cm}$. lang, 1 cm. breit; die parigen schräg nach hinten gekehrt, aussen stark gekielt und blass gelb, $\pm 2.20 \mathrm{~cm}$. lang, $1.10 \mathrm{~cm}$. breit. Petalen schräg nach hinten gekehrt, länglich spatelig, stumpf, etwas weit wellig, aussen mit einel Längsrippe, gefärbt wie die Sepalen, $\pm 2.20 \mathrm{~cm}$. lang, $0.90 \mathrm{~cm}$. breit. Labellum klein, gespornt, 3lappig; Sporn nach hinten gekehrt, schwach kegelig, seitlich zusammengedrückt, stumpf, gerade, glänzend hell gelbbraun, $\pm 0.85 \mathrm{~cm}$. lang, an der Basis $0.40 \mathrm{~cm}$. hoch, innen lang abstehend weiss behaart, am Eingang mit einer polsterigen, nit einer Längsfurche rersehenen, weissen, dicht behaarten Verdickung; Seitenlappen vertikal vorgestreckt, rautenförmig, stumpf, sehr concav, weiss, am Grunde etwas braun punktiert, kürzer als die Säule; Mittellappen vorgestreckt, sehr dick fleischig, spiessförmig; oben gelblich weiss, ausser der Spitze kurz abstehend behaart und mit 3Längsrippen, unten glänzend blass grünlich, mit einer Längsfurche und am Grunde vertieft, $\pm 0.95 \mathrm{~cm}$. lang, am Grunde $1.15 \mathrm{~cm}$. breit; die Fussläppchen rechtwinkelig abstehend, schmal 3eckig, spitz, das Endläppchen gegen die Spitze verschmälert, an der Spitze kurz 2lappig, $0.75 \mathrm{~cm}$. lang, $0.50 \mathrm{~cm}$. breit. Säule ziemlich schlank, schwach gebogen, in der Mitte eingeschnürt, am Grunde stark verbreitert und 6eckig, gelblich weiss, am Grunde unten braun gefärbt, $0.90 \mathrm{~cm}$. lang, an der Basis 0.67 .5 cm. breit. Anthera schwach gewölbt, rundlich, nicht geschnäbelt. Pollinien 4, vom Rücken zusammengedrückt, oval, gelb, ungleich gross, auf einem kurzen, 
breiten, weissen Stielchen mit grosser, rundlicher Klebmasse. Rostellum 2zähnig. Stigma quer oval. 'Ovarium + Stielchen $\pm 6.50 \mathrm{~cm}$. lang, 3kantig, gelblich weiss, die Seiten mit je 2 feinen Längsfurchen.

Ambon (Teysmann).

Herb. Lugd. Bat. n. 903, 16 - 2859.

Die Beschreibung ist angefertigt nach einem im botanischen Garten zu Buitenzorg in ziemlich tiefem Schatten kultivierten Exemplar, das in fast allen Teilen mit dem sehr guten, von Teysmann in Ambon gesammelten Exemplar im Leidener Herbar übereinstimmt. Das einzige Blatt in Leiden ist jedoch bedeutend schmäler (1.30 cm.), der Blütenstand zählt 6-7 Blüten, während der Mittellappen der Lippe beim getrockneten Exemplar verhältnissmässig schmäler ist.

Herr Prof. M. Treub und ich sammelten auf Ambon einige Exemplare einer Vanda, welche in Buitenzorg kultiviert werden, aber noch nicht geblüht haben, und wahrscheinlich zu dieser Art gehören. Auch Rumphius' Angraecum saxatile stellt vermutlich diese Art vor und kein Cymbidium, wie Hasskarl vermutet.

Reichenbach's $V$. hastifera Rchb. f. ist, wenn nicht dieselbe, jedenfalls eine sehr verwandte Art.

Vandopsis lissochiloides Pfitz. Orch. 210, f. 229. Fieldia lissochiloides Gaud. Voy. Freyc. 424, t. 36 ; Bl. Rumphia IV, t. 194, f. 2 ; Rchb. f. Xen. Orch. II, 38. Vanda lissochiloides Lndl. Gen. et Sp. Orch. 216; Bl. Rumphia IV, 49; Miq. Fl. Ind. Bat. III, 680. $-V$. Batemannii Lndl. Bot. Reg. 1846, t. 59; Fol. Orch. n. 
1. - Stauropsis lissochiloides Pfitz. Vergl. Morph. Orch.

14. - Angraecum quintum Rumph. Herb. Amb. VI, 102.

Ambon: Ohne nähere Fundortsangabe (Rumphius); auch Philippinen.

Sarcanthus subulatus Rchb. f. Bompl. 1857, 41; J. J. S. Fl. Buit. VI, Orch. 604. - S. secundus Griff. Not. III, 362 ; Ic. Pl. As. t. 336; Hook. f. Fl. Br. Ind. VI, 67 ; Ann. Bot. Gard. Calc. V, 51, t. 77 ; King et Pantl. Ann. Bot. Gard. Calc. VIII, 241, t. 321. - Cleisostoma subulatum Bl. Bijdr. 363; Lndl. Gen. et Sp. Orch. 226, Miq. Fl. Ind. Bat. III, 682. - Micropera pallida Lndl. Wall. Cat. n. 7321 (р. p.). - (?) Angraecum pungens Rumph. 1. c. 106.

Ambon: Zwischen Soeli und Paso (J. J. Smith); auch Borneo; Java; Riouw ; mal. Halbinsel ; Assam ; Ostindien.

Ich halte es für sehr wahrscheinlich, dass Rumphius mit seinem Anyr. pungens diese Pflanze gemeint hat. Schönorchis juncifolia Bl., wie Hasskarl voraussetzte, kann es nach der Beschreibung sicher nicht sein.

Cleisostoma cryptochilum F. v. Muell. Wing's South. Sc. Rec. I, (n. ser.) 1885. - Saccolobium purpurcum J. J. S. Bull. Inst. Buit. n. 7 ; Ic. bog. II, 115, t. CXXIII A.

Ambon: Hoetoe Mortetoe (J. J. Smith); auch S. O. Neu-Guinea.

Mein Saccolabium purpureum ist nach dem Exemplar im British Museum dieser Art völlig ähnlich. Nach del jetzigen Auffassung der Gattung Saccolabium gehört die 
Pflanze eher lierhin als zu Cleisostoma, aber eine Umtaufung werde ich vorläufig unterlassen, bis die Gattung Saccolabium einmal tüchtig revidiert worden ist.

Die nächst verwandte Art ist Sacc. calopterum Richb. f. (syn. Sacc. Schleinitzianum Klzl.), welche sich nach Reichenbach's Beschreibung, welche genau passt zu dem Exemplar im Berliner Herbarium, durch die längeren Seitenlappen der Lippe unterscheidet. Vielleicht sind jedoch die beiden Arten nur als Varietäten zu betrachten und in diesem Fall wäre Reichenbach's Name der älteste.

Cleisostoma Koordersii Rolfe, Kew Bull. 1899, 131.

Caulis longus, rigidus. Folia patentia, loriformia, inaequaliter biloba. Inflorescentiae erectae, elongatae, apice paniculatae, ramis brevibus, densifloris. Flores circ. $0.90 \mathrm{~cm}$. lati. Sepala petalaque patentia, carnosa, obovato-oblonga. Labellum 3lobum; calcar erectum, obovato-saccatum, lamella membranacea 2 dentata instructum; lobi laterales rectangulo-3angulati; lobus medius parvus, 3angulus, carnosus. Gynostemium breve, dor'so concavum. Anthera rostellata. Pollinia 4 stipiti lineari affixa.

Stengel starr, wurzelnd, stielıund. Blätter 2zeilig, ziemlich dicht beisammen, weit abstehend, riemenförmig, ungleich 2lappig, mit oben rinniger, unten vorragender Mittelrippe, dick ledrig, grün, unten blass punktiert, \pm $28 \mathrm{~cm}$. lang, $3 \mathrm{~cm}$. breit; Scheide röhrig, der obere Teil abstehend und rinnig, $\pm 4.50 \mathrm{~cm}$. lang. Blütenstände starl aufrecht, kräftig, $\pm 80 \mathrm{~cm}$. lang, an der Spitze 
in einige kurze, selırïg aufrechte, vielblütige $\Lambda$ ste geteilt. Pedunculus \pm 57 cm. lang, stielıund, $0.50 \mathrm{~cm}$. dick, dunkel grauviolett und grün marmoriert, mit einigen kurzen, röhrigen Schaftblätter'n. Bracteen kurz, breit 3eckig, stumpf, concav, abstehend. Blüten dicht beisammen, nicht ungedrelit, $\pm 0.90 \mathrm{~cm}$. breit, fleischig. Sepalen und Petalen abstehend, mit etwas einvärts gebogener Spitze, rerkehrt eirund länglich, stumpf, hellgrün, besonders aussen am Grunde braunviolett punktiert; unpaares Sepalum etwas concav, $0.75 \mathrm{~cm}$. lang, 0.3.5 $\mathrm{cm}$. breit; paarige Sepalen schief, etwas zugespitzt, mit aussen vorragender Mittelrippe', $0.70 \mathrm{~cm}$. lang, $0.25 \mathrm{~cm}$. breit: Petalen etwas sichelig, $0.65 \mathrm{~cm}$. lang, $0.25 \mathrm{~cm}$. breit. Labellum aufwärts gewandt, 3lappig, gespornt, hellgelb; Sporn verkehrt eiförmig sackig, vom Rücken zusammengedrückt, stumpf, $0.60 \mathrm{~cm}$. lang, $0.43 \mathrm{~cm}$. breit, am Eingang verengert zu $0.30 \mathrm{~cm}$, innen am Hinterwand mit einel länglichen, 2zähnigen, häutig’en, weisslichen, $0.25 \mathrm{~cm}$. langen Lamelle; Seitenlappen am Sporneingang vertikal, die Vorderränder einander etwas zugebogen, 3eckig rechtwinkelig, kurz, am Grunde dunkel violettbraun; Mittellappen vorwärts gebogen, klein, 3eckig, spitz, fleischig, blass gelb, $0.15 \mathrm{~cm}$. lang, $0.20 \mathrm{~cm}$. breit. Gynostemium kurz, mit etwas hohlem Rücken, hellgrün, $0.20 \mathrm{~cm}$. lang, $0.25 \mathrm{~cm}$. breit. Anthera kappig, quer oval, mit einem Schnäbelchen. Pollinien 4, zu 2 kugeligen Körperchen vereinigt, gelb, auf einem linearen Stielchen, mit länglicher Klebmasse. Rostellum länglich, 2zähnig, hell gelblich grün.

Ambon: Ohne nähere Fundortsangabe (Teysm.); Hila 
(Treub); Hoetoe Mortetoe (J. J. Smith); auch Obi (Ham); Minahasa (Koorders).

Jie von Koorders in der Minaliasa gesammelte und von Rolfe als $\mathrm{Cl}$. Koordersii beschriebene Art ist wohl die gleiche, welche Treub auf Ambon fand und lebend in Buitenzorg einführte. Meine Beschreibung ist nach diesem Exemplar angefertigt.

Eine von mir in Boeroe gesammelte Pflanze ist im allgemeinen der ambonschen Pflanze ähnlich. Die Blüten sind jedoch etwas kleiner; die Sepalen und Petalen breiter und dunkel violettbraun gefärbt, während die Lippe gelb und der Mittellappen derselben linnig ist; der Rücken der Säule ist weniger hohl. Der Stengel war bei dieser Pflanze $1 \mathrm{~m}$. lang. Vorläufig wäre diese Pflanze am besten als eine Var. buruense J. J. S. zu betrachten; die Untersuchung mehrerer Exemplare kann nur herausbringen ob man hier vielleicht mit einer eigenen Art zu tun hat.

Im Herb. Kew. liegt eine ebenfalls von Boeroe stammende, ganz ähnliche Pflanze unter dem Namen Saccolabium Riedelii Rchb. f., welcher Name jedoch, für so weit mir bekannt ist, nie publiziert würde.

Trichoglottis geminata J. J. S. - T. oblongifolia Rolfe, Kew. Bull. 1899, 132. - Sarcanthus geminatus 'T. et B. Nat. Tijdschr. Ned. Ind. XXIX, (1867) 243.

Ambon: Ohne nähere Fundortsangabe (Teysm.); auch Saparoea; Celebes; Borneo; ? Sumatra.

Saccolabium amboinense J. S. S. n. sp. 
Caulis elongatus, pendulus. Folia late loriformia, inaequaliter obtuse 2loba. Inflorescentiae deflexae, dense multiflorae, foliis paulo breviores. Flores erecto-patentes, pallide lutei, $1.37 \mathrm{~cm}$. lati. Sepala petalaque oblonga. Labellum lateraliter conpressum; lobi laterales parvi, 3angulares, acuti, valde convexi, apice recurvati; lobus medius porrectus, carnosus, angustus, convexus, apice tenuis obtusus; calcar magnum, retroversum, pars inferior lateraliter compressa, infundibuliformis, pars superior incurva, obtusa, intus antice in anfiactu costa carnosa. Pollinia 2, stipiti longo, angusto affixa. Rostellum deflexum, 2dentatum.

Stengel verlängert, herabhängend, mit aufwärts gekıümmter Spitze, kräftig, starı, zusammengedruckt, zickzackig, $\pm 40 \mathrm{~cm}$. lang, die Internodien $\pm 2-2.50 \mathrm{~cm}$. lang. Blätter 2zeilig, am Grunde gedreht, abstehend, breit riemenförmig; an der Spitze breit und ungleich 2lappig, mit abgerundeten Läppchen, im breiten Sinus mit einem sehr kleinen Spitzchen, mit oben gefurchtem, unten etwas stumpf vorragendem Mittelnerv, die beiden Hälften convex, ziemlich dick fleischig, grün, $\pm 21 \mathrm{~cm}$. lang, 4 cm. breit; Scheiden röhrig, zusammengedıückt, vorn und hinten mit einer von je 2 Furchen begrenzten Längsleiste. Blütenstände die Scheiden hinten am Grunde durchbohrend, abwarts gewandt, dicht vielblütig, \pm 17.50 cm. lang. Pedunculus hellgrün, $\pm 6 \mathrm{~cm}$. lang, 0.30 cm. dick, mit wenigen kurzen Scheiden. Rachis längsfurchig, blass grün, mit kleinen, schwarzen Schüppchen. Bracteen zurückgebogen, lanzettlich, spitz, concar, + 
$0.50 \mathrm{~cm}$. lang. Blüten allseitswendig, schıäg aufrecht, blass gelb, $\pm 1.37 \mathrm{~cm}$. lang, aussen mit kleinen, schwill\%en Schüppchen. Sepalen länglich, stumpf, innen schwach rötlich gefleckt; das unparre stark concav, $0.65 \mathrm{~cm}$. lang, $0.35 \mathrm{~cm}$. breit; die parligen schief, etwas concav, $0.70 \mathrm{~cm}$. lang, $0.30 \mathrm{~cm}$. breit. Petalen lünglich, gegen die spitze etwas verbreitert, spitzlich, concav, an der Spitze verdickt, gefärbt wie die Sepalen, $0.47 \mathrm{~cm}$. lang, $0.23 \mathrm{~cm}$. breit. Labellum seitlich zusammengedrückt, gespornt, 3lappig, am Grunde der Säule (Säulenfuss) etwas angewachsen, $1.35 \mathrm{~cm}$. lang; Seitenlappen klein, 3eckig, spitz, stark convex, mit zurẗckgekrümınter Spitze, die Innenflächen einander am Grunde berührend, so dass der Sporneingang sehr verengert ist, innen mit rötlichem Anf̣lug; Mittellappen vorgestreckt, fleischig, seitlich zusammengedrückt, sehr schmal, die Oberseite convex und an der Spitze als ein kleines, stumpfes, dünnes Läppchen volragend, $0.40 \mathrm{~cm}$. lang, $0.15 \mathrm{~cm}$. breit; Sporn gross, nach hinten gekehrt, in der natürlichen Lage \pm 0.95 cm. lang, der untere Teil seitlich zusammengedrückt trichterig und innen mit einigen roten Längsstreifen, der obere Teil abwärts gekrümmt, etwas keulig, stumpf, innen auf der Vorderseite in der Bucht mit einer fleischigen Längsleiste. Gynostemium kurz, etwas seitlich zusammengedrückt, mit breiter, stumpfer Spitze und fleischigen, stumpfen Ohrchen. Anthera aus breitem Grunde in ein grosses, 3eckiges, spitzes Schnäbelchen zugespitzt, $0.27 \mathrm{~cm}$. lang. Pollinien 2, klein, gefurcht, nahezu kugelig, blass gelb, auf einem langen, schmalen Stielchen und länglicher Klebmasse. Rostellum abwärts 
gewandt, 2zähnig. Stigma klein. Ovarium + Stielchen $\pm 1 \mathrm{~cm}$. lang, gelblich weiss, mit schwarzen Schüppchen. Ambon: Zwischen Alang und Hina Niwel (J. J. Smith).

Diese Art ist sehr verwandt mit S. ascendens Gaud. und S. Mooreamm Rolfe, von beiden jedoch verschieden durch den stark gekrümmten Sporn und die lïngeren, 3eckigen, spitzen, convexen, zurückgekrümmten Seitenlappen der Lippe. Alle 3, und vielleicht noch einige andere Arten gehören in der nächsten Verwandtschaft ron Cleisostoma spatulatum Bl., welche Pflanze, wie Ridley schon früher bemerkte, eigentlich ein Sarcanthus ist.

Saccolabium insectiferum .J. J. S. Fl. Buit. Orch. VI, (6t1. ? Ambon; auch Java.

Diese Pflanze sammelte ich auf meiner Reise nach Ambon. Die Nummer ging leider verloren, so dass ich nicht mit sicherkeit sagen kann, ob sie auf Ambon selbst, oder auf einer der anderen besuchten Inseln gefunden worden ist.

Das in Buitenzorg kultivierte, javanische Exemplar unterscheidet sich hauptsächlich durch die etwas kleinelen Blätter und Blüten und den mehr in der Mitte eingeschnürten Sporn.

Die nächsten Verwandten sind S. Witteanum Rchb. f. und S. undulatum Ridl.

Saccolabium rhopalorrhachis J. J. S. Fl. Buit. Orch. VI, 644. - Dendrocolla rhopalorhachis Rchb. f. Xen. Orch. I, 214, t. 86, IIl. - Thrispermum rhopalorrhachis Rchb. f. I. c. II, 121. - T. brachyglottis O. K. Rev. Gen. Pl. II, 
682. - Sarcochilus brachyglottis Hook. f. Ann. Bot. Gard. Calc. V, 42, t. 63.

Ambon: Ohne nähere Fundortsangabe (Teysm.); auf Bäumen in der Hauptstadt (Boerlage, J. J. S.); auch Java; Perak.

Diese Pflanze steht mit einer anderen javanischen Art S. pusillum Bl., dem Typus der Gattung, nahe. Zusammen stellen sie eine Gruppe dar welche mit den übrigen Saccolabium-arten ziemlich wenig Verwandtschaft zeigt, dagegen mehr in die Nähe von Sarcochilus gehört.' Die ambonsche Form einerseits unterscheidet sich von der javanischen und perakschen Form anderseits durch den längeren, etwas sichelig aufwärts gebogenen, spitzen Mittellappen der Lippe. 


\section{N A CHTRAG.}

Die nachstehenden Arten haben neulich im Buitenzorger Garten geblüht: nur Plreatia sulcata .J. J. S. fand ich im Herbar.

Dendrobium scalpelliforme T. et B. Nat. Tijdschr. Ned. Ind. XXVII, 17.

Ambon: Hila (Treub); Molukken (Teysm.)

Die Stengel sind verlängert, zusammengedrückt und das dritte Internodium über der Basis ist zu einer auf dem Querschnitt schmal rautenförmigen Trugknolle verdickt; der obere Teil der Stengel trägt nur rudimentäre Blätter, während die Blütenstände meistens aus diesem Teil hervorgehen. Die Blüten sind klein, gelb, \pm 1 cm. breit. Das Mentum (Säulenfuss) ist gebogen und hat hinten 2 starke Längsfurchen. Die Petalen sind kleiner als die Sepalen, lanzettlich, spitz, convex, 0.40 $\mathrm{cm}$. lang, $0.15 \mathrm{~cm}$. breit. Das Labellum ist im Umriss länglich verkehrt eirund, $0.90 \mathrm{~cm}$. lang, an der Spitze 3lappig, mit kurzen, stumpfen Seitenlappen und breitem, breit ausgerandetem, fast 3lappigem Mittellappen; innen ist es mit einem breiten, verdickten, nach unten hin 3rippigen Längsbande versehen. Der Säulenfuss ist concav, innen mit einer Längsrippe versehen, $0.55 \mathrm{~cm}$. lang. 
Dendrobium orientale J. J. S.

Die Beschreibung dieser Art ist nach während der Reise gemachten Notizen angefertigt. Diesem Umstande ist es wohl zuzuschreiben, dass die Beschreibung der Blütenstände ziemlich lückenhaft ist.

Im botanischen Garten zu Buitenzorg wird eine Pflanze kultiviert, welche unzweifelhaft zu dieser Art gehört. Diese fing neulich zu blühen an; leider fielen die Knos. pen ab, als sie kaum eine Länge von $0.20 \mathrm{~cm}$. erreicht hatten. Ich konnte jedoch feststellen, dass der Blütenstand 2blütig und am Grunde von seitlich zusammengedrückten Bracteen umgeben war. Dass sie der Sektion Grastidium angehört, ist also nicht zweifelhaft.

\section{Dendrobium Koordersii J. J. S.}

Zu dieser Art möchte ich noch bemerken, dass sie sehr nahe verwandt ist mit $D$. bilobum Lndl. und $D$. isochiloides Krzl. Erstere unterscheidet sich durch verhältnissmässig viel kürzere Petalen und einen warzigen Mittellappen, letztere durch gekielte Blatter, bedeutend kleinere Blüten $(0.60 \mathrm{~cm}$.$) , eine von innen mit mehreren$ Längsrippen versehene Lippe und durch einen Mittellappen mit eingerollten Rändern.

Bulbophyllum odoratum Lndl. var. niveum J. J. S. n. var.

Pseudobulbi parvi. Folia lanceolata, obtusa. Inflorescentiae foliis longiores, laxe multiflorae, graciles. Flores iis B. odorati similes, sed majores, nivei, sepalis lanceolatis. 
Trugknollen ziemlich dicht beisammen, klein, rund scheibenförmig, c. $0.70 \mathrm{~cm}$. breit, $0.50 \mathrm{~cm}$. hoch. Blatt lanzettlich, stumpf, mit oben rinnig vertiefter Mittelrippe, dick fleischig, glänzend grün, unten matt hellgrün, c. 16 $\mathrm{cm}$. lang, $3.50 \mathrm{~cm}$. brẻit, in einen zusaminengefalteten, rinnigen, $3 \mathrm{~cm}$. langen Stiel verschmälert., Blütenstïnde aufrecht, locker vielblütig, c. $27 \mathrm{~cm}$. lang. Pedunculus sehr kurz. Rachis längsfurchig, hellgrün. Bracteen pfriem lich, concar, weiss, $0.30 \mathrm{~cm}$. lang. Blüten abstehend, reinweiss, $0.80 \mathrm{~cm}$. breit, nahezu geruchlos. Sepalen abstehend, lanzettlich, concav, gegen die Spitze verschmälert und fleischig kegelig, spitz; das unpaare $0.47 \mathrm{~cm}$. lang, $0.13 \mathrm{~cm}$. breit, die paarigen etwas grösser, am Säulenfuss herablaufend, 3eckig, schwach sichelig. Petalen sehr klein, länglich, spitzlich, transparent, 0.10 cm. lang. Lippe sehr klein, beweglich, 3lappig, 0.10 cm. lang; Seitenlappen aufrecht, 3eckig; Mittellappen 3eckig, einwärts gebogen, unten convex; zwischen den Seitenlappen mit einem auf den Mittellappen fortlaufenden und an der Spitze etwas frei hervorragenden, unregelmässigen, stumpfen Callus. Säule sehr kurz; Öhrchen der Anthera gleich lang, breit, sehr kurz zugespitzt. Säulenfuss sehr kurz, mit dem Ovarium einen rechten Winkel bildend, viel dünner als die Säule, $0.07 \mathrm{~cm}$. lang. Ovarium + Stielchen $0.30 \mathrm{~cm}$. lang, reinweiss.

Ambon (Karsten).

Die Beschreibung ist angefertigt nach einem in Buitenzorg kultivierten Exemplar.

Die Pflanze ist kleiner als das typische $B$. odoratum Lndl., die Blüten sind grösser, reinweiss und fast ohne 
Geruch. Der Bau der Blüten ist bei beiden jedoch völlig gleich; charakteristisch sind die kegelig verdickten Sepalen und das Labellum.

Die reichlich gebildeten Blütenstände sind sehr zierlich.

Bulbophyllum amplebracteatum T. et B. Nat. Tijdschr. Ned. Ind. XXIV, 307.

Pseudobulbi congregati, ovoidei. Folium oblongum. Inflorescentia elongata, pluriflora. Bracteae distichae, infundibuliformes, valde compressae. Flores majusculi. Sepala lanceolata, lateralia porrecta, conduplicata. Petala minora, oblongo-triangularia. Labellum carnosum, 3lobum, lobis lateralibus linearibus falcatis, apice et intus denticulatis, lobo medio in appendicem longam, linearem attenuato. Gynostemii auriculae elongatae, tenuiter subulatae, margine superiore ad basin dente instructa. Pes gynostemii brevis.

Trugknollen zusammengehäuft, ungleich eiförmig, ziemlich hellgrün, c. $3.30 \mathrm{~cm}$. lang, $2.80 \mathrm{~cm}$. breit, 1blättrig; anfangs von grossen, weitröhrigen, stark gekielten Scheiden umgeben. Blatt aufrecht, gestielt, länglich, mit stumpfer, etwas zurückgebogener Spitze, und oben tief gefurchter, unten stumpf gekielter Mittelrippe, glänzend grün, unten matt hellgrün, c. $15.50 \mathrm{~cm}$. lang, $5.30 \mathrm{~cm}$. breit; Stiel kräftig; zusammengefaltet gefurcht, c. $3 \mathrm{~cm}$. lang. Blütenstände am Grunde der Trugknollen, aufrecht, später mehr oder weniger übergeneigt, in Zwischenräumen mehrere Blüten entwickelnd, locker. Pedunculus auf dem 
Querschnitt oval, schwarzgrau, glänzend, ‘. $27 \mathrm{~cm}$. lang, $0.27 \mathrm{~cm}$. breit, gegen die Spitze bis $0.55 \mathrm{~cm}$. verdickt und grün, mit einigen röhrigen, spitzen, scharf gekielten scheiden. Rachis lange fortwachsend, Internodien gegen ilre Spitze verdickt, an der Seite der Blüte abgeflächt, grün, c. 2 cm. lang. Bracteen 2zeilig, gross, weit und schief röhrig trichterig, spitz, seitlich zusammengedrückt, scharf gekielt, schwach transparent, hellgrün, c. 2.50 cm. lang, bleibend. Blüten gross, fleischig, stinkend, mit feinen, schwarzen Pünktchen. Unpaares sepalum aufrecht, eirund lanzettlich, der obere T'eil zusammengelegt und aussen scharf gekielt, spitz, der untere Teil innen mit einer Längsrinne und die beiden Hälften convex, 13nnervig, grünlich gelb, c. $3.60 \mathrm{~cm}$. lang, $1.1 \mathrm{~J}$ cm. breit. Paarige Sepalen etwas am kurzen süulenfuss herablaufend, einander parallel vorgestreckt, mit abwirts gebogener Spitze, nicht verklebt, lanzettlich, ungleichseitig, spit\%, am Grunde vertikal und concar, nach rorn hin der Länge nach scharf zusammengelegt, sehr stark gekielt und gedreht, so dass die breiteren, dem unpaaren Sepalum zugewandten Hälften horizontal nach oben gekehrt sind und in der Mitte zum Teil übereinander liegen; die schmälere Hälfte mit einwärts gebogenem Rande, der Kiel auswärts gewandt, gelb, am Grunde bräunlich, mit hellgrünem Kiel; beiderseits mit zerstreuten, schwarzen Pünktchen, c. $4.50 \mathrm{~cm}$. lang, die breitere Hülfte $0.95 \mathrm{~cm}$. breit. Petalen viel kleiner, vertikal vorgestreckt, divergierend, schief länglich dreieckig, spitz, aussen mit einer Lüngsrerdickung, schwach durchscheinend, hell gelbgrün mit 7 besonders am Grunde braunrot 
gefärbten Nerven, c. $1.90 \mathrm{~cm}$. lang, $0.75 \mathrm{~cm}$. breit. Labellum dem Säulenfuss sehr beweglich angeheftet, tleischig, dreilappig, der untere Teil seitlich zusammengedrückt mit hohlen Seiten, oben convex, am Grunde abgerundet, breit rinnig und mit 2 starken Längsrippen, zum grössten 'Teil dunkel purpurrot, $1.90 \mathrm{~cm}$. lang; Seitenlappen am Grunde der Lippe aufrecht, breit linear, schwach sichelig, stumpf, die Spitze innen und am Rande mit ziemlich langen, spitzen Zähnen, dunkelrot punktiert, c. $0.40 \mathrm{~cm}$. lang, $0.14 \mathrm{~cm}$. breit; Mittellappen stark abwärts gekrümmt, in einen linearen, spitzen, c. 0.80 cm. langen, zwischen den paarigen Sepalen herabhängenden Fortsatz ausgezogen, convex, unten concav, warzig, mit einer klebrigen Flüssigkeit bedeckt, schwarzrot, mit goldgelber Spitze. Gynostemium gegen die Spitze dümner werdend, blass gelbgrün, glänzend, im ganzen c. $1.20 \mathrm{~cm}$. lang; Öhrchen sehr lang fädlich ausgezogen, am Grunde am oberen Rande mit einem grossen Zahn, c. $0.65 \mathrm{~cm}$. lang. Anthera kappig, mit kegelig verdicktem Konnektiv, goldgelb. Pollinien 4, liegend, länglich birnförmig, seitlich zusammengedrückt, gelb, ohne Klebmasse. Narbe gross. Säulenfuss mit dem Ovarium einen stumpfen Winkel bildend, vorwärts gebogen, am Grunde mit einer Verdickung, der obere Teil frei, an der Spitze zweilappig, stark glänzend, dunkelrot punktiert, $1 \mathrm{~cm}$. lang. Ovarium tief Gfurchig, grün, 1 cm. lang; Stielchen heller, $2.50 \mathrm{~cm}$. lang.

Ambon: Ohne nähere Fundortsangabe (Karsten), Sirimau (J. J. S.), wahrscheinlich auch Hatoe Lalikoel (J. J. S.); Ceram, an der Küste (Teysm.); Celebes (Sarasin, 
im Berliner Herbar als B. macrochilum Krzl.), Sepoetan Geb. in der Provinz Minahasa (Koorders n. 29565\% ${ }^{\beta}$.

Die Besclreibung ist angefertigt nach in Buitenzorg kultivierten, von Ambon stammenden Pflanzen, wozu die Beschreibung von 'Teysmann und Binnendijk sehr gut passt.

Die von Koorders in Celebes gesammelte Pflanze war in allen Teilen etwas grösser, was auch der Fall ist mit der Pflanze von Teysmann und Binnendijk und mit dem von mir bei Hatoe Lalikoel auf Ambon gesammelten Exemplar.

Bei der Pflanze von Celebes waren die 'Irugknollen c. $7.50 \mathrm{~cm}$. lang, die Blätter $25-30 \mathrm{~cm}$. lang, $6.50 \mathrm{~cm}$. breit, der Blütenstand $30-40 \mathrm{~cm}$. lang, c. 9blütig, die Blüten grünlich gelb mit goldgelber Lippe, das unpaare Sepalum $4.20 \mathrm{~cm}$, die Lippe $2.40 \mathrm{~cm}$. lang.

Die Art gehört Ridley's Sektion Intervallata an, mit welcher Kränzlin's Imbricantia identisch ist.

Bemerkenswert sind die grossen, trichterförmigen, stark zusammengedrückten und gekielten Bracteen, die gedrehten, scharf zusammengelegten und gekielten Sepalen, das 3lappige Labellum mit verlängertem, herabhängendem Mittellappen, wie auch $z$. B. bei B. megalanthum Griff. und B. Blumei J. J. S. vorkommt.

Phreatia densiflora Lndl. Gen. et Sp. Orch. 64; Miq. Fl. Ind: Bat. III, 655; J. J. S. Fl. Buit. VI, Olch. 502 ; -P. Myosurus Lndl. Journ. Linn. Soc. Bot. III, 1859, 61 ; Miq I. c.; Hook. f. Fl. Br. Ind. V, 810 ; - Dendrolirium densiflorum Bl. Bijdr. 350. - Eria Myosurus Rchb. f. Bonpl. 1857, 54. 
Ambon: Hatoe Lalikoel (J. J. S.); auch Java; Sumatı:a; Perak.

Phreatia sulcata J. J. S. Fl. Buit. VI, Orch. 505 ; Dendrolirium sulcatum Bl. Bijdr. 347; - Eria sulcata Lndl. Gen. et Sp. Orch. 69; Miq. Fl. Ind. Bat. III, 664. Ambon: Salhoetoe (Teysm.); auch Java und Sumatra. Diese Art fand ich noch im Buitenzorger Herbarium. 


\section{LISTE DER RUMPFSCHEN NAMEN.}

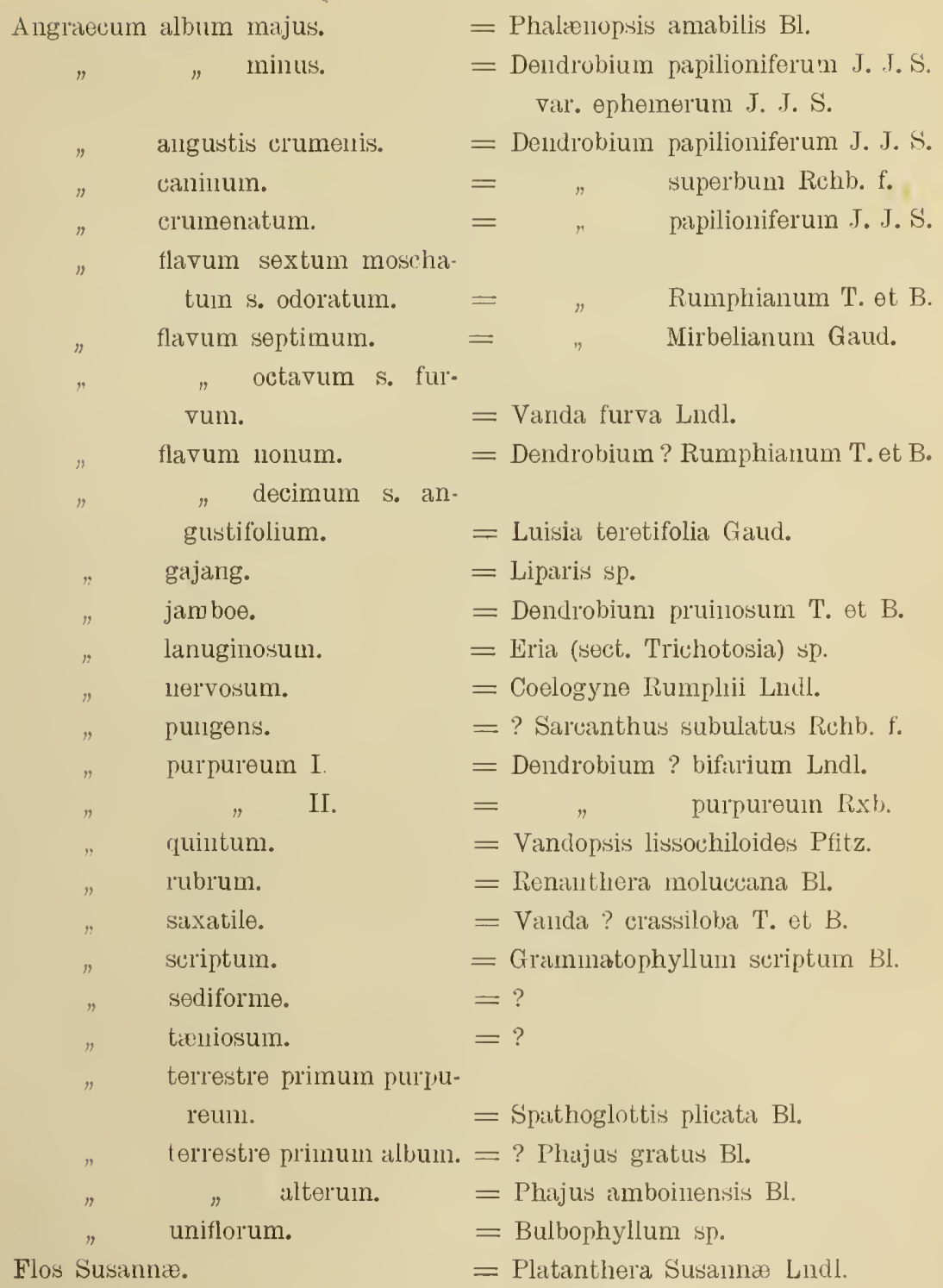


Flos triplicatus.

Folium petiolatum I mas.

II femina.

Herba supplex major prima.

\begin{tabular}{|c|c|c|}
\hline " & $"$ & $"$ secunda. \\
\hline & $"$ & tertia. \\
\hline & $"$ & $"$ quarta. \\
\hline & $n$ & $\begin{array}{l}\text { quinta. } \\
\text { minor. }\end{array}$ \\
\hline
\end{tabular}

Orchis amboinica major radice digitata.

Orchis amboinica major radice raphanoide.

Orchis amboinica minor $\mathrm{I}$.

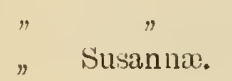

"-Susanno.
$=$ Calanthe veratrifolia $\mathrm{R}$. Br.

$=$ ? Zeuxine amboinensis J. J. S.

$=$ Anoectochilus Reinwardtii Bl.

$=$ ? Dendrobium sp.

$=$ Dendrobium sp.

$=$ ? $" n$

$=? \quad n \quad "$

$=\quad$ calceolum Rxb.

$=\quad " \quad$ atropurpureum Miq.

$=$ ?

$=$ Orchidacea ?

$=$ Habenaria Rumphii Lndl.

$=$ Peristylus sp.

$=$ Platanthera Susannæ Lndl. 


\section{ALPHABETISCHES REGISTER.}

Acanthephippium sp. . . . . 24 Acriopsis sp. . . . . . . . . 91 Adcnostylis cmarginata BI.. . . 13 " integerrima Bl. . . 13 Acridcs amplexicaulc Lndl.. . . 96

" diurnum T. et B. . . . 92

" pallidum Lndl. . . . 92

" subulatum Lndl. . . . 97

Agrostophyllum amboinense J. J.

S. . . . . . . . 37 Agrostophyllum atrovirens J. J.S. 37 longifolium Rehb.

f. . . . . . . . 37 Agrostophyllum majus Hook. f. . 37 Alismorchis furcata O. K. . . 24 veratrifolia O. K. . 24 Ambtygtottis veratrifolia $\mathrm{Bl}$. . . 24 Anoectochilus lieinwardtii Bl. . 12 Aporum Roxburghii Griff. . . 49 Appendicula cordata Hook. f. . 88 latilabium J. J. S. 89 longifolia $\mathrm{Bl}$.. . 37 reflexa Bl.. . . 88 irictiflora T. et B. 88 Btetıa angustifolia Gaud. . : . 24 Bulbophyllum amplebracteatum T. ot B. . . . . . . . . 114 Bulbophyllum crassinervium J. J. S. . . . . . . . 78 Bulbophyllum elegans J. J. S. . 83 "Epicrianthes Hook. f.
Bulbophyllum infundibuliforme $J$.

J. S. . • . . . . 78

Bulbophyllum macranthum Lndl.

var, albescens J. J. S. • . 81 odoratum Lndl. var.

niveum J. J. S. . . . . . 112

Bulbophyllum psittacoides J. J.S. 84 recurviflorum J.J.

S. . . . . . . 79

Bulbophyllum Teysmannii J. J. S. 79 virescens J. J. S. 83

Cadctia umbcllata Gaud. . . 40

Calanthe catilligera Rchb. f. . . 23 celebica Rolfe.. . . . 22 comosa Ruhb. f. . . . 23 furcata Bat. . . . 23 Perrotteti Rich. . . 23 proboscidca Rehb. f. . 23 saccata J. J. S. . . . 22 sematrana Bl.. . . 23 tunensis J. J. S. . . . 22 veratrifolia $\mathrm{R}$. Br. . . 23

Callista amboincnsis O. K. . . 55 anosma O. K. . . 67 atropurpurca $\mathrm{O}$. K. . . 54 bifaria O. K. . . . 62 biflora O. K. . . . 63 catceota O. K. . . . 49 calophylta O. K. . . 56 crumenata O. K. . . 42 foliosa O. K. . . . 72 lancifolia O. K. . . 64 
Callista Mirbeliana O. K. . . . 56 " purpurea O. K. . . . 63

" Scortechinii O. K. . . 67

"spinescens O. K. . . . 72

"Veitchiana O. K. . . . 56

Ceratostylis latuensis J. J. S. . 37

Cirrhopetalum elegans T. ot B. . 83 psittacoides Ridl. . 84

Cleisostoma cryptochilum F. v.

Muell .

Cleisostoma Koordersii Rolfe. . 104 subulatum Bl. . . 103

Coelogyne psittacina Rchb. f. . . 16 " Rumpliii Lndl. . . . 16

Corymbis risticha Lndl. . . . 16

"veratrifolia Rchb. f. . 16

Corymborchis assamica Bl. . . 16 veratrifolia $\mathrm{Bl} . \quad 16$

Cryptochilus bicolor J. J. S. . . 36

Cymbidium amabite Rxb. . . . 92

furvem Wlld. . . 98

scriptum Sw. . . 85

tenuifolium Wight . 91

triste Roxb.. . . . 91

Cypripedium Mastersianm Rehb.

f. . . . . . . 7

Cystopus muricatıs J. J. S. • . 13

Dendrobium amboinense Hook. . 55

S." . . . . . . . . 59

Dendrobium anosmum Lndl. . . 67 atropurpureum $\mathrm{Mic} .54$ bifarium Lndl. . . 62 calceolum Rxb. . . 49 calophyllum Rehb. f. 56 colluavum J. J. S. . 50 crumenatum Sw. . 42 crumenctum Sw. fl.

lilac. Miq. . . . . . . . . 43

Dendrobium Dendrocolla J. J. S. 39
Dendrobium ecolle J. J. S. . . 40 ferox Hassk. . . . 56 foliosum Brongn . 72 gemelluin Lndl.. . 63 glaucum T. ot B. . 78 javanicum Sw. . . 73 Koordersii J. J. S. 67, 112 lancifolium A. Rich 64 lilacinum T. et B. 64 lobulatum Rolfe et

J. J. S. . . . . . . . 49

Dendrobium macranthum Miq. . 67 macrophyllum A.

Riclı. . . . . . . . . 55

Dendrobium macrophytlnm Lndl 67 minax Rchb. f . . 57 Mirbelianum Gaud. 56 orientale J.J.S. 70, 112 papilionfferum J. J.

S. . . . . . . . . . 42 Dendrobium papilioniferum J. J. S. var. ephemerum J. J. S. . 45 Dendrobium pruinosum T. et B. 57 purpureum Rxb. . 63 rorulentum T. et. B. 73 Roscnbergii T. et B. 56 Roxburgii Lndl. . 49 Rumphianum T. et

B. . . . . . . 57

Dendrobium salicornioides T.etB. 52 scialpelliforme T. et

B. . . . . . . . . 111

Dendrobium Scortechinii Hook. f. 67 spinescens Lindl. . . 72 superbun Rchb. f. 67 taurinum lndl. var.

amboinense Rolfe. . . . 57

Dendrobiun Treubii J. J. S. . . 65 umbellatum Rehb. f. 40 utile J. J. s. . . . 39 
Deudrobium Veitrhianum LndI. . 55 viridiroseum Rchb.f. 6:3

Dendrochilum sp. . . . . . 17

Dendrocolla amplericaulis BI. . 96 pallicla Bl. . . . 92 rhopalorrhachis

lichb. f. . . . . 109

Denrtracolla subuluta Bl. . . . 97 Zollingeri lichb. f. . 95

Dendrolirium rugosum Bl. . . . 73 densiflorum Bl. . . 117 suleatum Bl. . . 118

Dipodium sp.. . . . . . . 86

Empusa paradora Lndl.. . . . 31

Epecrianthes jananica Bl. . . . 79

Epidendrum amabile L. . . . . 92 furvum L. . . . . 98 scriplum L. . . . 85

Eria bractescens Lndl. . . . . 74 Dillwynii Hook. . . . . 74 foliosa Ridl. . . . . 72 lilloralis T. et B. . . . . 74 moluceana Schlitr, өt J. J. S. 74 Myosurus Rulib. f. . . . . 117 quinquangularis .J. J. S. . 76 lugosil l.ndl. . . . . . 73 stellata Lndl. . . . . 73 striolale Richb. f. . . . 73 suleala Lndl. . . . . . . 118 varginala Bth. . . . . 73 Fintlia lissochitoides Gaurd. . . 102 Gabrertire scripla Gaud. . . . . 85 Geodorum sp. . . . . . 25 Glomera erythrosma Bl.

Glossorhyncha anboinensis Ridl. 39 Grammatophyllum Fenzlianum

Ruhb. f. 85 Granmatophyllum Gritelmi II Kızl. . . . 85 loojardinum Rehb. f. 85
Grammatophyllum Rumphianum

Miq. . . . . .. . . 84

Grammatophyllum seriptum Bl. 84 speciosuin Ludl. 85

Grossourdya Zollingeri Ruhb. f. 95 Habenarid bumbusctonum krzl. . 8 giganlea Dolı. . . . 8 Rumphii Lndl . . . 9 Susannce R. Br. . . 8

Haplochilus amboinensis J. J. S. 13

var. aigenlea J. J. S. . . . - 13

Hysteria veratri'olia Reinw. . . 16

Leptorehis odorala O. K. . . . 31

Limatoris grala Miq. . . . . . 22

Limortorum veralrifolium WIld. . 2:3

Liparis amboinensis J. J. S. . . :31

" cleistogama J. J. S. . . 33

n confusa J. J. s. var. am-

boinensis J. J. S. . . . . . 35

Liparis odorata Lndl. . . . . 30

" paradoxa kichb. f. . . . 30

" tunensis J. J. S . . . . 35

Luistia brachystarluys BI. val flaveola Par. et Ruhb. f. . . . 9!

Luisia bnrmanica Rehb. f. . . 91 platyglossa Ruhb. f. . . 91 teretifohia Gaud. . . . 91 zeylanica Lndt. . . . . 91

Macrostylis disticha Bredid. . . 16 Malaxis lancifolia Sm. . . . . 31 orlorala Wlld. . . . 31 ventilabrum O. K. . . 27 Nerlineatear bicolor J. J. S . . 37 Micropera pallicla Lindl. . . . 10:3 Microstylis horielensis J. J. S. . 29 molucuina .J. J. S. . 27 ventilabrum Rchb. f. 27 Nervilia Aragoana Gaud. . . . 10 Neuwiedid sp. . . . . . . 6 
Oberonia lucida J. J. S. . . . . $26 \mid$ Platanthera Susannæ Lndl. . . 7

Octomeria stcllata Spr. . . . . 78 vaginata Breda. . . . 73

Onychium crumenatum Bl. . . 42 Orchis gigantea Sm . . . 8

"Susannce L. . . . 8

" triplicata Willen. . . . 24

Orsillice amplexicaule Rehb. f. . 96

Oxystophyllum atropurpureum Bl. 54

Paphiopedilum Mastersianum

Pfitz. . . . . . . . 7

Paphiopedium Mastcrsianum

Kerch. . . . . . . 7

Pcdilonium biflorum BI. . . . 63

Peristylus candidus J. J. S. . . 8

" gracilis Bl. . . . 8

" sp. . . . . . 8

Plıajus amboinensis Bl. . . . 21

, callosus Lndl. var. ecalcaratus J. J. S. . . . . . 18

Phajus gratus Bl. . . . . . 22

" Rumphii Bl. . . . . 24

"Zollingeri Relib. f. . . . 21

Phalænopsis amabilis Bl. . . . 92

" fugax kirzl. . . . 93

" grandiflora Lindl. . 92

Phreatia densiflora Lndl. . . 117

" Myosurus Lndl. . . . 117

" sp. . . . . . . . 88

" sulcata J. J. S. . . . 118

Phyllorchis javanica O. K. . . 79

Physurus herpysmoides K. et P.

var. amboinensis J. J. S. . . 10

Pinalia bractesccns O K. . . 74

" rugosa O. K. . . . 73

" stcllata O. K. • . . 73

" striolata O. K. • • 73

Platanthera gigantca Lndl. . 7

" robusta Lndl. . . 8

" Kumphii Brongn. . 9

Plcione Rumphii 0. K. . . . 16

Plocoglottis Lowii Rehb. f. . . 18

molucciana Bl. . . 17 porphyrophylle lidl. 18

Podochilus appendiculatus J. J.S. 88

" reflexus Schlttr. . 88

Pogonia flabelliformis Lndl. . . 10

Nervilia Bl. . . . . 10

Pterygodium sulcatum Roxb. . . 13

Renanthera inoluccana Bl. . . 97

Rhynchanthcra paniculata Bl. . 16

Saccolibium amboinense J. J. S. 106

insectiferuin J. J.S. 109

purpurcum J. J. S. 103

rhopalorrhachis J.J.

S. . . . . . . 109

Sarcanthus geminatus T. et B. . 106 secundus Griff. . . . 103 subulatus Rchb. f. . 103

Sincochilus amplexicaulis Rchb.f. 96

" aureus Hook. f. . . 92

" brachyglottis Hook. f. 110

" cladostachys Hook. f. 92

" lilacinus Griff. . . . 96

" pallidus Richb. f. . . 92

" subulatus Ruhb. f. .97

" Tæniophyllum J. J.S. 93

" unguiculatus Lndl. . 92

"Zollingeri Rchb. f. . 95

Spathoglottis lilacina Griff. . . 24

plicita Bl. . . 24

Stauropsis lissochiloides Pfitz. . 103

Tainia penangiana Hook f. . . 17

Thelasis elongata Bl. var. amboi-

nensis J. J. S. . • . . 86

Thrixspermum amplexicuule

Rchb. f. . . . . . . . 96

Thrixspermun aureum O. K. . 92 brachyglottis O. K. 109 
Thrixspermum cladostachyum $\mathrm{O}$.

K. . . . . . . (9)

Thrixspermum lilacimum Rehb.f. 96 pallitlum Rehb. f.. 92 " rhopalorhachis Rehb.f. 109 Thrixspermum subteres J. J. S. 97 subulatum Rohb. f. 97 unguiculatum Relıb. f. 92

Trichoglot.tis geminata J. J. S. . 106 oblongifolia liolfe. 106

Triplewra pallida Lndl . . . . 12

Vanda Batemannii Lndl. . . . 102 crassiloba T. et B. . . . 99 furva Lndl. . . . . . 98 hastifera Rchb. f. . . . 99
Vanda lissochiloides Lndl. • . . 102 " scripta Spr. . . . . 85

Vandopsis lissochiloides Pfitz. . 102

Zeuxine amboinensis J. J. S. . 13

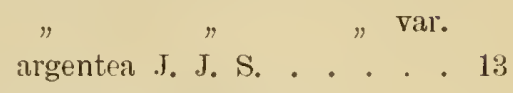

Zeuxine bracteata Wight. . . . 12

" brevifolia Wight. . . 12

cmarginata Lndl. . . . 13

integerrima Lndl. . . . 13

membranacea Lndl. . . 12

procumbens Lndl. . . . 13

robusta Wight. . . 12

sulcata Lndl. . . . . 12

Tripleura Lndl. . . 13 



, 

An 


$$
\begin{aligned}
& \text { L } \\
& \text { a to }
\end{aligned}
$$

1)

(1)

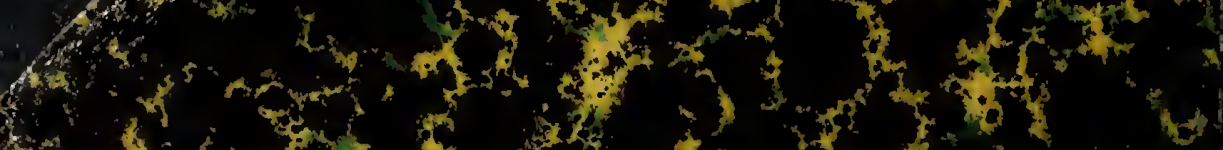

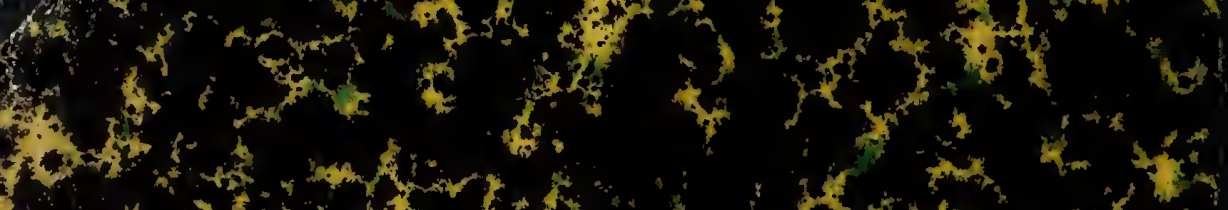

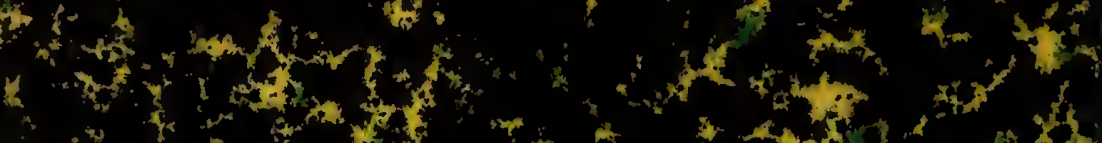

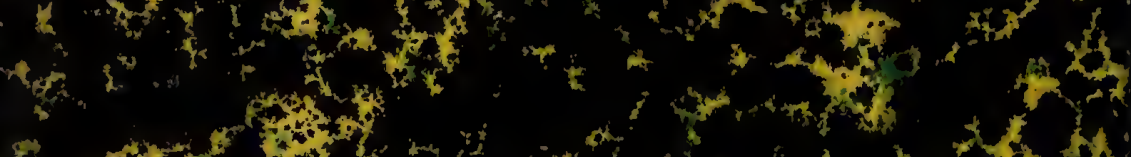

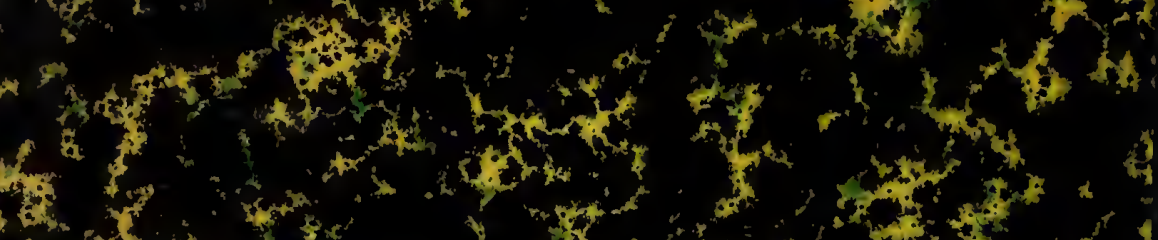

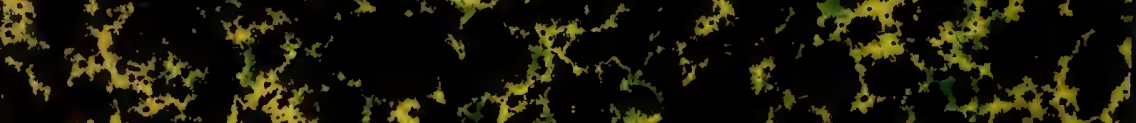

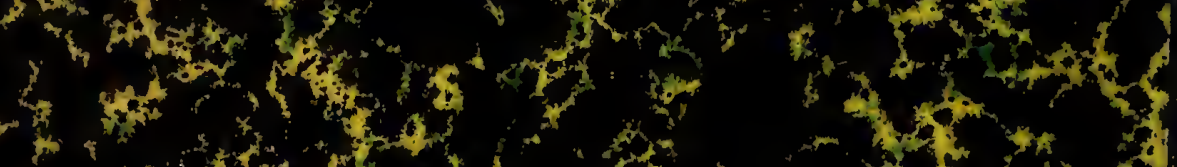

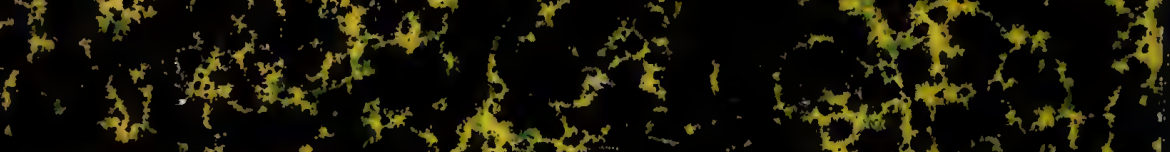

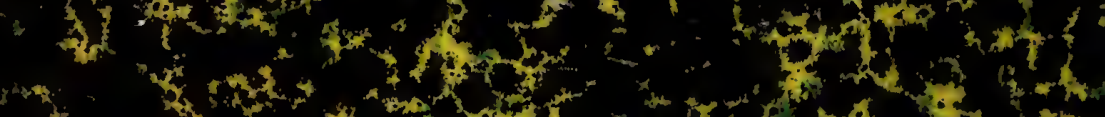

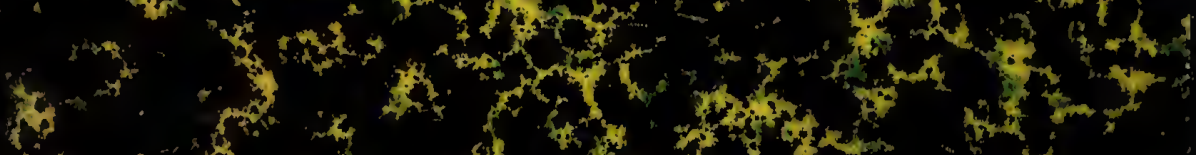

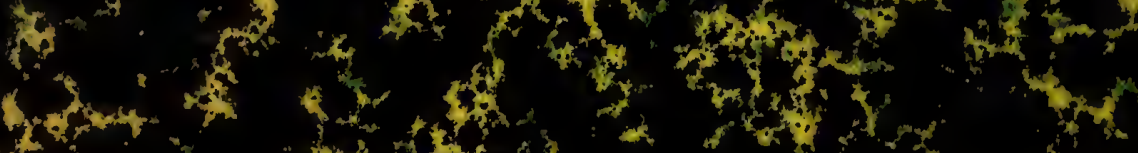

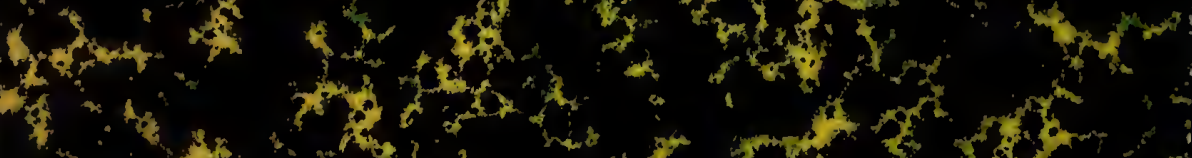

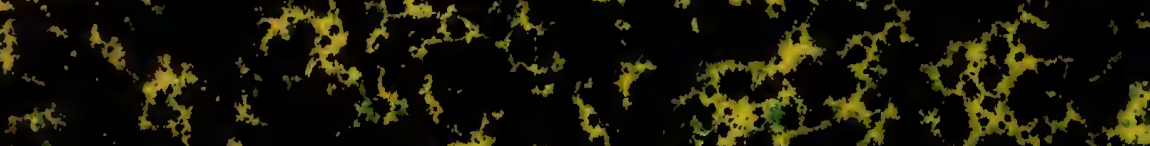
(1) of (3) (3)

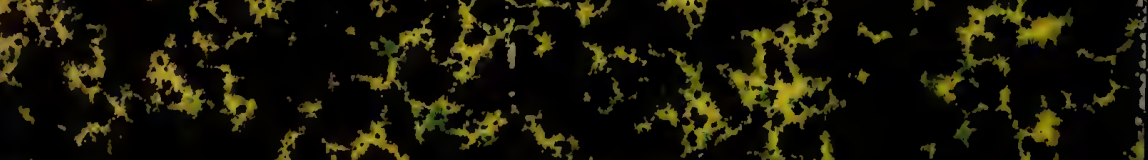

$$
\text { (1) }
$$

